Universidade de São Paulo

Escola Politécnica

ALTAMIRO MANN PRADO

SISTEMA ELÉTRICO AUTOMATIZADO

OBJETIVANDO OTIMIZAÇÃO NA ALIMENTAÇÃO

DE CENTROS DE CONSUMO

São Paulo

2006 


\title{
SISTEMA ELÉTRICO AUTOMATIZADO OBJETIVANDO OTIMIZAÇÃO NA ALIMENTAÇÃO DE CENTROS DE CONSUMO
}

\author{
Dissertação a ser apresentada à Escola \\ Politécnica da Universidade de São Paulo \\ para obtenção do título de Mestre em \\ Engenharia \\ Área de Concentração: Departamento de \\ Energia e Automação \\ Orientador: Prof. Dr.Cícero Couto de Moraes
}

\section{São Paulo}

2006 
Este exemplar foi revisado e alterado à versão original, sob responsabilidade única do autor e com a anuência de seu orientador.

São Paulo, 30 de novembro de 2006.

Assinatura do autor

Assinatura do orientador

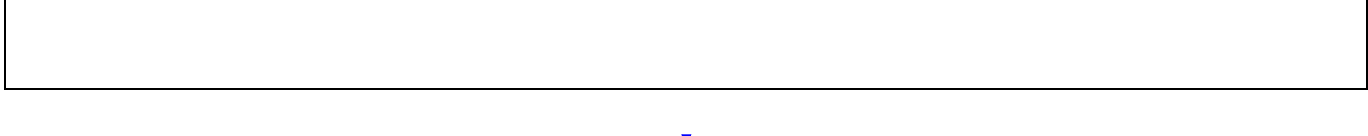

\section{Excluído:}

TI

$\pi$

FICHA CATALOGRÁFICA

Prado, Altamiro Mann

Sistema elétrico automatizado objetivando otimização na

alimentação de centros de consumo / A.M. Prado. - ed. rev.- São Paulo, 2006.

$81 \mathrm{p}$.

Dissertação (Mestrado) - Escola Politécnica da Universidade

de São Paulo. Departamento de Engenharia de Energia e Automação Elétricas.

1.Rede de Petri 2.Automação industrial I.Universidade de São

Paulo. Escola Politécnica. Departamento de Engenharia de Energia e Automação Elétricas II.t. 
Para meus pais.

Para minha querida esposa Gisele.

Para meus filhos Rafael e Letícia 


\section{AGRADECIMENTOS}

À Escola Politécnica da Universidade de São Paulo pela oportunidade de participar deste seleto grupo que busca o aprimoramento acadêmico e tecnológico.

À Rockwell Automation do Brasil, Atlas Copco, GE e Lavill pela contribuição tecnológica na solução das dúvidas e contribuições gerais para o enriquecimento do projeto.

Ao meu orientador Professor Doutor Cícero Couto de Moraes, pela orientação e amizade.

Ao colegas do Centro de Estudos em Regulação e Qualidade de Energia (Enerq) pelas contribuições feitas na forma de sugestões, conselhos e apoio em geral.

A todos os amigos e colegas do GAESI e em especial à Luzia, pelo apoio, sugestões e amizade. 


\section{RESUMO}

Este trabalho descreve a utilização da Rede de Petri como ferramenta de análise e desenvolvimento da automação de uma Micro-usina de cogeração piloto de $130 \mathrm{~kW}$. O projeto foi implantado no centro laboratorial de qualidade de energia da Escola Politécnica da Universidade de São Paulo. O objetivo principal desta Micro-usina é estudar as principais variáveis inerentes à qualidade de energia e funcionalidades destes tipos de sistemas automatizados.

A utilização da Rede de Petri (RP) permitiu prever a alcançabilidade, vivacidade, segurança e reversibilidade do programa aplicativo desenvolvido e implantado em um controlador programável (CLP) de última geração. Através de uma rede de comunicação de protocolo aberto foi possível a troca de informações entre o CLP e os módulos de controle.dos geradores (G1 e G2). Entradas e saídas digitais foram utilizadas para monitorar e comandar as chaves de transferência automática (Close e Open Transition) e também os disjuntores motorizados. As operações realizadas são sinalizadas no painel local de controle e transferência (PCT) assim como, via rede Ethernet, na interface remota de supervisão e controle (SCADA).

No estudo de caso da Micro-usina de cogeração foram identificadas um total de 24 posições (Position) distintas, considerando as quatro fontes de geração atuais e os dois centros de consumo de energia. Através de uma IHM local ou um supervisório remoto (SCADA) é possível a mudança entre as posições (topologia) permitindo realizar as principais manobras de paralelismo momentâneo e transitório dos grupos geradores com a concessionária. No programa aplicativo do CLP foi implementado o intertravamento de segurança para todos os equipamentos comandados, assumindo sempre o desconhecimento, por parte do operador, dos critérios e seqüências de segurança exigidos para execução das transições entre topologias (pior caso). 


\begin{abstract}
This study is about the usage of the Petri Net as an analysis and development tool of the automation of a pilot micro plant of $130 \mathrm{~kW}$. The project was carried out in the energy quality laboratory center at the Escola Politécnica de São Paulo. Its main goal was to study the most important variables related to the quality of energy and the functionalities of the automatized system types.

By using the Petri Net, it was possible to foresee the attainment, vivacity, reliability and reversibility of the software, developed and installed in a state-of-the-art programmable logical controller (PLC). Through an open protocol communication network, information was exchanged between the PLC and the generators (G1 and G2) control modules. Digital inputs and outputs were used to monitor and switch the automatic transfer keys (Close and Open Transition) and the motor switches. The procedures done were shown on a local panel of control and transfer, as well as on the Ethernet, at a remote supervision and control interface (SCADA).

In this case study, 24 different positions were identified, taking into account the four sources of generation at the moment and the two centers of energy consumption. Through local IHM or remote supervision (SCADA), it was possible to switch positions (topology) and perform the main maneuvres of momentary and transitional parallelism from generator groups to concessionary. As to the PLC application program, a security block was set to all commanded devices, assuming that the operator was unaware of the criteria and security steps needed to proceed with transitions in topology (worst case).
\end{abstract}




\section{Lista de Figuras}

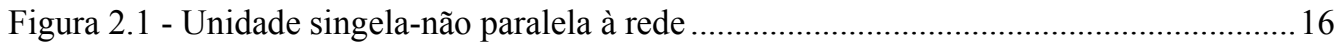

Figura 2.2 - Múltiplas Unidades -não paralelas à rede …………………………………....... 17

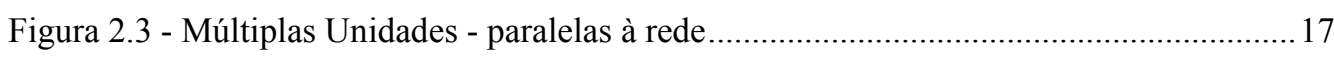

Figura 2.4 - Sistema com transferência em rampa ………...............................................2.

Figura 2.5 - Partida na condição de emergência...................................................................21

Figura 2.6 - Partida na condição normal com rampa.................................................................2

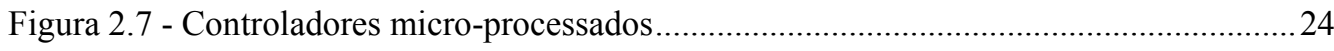

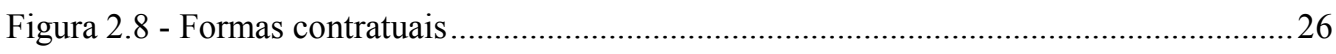

Figura 2.9 - Curva de carga diária do sistema elétrico ( Eletrobrás, 2003) ..............................29

Figura 2.10 - Tarifa azul ............................................................................................. 30

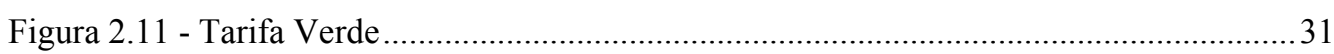

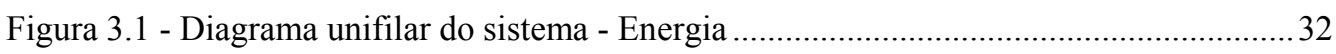

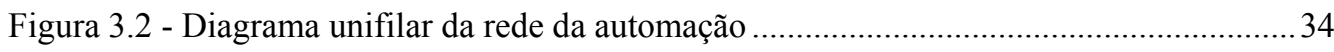

Figura 3.3 - Principais parâmetros e operações trocados pelo CLP com o módulo controlador

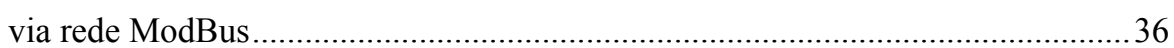

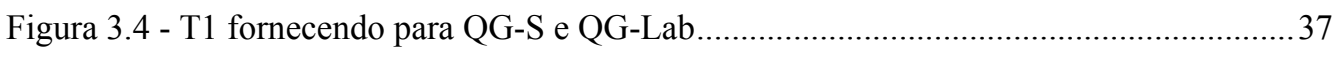

Figura 3.5 - T1 fornecendo para QG-Lab e G1 fornecendo para QG-S ...................................... 38

Figura 3.6 - T1 fornecendo para QG-Lab e G1//G2 fornecendo para QG-S.............................39

Figura 3.7 - G1 fornecendo para QG-Lab e para QG-S ........................................................... 39

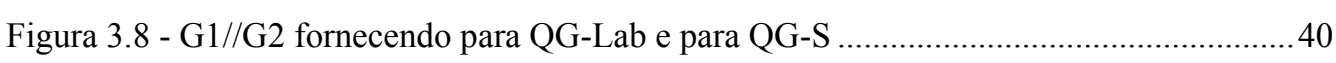

Figura 3.9 - G1//G2//T1 fornecendo para QG-Lab e para QG-S............................................. 41

Figura 4.1 - Todos os geradores (G1, G2 e T1) fornecendo energia para QG-Lab e QG-S. ...43

Figura 4.2 - Alimentação da carga QG-Lab pelo gerador G1 e alimentação do QG-S pelo T1 (G1/T1) .....

Figura 4.3 - Alimentação da carga QG-Lab pela concessionária T1 e alimentação do QG-S pelo G1 (T1/G1)

Figura 4.4. - Alimentação da carga QG-Lab pela concessionária T1 e alimentação do QG-S

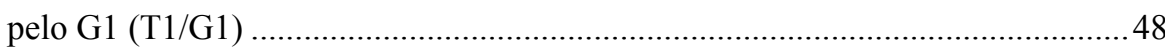

Figura 4.5 - Alimentação da carga QG-Lab e QG-S pelo gerador G1 (G1/G1),_.....................48

Figura 4.6 - Alimentação da carga QG-Lab e QG-S pelo gerador G1 (G1/G1).......................49

Figura 4.7 - Alimentação da carga QG-Lab e QG-S pelo gerador G1 em paralelismo permanente com a concessionária (G1T1/G1T1). 
Figura 4.8 - Alimentação da carga QG-Lab pelo gerador G1 e alimentação do QG-S pela concessionária $\mathrm{T} 1$ (G1/T1)

Figura 4.9 - Alimentação da carga QG-Lab pelo gerador G1 e alimentação do QG-S pelo

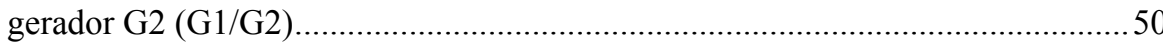

Figura 4.10 - Alimentação da carga QG-Lab e QG-S pelo gerador G1 (G1/G1)....................51

Figura 4.11 - Alimentação da carga QG-Lab e QG-S pelo gerador G1 em paralelismo permanente com a concessionária (G1T1/G1T1) .................................................52

Figura 4.12 - Alimentação da carga QG-Lab e QG-S pela concessionária T1 (T1/T1)..........52

Figura 4.13 - Alimentação da carga QG-Lab e QG-S pela concessionária T1 (T1/T1)...........53

Figura 4.14 - Alimentação da carga QG-Lab pelos dois geradores em paralelo e QG-S pela

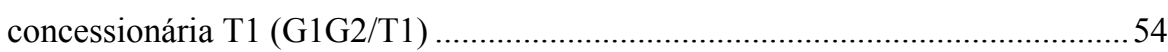

Figura 4.15 - Alimentação da carga QG-Lab e QG-S pela concessionária T1 (T1/T1)...........55

Figura 4.16 - Alimentação da carga QG-Lab e QG-S pelos grupos geradores em paralelo entre

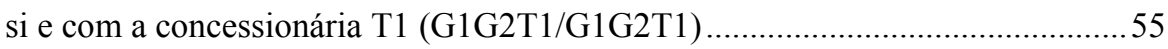

Figura 4.17 - Alimentação da carga QG-Lab e QG-S pelos grupos geradores em paralelo entre

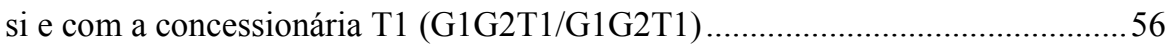

Figura 4.18 - Alimentação da carga QG-Lab e QG-S pelos grupos geradores em paralelo entre

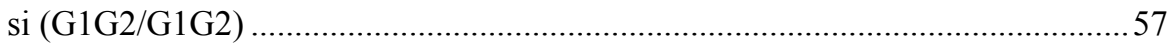

Figura 4.19 - Formas operacionais típicas ou convencionais (G1/T1) ……………..............57

Figura 4.20 - Formas operacionais atípicas ou não convencionais ..........................................58

Figura 4.21 - Formas operacionais típicas ou convencionais …………………………..........59

Figura 4.22 - Formas operacionais atípicas ou não convencionais ……………………….......6 60

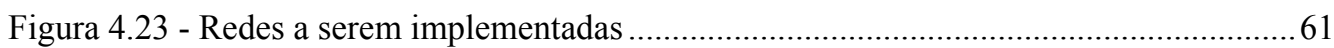

Figura 4.24 - Possibilidades usando G1, T1 e QG - S ( cargas essenciais) ................................63

Figura 4.25 - Configuração dos equipamentos para fornecimento de energia por T1 para QG-S

Figura 4.26 - Topologia gerador desligado e transformador ligado. .64

Figura 4.27 - Configuração dos equipamentos para fornecimento de energia por G1 para QG-

$\mathrm{S}$ 65

Figura 4.28 - Topologia gerador ligado e transformador desligado. .65

Figura 4.29 - Configuração dos equipamentos para fornecimento de energia por G1 e T1 para

QG-S (paralelismo permanente) .66

Figura 4.30 - Topologia gerador e transformador em PP .......................................................66

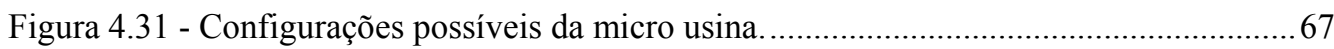


Figura 5.1 - Arquivos do programa aplicativo do CLP .70

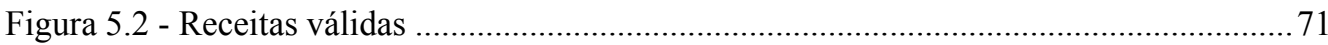

Figura 5.3 - Alimentação da carga QG-Lab e QG-S pela concessionária T1 (T1/T1).............72

Figura 5.4 - Alimentação da carga QG-Lab e QG-S pelos grupos geradores em paralelo entre

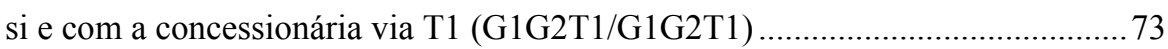

Figura 5.5 - Indicação no supervisório do estado atual das chaves e disjuntores.....................74

Figura 5.6 - Indicação no sinótico do painel de controle e transferência (PCT) .................... 74

Figura 5.7 - Giga de testes simulando falhas nos sinais de retorno dos dispositivos ............... 75 


\section{Sumário}

Capítulo 1 - Introdução e Descrição dos Objetivos do Trabalho ...........................................12

Capítulo 2 - A importância do Sistema de Cogeração e Características Operacionais ...16

2.1 Características Gerais de Operação dos Grupos Diesel Geradores ...........................16

2.1.1 Operação "Peak Shave"...................................................................................... 18

2.1.2 Transferência com rampa de carga ...............................................................20

2.1.3 Problemas da transferência...............................................................................22

2.2 Controlador Micro-processado para Grupos Geradores............................................24

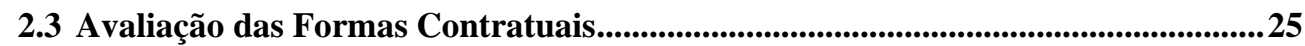

2.3.1 Procedimentos de distribuição [17] ................................................................26

2.4 Modalidades Tarifárias ................................................................................................28

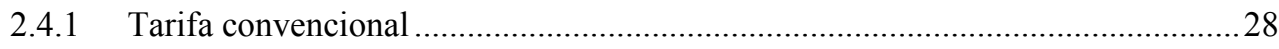

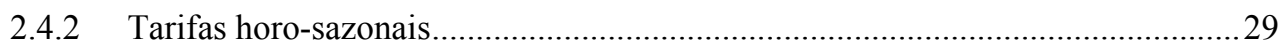

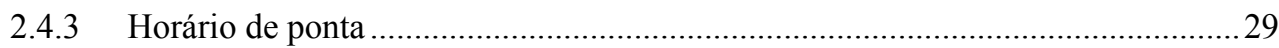

Capitulo 3 - Descrição do Sistema Desenvolvido ................................................................32

3.1 Diagrama Elétrico do Sistema................................................................................................ 32

3.2 Topologia da Automação do Sistema ............................................................................34

3.3 Formas Operacionais do Sistema .......................................................................................35

3.3.1 Concessionária fornecendo energia para ambas as cargas QG-Lab e QG-S (essenciais)

3.3.2 Concessionária T1 fornecendo energia para QG-Lab e o Gerador G1 fornecendo

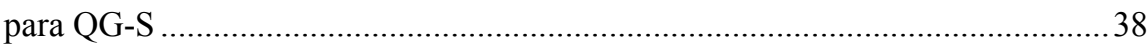

3.3.3 Concessionária fornecendo para QG-Lab e o Gerador G1 em paralelo com G2

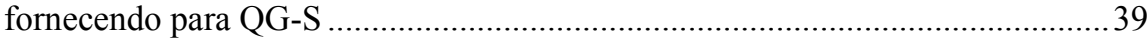

3.3.4 Gerador G1 fornecendo para QG-Lab e para QG-S ............................................. 39

3.3.5 Gerador G1 em paralelo com G2 fornecendo para QG-Lab e para QG-S ..........40

3.3.6 Gerador G1 em paralelo com G2 e em paralelo com T1 fornecendo para QG-Lab e para QG-S

Capítulo 4 - Modelagem e Simulação da Automação do Sistema .....................................42

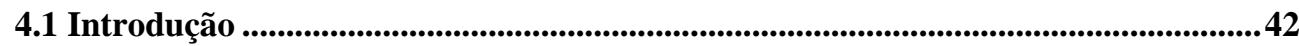


4.2 Modelagem do sistema considerando as fontes de alimentação nas duas cargas

(Laboratório e Essenciais)

4.3 Análise de mudanças de estados do sistema considerando as fontes de alimentação nas duas cargas (Laboratório e Essenciais) ......................................................................45

4.4 Formas operacionais típicas e formas operacionais atípicas ..................................... 57

4.5 Hardware da Automação Empregada ......................................................................60

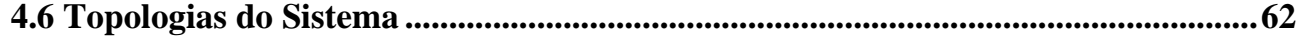

4.6.1 Topologia Gerador G1, Transformador T1 e Cargas Essenciais .............................62

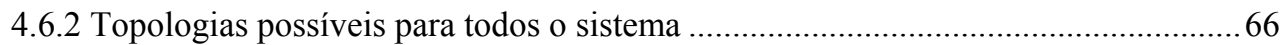

Capítulo 5 - Desenvolvimento do Projeto do Programa Aplicativo do CLP ......................68

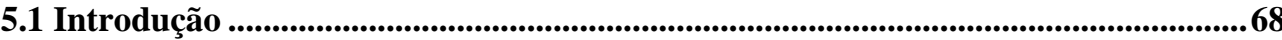

5.2 Distribuição dos Arquivos de Programa ..................................................................69

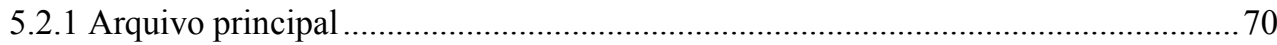

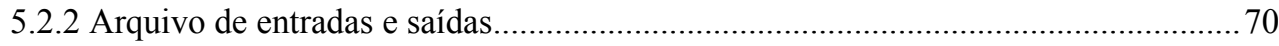

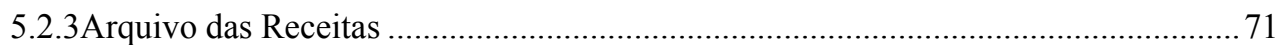

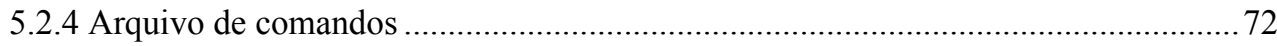

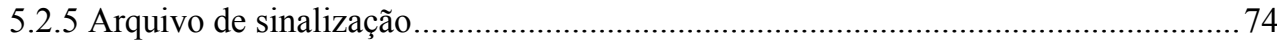

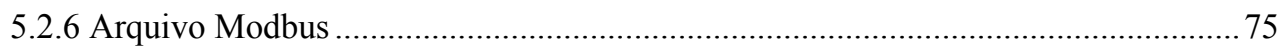

5.3 Testes do Programa Aplicativo do CLP e do Supervisório......................................... 75

Capítulo 6 - Conclusões ...........................................................................................................................76

REFERÊNCIAS BIBLIOGRÁFICAS .........................................................................77

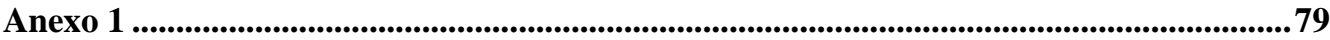




\section{Capítulo 1 - Introdução e Descrição dos Objetivos do Trabalho}

Este trabalho apresenta a metodologia utilizada no projeto e no desenvolvimento conceitual da automação de um sistema de geração de energia visando principalmente a gestão energética de centros de consumo. Utilizou-se a Rede de Petri como ferramenta para estruturar o projeto visando mostrar principalmente a alcançabilidade de um estado a outro.

O projeto utilizado como estudo de caso foi automatizado com o objetivo de permitir a proteção, transferência, manobra e operação de uma micro-usina contendo dois geradores diesel de 50kVA cada e outro a gás de 30kVA (unidades diesel a gás). Nesta automação é possível permitir uma operação local ou remota, controlada por Controlador Lógico Programável (CLP) coordenando um sistema SCADA (Supervisory Control and Data Aquisition System). Manobras são realizadas de forma total ou parcial em todas as topologias envolvendo grupos de geradores de emergência, com maior ou menor grau de complexidade, mas guardando as mesmas operações disponibilizadas. [13][14][15]

A automação da micro-usina fornece, portanto, uma importante ferramenta de manobras, acompanhamento e registro das variáveis inerentes à qualidade de energia e funcionalidades destes tipos de sistemas automatizados.

Neste trabalho houve a necessidade de integrar equipamentos de diferentes fabricantes contendo cada um o seu grau de automatismo e funcionalidades. Essa integração tem como base as determinações da AES Eletropaulo [9] [10] [11] e ANEEL [17] quanto ao paralelismo entre os grupos geradores e a rede concessionária. Uma análise detalhada das configurações possíveis, suas transições e eventuais contingências são feitas por Rede de Petri observandose as propriedades de vivacidade, segurança e reversibilidade (VSR) e conflitos mortais (“dead-lock"). Na etapa de implantação e testes de campo, todas as topologias foram testadas e ajustadas, conforme a necessidade de cada equipamento do sistema.

A Micro-usina foi utilizada para estudo de caso por apresentar uma automação com um grau de complexidade que necessita de uma análise mais detalhada na fase de projeto, por ser de grande aplicação no mercado nacional e por estar sendo implantada em um importante Centro de Estudos em Regulação e Qualidade de Energia (Enerq). 
O paralelismo entre sistemas geradores de energia elétrica e a concessionária, visando suprir parcial ou na sua totalidade o fornecimento de energia para suas cargas, é um assunto muito discutido entre profissionais de órgãos reguladores, concessionárias de energia elétrica e do setor privado, principalmente de médio e grande porte. Para estes consumidores o fornecimento da energia para suas cargas constitui não somente um fator puramente estratégico, mas principalmente econômico.

A utilização de fontes primárias de energia (eólica, química, gases quentes, vapor, etc) para cogeração pode ser vista como tendo um importante papel na diminuição do desperdício de insumos energéticos e/ou poluição ambiental. Do ponto de vista econômico, a cogeração deve ser analisada como estratégica ao suprir parte do consumo interno da indústria, frente a custos que podem sofrer com fatores externos e conjunturais, como a tarifa de energia elétrica, a disponibilidade da energia, custo dos combustíveis fósseis, oscilação da moeda, etc.[7] [8]

Atualmente, um importante fator da crescente iniciativa por uma instalação própria de geração tem sido a necessidade de altos índices de qualidade no fornecimento da energia elétrica. A qualidade na geração e distribuição exige contínuos investimentos, devido à crescente demanda por este bem de consumo, tão importante nos vários níveis da sociedade moderna. .[7] [8]

A utilização de um grupo gerador em paralelo com a concessionária possui muitas vantagens frente a sistemas totalmente isolados. Algumas destas vantagens são:

- A não necessidade da geração de toda energia consumida na planta, ou seja, poderse optar pela geração apenas do excedente ao contratado da concessionária ("peak shave") ou de um valor fixo necessário ao funcionamento das principais operações da planta ("base-load")

- A possibilidade de entrar com o sistema de geração auxiliar (standby) a fim de suprir com energia as cargas essenciais em uma eventual falha no fornecimento de energia por parte da concessionária. Da mesma forma, pode-se pensar no retorno ao fornecimento pela concessionária, no caso de haver uma falha no fornecimento feito pelas fontes alternativas. 
- A possibilidade de que, tanto ao assumir quanto ao devolver as cargas à concessionária, a transferência ocorra de forma gradual (em rampa) evitando variações bruscas nos geradores e mesmo para a concessionária.

- O sistema automatizado deverá propiciar não somente a operação em modo local ou remota, como também garantir todas as características operacionais de paralelismo permanente e a transferência transitória das fontes de cogeração. Desta forma, por trás dos comandos feitos pelo operador devem estar também comandos enviados por rede ou fio para os equipamentos microprocessados.

No projeto da Micro-usina foram previstas seqüências de operações pré-definidas que são disparadas em situações conhecidas (emergência) ou sob o comando do operador. A dinâmica destas operações necessita de um estudo prévio em uma fase inicial, onde ainda podem ser alterados os equipamentos a serem utilizados, disposições dos barramentos no painel de transferência, combinações permitidas (alcançabilidade), etc. Nesta fase é de extrema importância a representação e simulação das operações do projeto, a fim de verificar através dos objetos (grafos) animados como será o projeto implantado e se está de acordo com o previsto inicialmente. Não é incomum que dessa simulação saia uma terceira forma de operação ainda não prevista nas fases anteriores do projeto, mas necessária ao processo ou desejada pelo operador final. Alterações nas fases iniciais do projeto são relativamente menos caras que em fases futuras, permitindo negociações de custos e aumento da satisfação e confiança por parte do operador.

As simulações feitas com o auxílio de supervisórios e simuladores, realizadas geralmente em uma etapa pré-implantação em campo, são de grande valia neste processo de análise do projeto. Essas simulações, por razões de custos e amadurecimento do projeto, são feitas em uma etapa avançada onde alterações representam custos muito altos e conseqüente diminuição do grau de satisfação do cliente ou do desenvolvedor do projeto. A Rede de Petri, por ser relativamente mais simples de ser implementada, ao mesmo tempo que possui as características dinâmicas de análise do projeto, fornece essa ferramenta de análise do projeto na fase inicial.

O número de combinações possíveis de serem feitas e a seqüência entre estas combinações somente foram passíveis de análise e estruturação na fase de projeto quando da utilização de ferramentas de vivacidade, segurança e reversibilidade (VSR). Na Rede de Petri foi simulada a seqüência inicialmente planejada para as operações da Micro-usina. Este 
importante modo de representação por grafos pode ser utilizado como ferramenta de verificação e correção de caminhos entre operações a serem implementados. Esses caminhos foram posteriormente implementados e testados no projeto do laboratório do Centro de Estudos em Regulação e Qualidade de Energia (Enerq) 


\section{Capítulo 2 - A importância do Sistema de Cogeração e Características Operacionais}

\subsection{Características Gerais de Operação dos Grupos Diesel Geradores}

Existem basicamente três topologias [13] [14] [15]de funcionamento dos grupos geradores para fornecimento de energia para as cargas. Estas formas são:

1 Singelo e sem paralelismo: Nesta forma de funcionamento o gerador estará suprindo toda a energia necessária ao pleno funcionamento das cargas. Neste tipo de acionamento há apenas 01 grupo gerador isolado para cada grupo de cargas a serem atendidas.

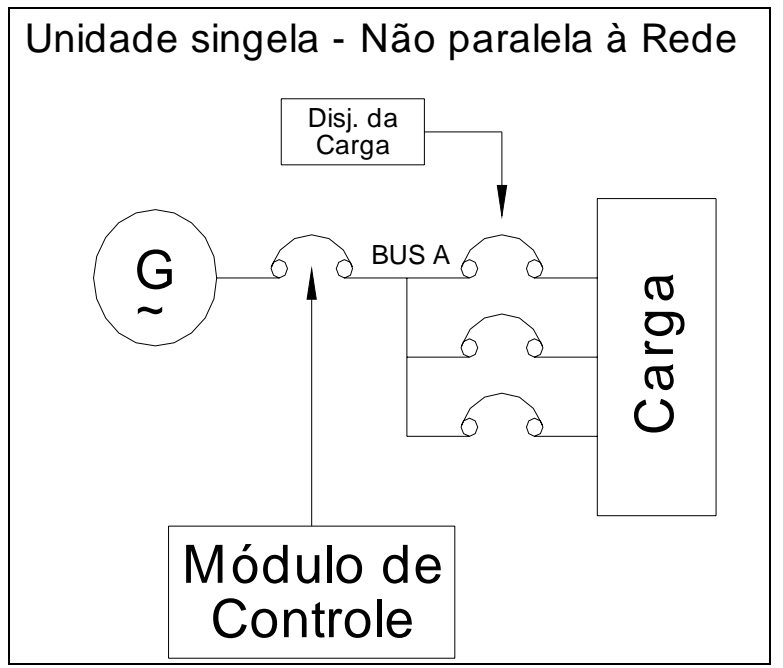

Figura 2.1 - Unidade singela-não paralela à rede

2 Múltiplas unidades sem paralelismo com a rede: Nesta forma de funcionamento há o paralelismo entre geradores, ocorrendo a divisão de cargas entre os mesmos. 


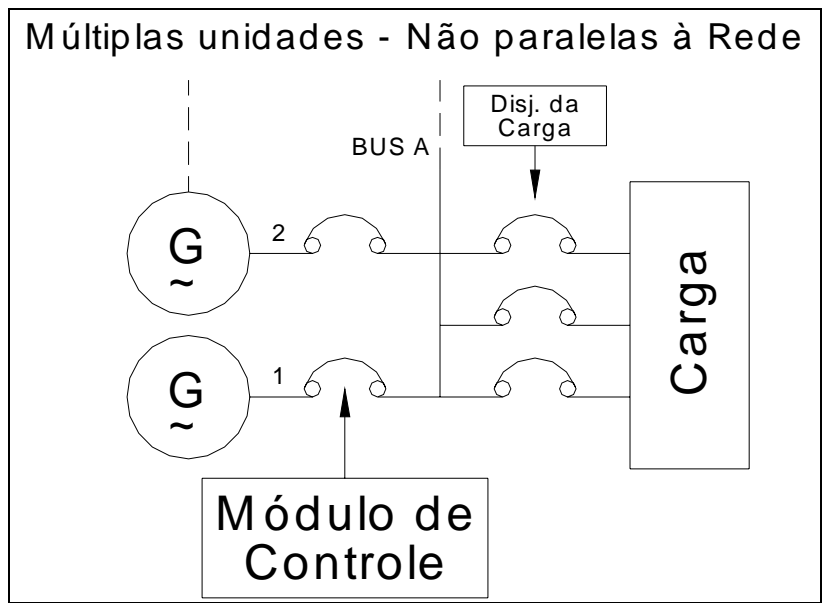

Figura 2.2 - Múltiplas Unidades -não paralelas à rede

3 Múltiplas unidades paralelas à rede: Nesta configuração há uma divisão de cargas entre a concessionária e os grupos geradores. Esta topologia engloba as operações de "peak shave", "base load", paralelismo momentâneo e permanente.

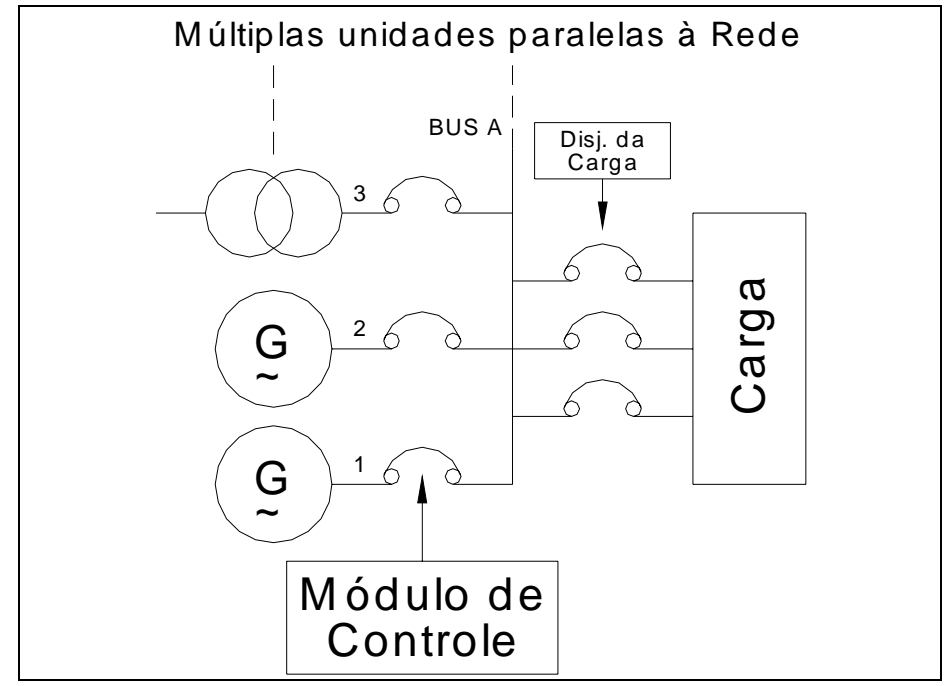

Figura 2.3 - Múltiplas Unidades - paralelas à rede

A operação de colocar um ou mais geradores atendendo à demanda de energia das cargas, sem a presença da rede, é conhecida pelo nome de Operação por Demanda de carga ("Load Demand Operation"). Esta configuração corresponde à topologia "Singelo ou Múltiplo sem paralelismo com a rede". A seguir são descritas as operações típicas realizadas pelo controlador. 


\subsubsection{Operação "Peak Shave”}

Geradoras de energia elétrica, produtores independentes e algumas empresas que geram com recursos próprios a energia elétrica que consomem (autoprodutores), necessitam manter o nível de suprimento de energia compatível com a demanda. Uma forma possível deste tipo de topologia de fontes de geração consiste em manter a carga de base (base load) suprida por uma fonte geradora, por exemplo, concessionária, e complementar o suprimento adicional necessário com uma ou mais fontes suplementares. Essas fontes adicionais são incorporadas ao sistema de geração na medida em que a demanda supera a carga de base contratada. Este processo é conhecido como "peak shave" e, muito freqüentemente, são utilizados os grupos diesel geradores como uma destas fontes complementares. Esses grupos geradores diesel são dotados de controles automáticos capazes de detectar os valores de carga e executar todas as operações necessárias, automaticamente, para assumirem a parcela de carga que excede à carga de base, bem como se desligarem do sistema, quando a demanda se encontra em níveis inferiores aos da carga de base.

Há também casos de grandes consumidores, que embora abastecidos por uma concessionária, podem ter grupos geradores para corte de picos de demanda, com a possibilidade de fornecimento de excedentes à concessionária. Algumas empresas distribuidoras de energia elétrica já se interessam por este tipo de contrato e estudam até mesmo a possibilidade de concessão de financiamento para instalações deste tipo.

Em termos de comandos para os controladores micro-processados, este modo estará disponível se a opção "close transition” e modo automático estiverem ativas. A seleção deste modo pode ser feita localmente (interface presente no controlador) ou de forma remota (SCADA). As seguintes etapas ocorrem para que os grupos assumam a topologia "peak shave".[13][14]

a) Primeira etapa: Os geradores recebem, via sinal de rede, a solicitação para mudar a sua configuração para "Peak Shave" e modo "Singelo" ou "Múltiplo". Entende-se por "Singelo"ou "Múltiplo" a ausência ou não de outros geradores diesel em paralelo com o módulo atualmente comandado. Por razões de segurança, qualquer alteração na configuração do módulo somente será aceita quando os respectivos geradores estiverem parados. 
b) Segunda etapa: Os grupos geradores recebem comandos, via rede ou diretamente no módulo local, para "Início de operação". Os disjuntores da rede são fechados e há a efetiva energização da barra na "cabeça" do gerador. Este procedimento é necessário para que a tensão da rede possa ser usada como referência de sincronismo para os grupos geradores.

c) Terceira etapa: O primeiro grupo gerador (configurado como principal) inicia seu funcionamento ajustando sua fase e módulo ao da rede. Estando em condições para o paralelismo, o disjuntor da "cabeça" do grupo gerador é fechado e o gerador fica acompanhando a rede sem assumir cargas.

$\mathrm{O}$ segundo grupo gerador, respeitando o grau de prioridade pré-estabelecida, ajusta o módulo e a fase de sua tensão para os valores do barramento de emergência. Assim como aconteceu com o grupo principal, o disjuntor do segundo grupo gerador é fechado e passa a acompanhar a concessionária sem trocar praticamente nenhuma potência com a rede ( corrente praticamente nula).

Estando todos os grupos geradores acoplados ao barramento de emergência, os grupos geradores passam a assumir progressivamente a carga estipulada (picos) de modo a manter o montante fornecido pela concessionária em um valor fixo. Esta etapa permanecerá enquanto o sinal de "Início de operação" estiver sendo enviado pela interface local ou estação remota.

Ao final do período destinado para que os grupos geradores forneçam energia para suprir a energia de ponta, ocorrerá a etapa de desligamento dos geradores com transferência em rampa ("soft-transfer"). Ao final desta etapa, ou seja, quando a concessionária estiver fornecendo toda a energia às cargas, dá-se a abertura dos disjuntores individuais para cada grupo gerador. Com os disjuntores abertos, os grupos geradores passam à etapa de resfriamento e parada controlada.

A princípio, pode parecer que as vantagens previstas na geração própria sejam alcançadas operando-se isoladamente da rede pública. Porém, na prática, considerações econômicas e de confiabilidade favorecem a operação em paralelo. Dentre estas considerações, pode-se citar:

- otimização da operação do sistema termoelétrico pela possibilidade de se operar os turbo geradores de acordo com o consumo de energia térmica, comprando da rede a 
energia elétrica suplementar para a indústria ou até mesmo exportando os excedentes de geração para a concessionária;

- regulação automática do intercâmbio de potência ativa e do fator de potência no ponto de interligação;

- possibilidade de se isolar o sistema da indústria do sistema da rede pública quando ocorre falha nesta última, garantindo-se o fornecimento de energia elétrica ao menos para as cargas prioritárias da indústria. Também, em caso de falha na geração própria, não haverá interrupção do fornecimento de energia elétrica.

A avaliação da interligação do sistema auto-produtor com a rede pública é de fundamental importância para permitir que sejam atingidas todas as vantagens do paralelismo. Esta avaliação deve definir aspectos de operação e controle do sistema, configuração do circuito, sua monitoração e sua proteção, pontos de sincronização e de isolamento do circuito em caso de falhas, aterramento, entre outros.

\subsubsection{Transferência com rampa de carga}

É feita na condição de transição fechada, em paralelo com a rede, durante um tempo programado. O sistema de transferência necessita monitorar, por meio de transformadores de corrente, a energia circulante e atuar sobre o sistema de combustível do motor. Sua utilização requer proteções definidas pela concessionária local.(8)(9)(10) 


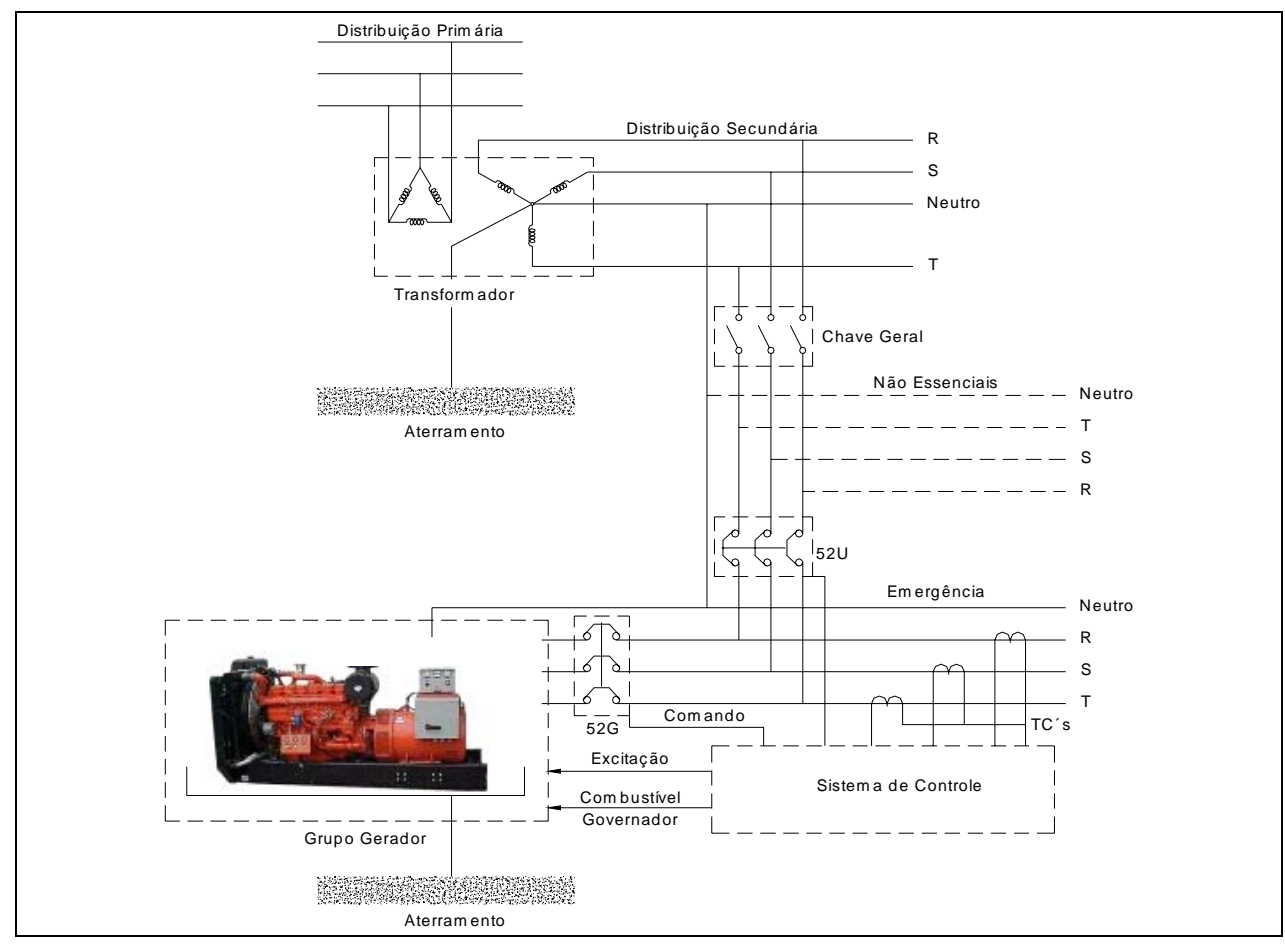

Figura 2.4 - Sistema com transferência em rampa

A transferência com rampa de carga é feita sincronizando o grupo gerador com a rede e, em seguida, comandando o fechamento das chaves de paralelismo (52). O paralelismo, feito por um sincronizador automático, controla tensão e freqüência do grupo gerador e verifica a seqüência de fases. No caso de falha da rede e entrada do grupo gerador na condição de emergência, teríamos a seqüência:

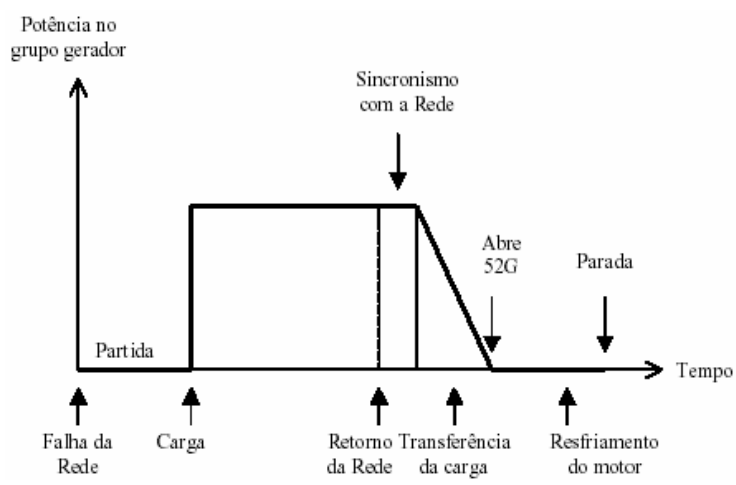

Figura 2.5 - Partida na condição de emergência

No caso da partida do grupo gerador com a rede presente (horário de ponta): 


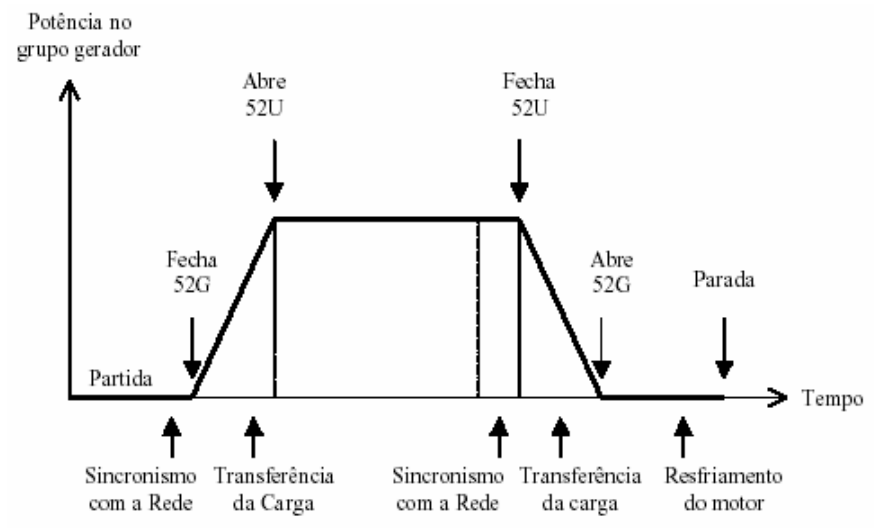

Figura 2.6 - Partida na condição normal com rampa

O sistema deve supervisionar o fluxo de corrente e manter a dosagem do combustível para que, no momento do fechamento de 52G, o grupo gerador não entre em carga nem seja motorizado pela rede. Uma vez fechado 52G, tem início o processo de transferência de carga, numa taxa programada com incremento em $\mathrm{kW}$ por segundo. Essa taxa e o limite não pode exceder a potência do grupo gerador.

Em geral, o mesmo sistema pode ser utilizado para suprimento de energia em regime de peak shaving, isto é, o grupo gerador permanece em paralelo com a rede suprindo a energia que exceder à demanda prefixada para a rede. As configurações de operação são oferecidas em diversas modalidades e praticamente todos os fornecedores atualmente dispõem de sistemas digitais que podem ser configurados para atender às necessidades do cliente.

O grupo gerador poderá também ser utilizado em paralelo com a rede para geração de potência reativa $(\mathrm{kVAr})$. Neste caso, o sistema de controle deverá ser programado para operar com fator de potência constante, fazendo variar a excitação do alternador e gerando mais ou menos potência reativa. Para a geração de potência ativa o sistema atua sobre o governador de rotações, fornecendo mais ou menos combustível, mantendo a rotação constante e variando a quantidade de $\mathrm{kW}$ fornecidos às cargas.

\subsubsection{Problemas da transferência}

Os circuitos consumidores têm características próprias dependentes dos tipos de carga alimentadas. Em um edifício típico, por exemplo, essas cargas seriam: iluminação, elevadores, pequenos no-breaks, computadores e ar condicionado. Em uma indústria a carga predominante será quase que somente composta por motores elétricos. 
Havendo falta de energia, o grupo gerador de emergência, dotado de sistema de transferência automática, deverá ser acionado assumindo as cargas em um intervalo médio de 10 a 15 segundos. Este intervalo é suficiente para que os motores em funcionamento parem de girar e todos os circuitos se desenergizem. Entretanto, quando do retorno da concessionária, o sistema irá desligar o gerador e religar a rede, no intervalo médio de 100 a $200 \mathrm{~ms}$. Isto faz com que, ao ser religada à rede, os motores, por inércia, mantenham praticamente a mesma rotação. O mesmo acontece nas transferências de cargas para grupos geradores nos horários de ponta ou mesmo no retorno à rede, desligando os geradores.

Os motores em movimento, no intervalo da transferência, devolvem sua energia na forma de tensão que irá se contrapor à fornecida pela fonte principal, produzindo um surto capaz de trazer perturbações e a queima de equipamentos. Em topologias onde possa haver este tipo de transitório, é comum programar o religamento da fonte substituta somente após o tempo necessário para desligar todos os motores.

Para os edifícios comerciais com muitos elevadores, uma alternativa freqüentemente adotada é a inclusão no sistema de um relé temporizado que permanece fechado apenas durante o tempo suficiente para que todos os elevadores sejam desligados no andar térreo (ou no mais próximo de onde se encontram), permanecendo desligados durante o tempo de transferência. Esta providência é interessante porque, no caso da transferência da rede para o gerador, permite que os elevadores sejam acionados um após o outro, reduzindo assim o surto de corrente de partida que ocorreria com a partida simultânea de todos os elevadores.

Uma outra forma de efetuar a transferência sem perturbações é a transição fechada, em paralelo com a concessionária, que pode ser instantânea ou com rampa de carga. Para adotar esta solução, é necessário consultar a concessionária e, conforme o caso, aditar o contrato de conexão e uso, para prever esta função. É a forma mais conveniente para quem utiliza grupos geradores para geração nos horários de ponta.

A transferência instantânea significa aplicar carga brusca e a rampa de carga só pode ser utilizada nas transferências com as duas fontes presentes e normais. No caso de uma falta de energia, a entrada do grupo gerador na condição de emergência é feita em barramento morto, assumindo todas as cargas que estiverem ligadas, instantaneamente.

Existem chaves que efetuam a transferência em transição fechada com um tempo de paralelismo menor do que 5 graus elétricos $(0,00023 \mathrm{seg})$. Como as proteções normalmente 
exigidas pelas concessionárias têm tempos de atuação de $100 \mathrm{~ms}$, estas se tornam desnecessárias, porém, podem ser exigidas, a seu critério, por condições contratuais. [7] [8]

\subsection{Controlador Micro-processado para Grupos Geradores}

Os controladores devem possuir uma Interface Homem-máquina (IHM) para indicar as principais variáveis do sistema e também permitir ao operador acesso às opções de configuração disponíveis. Alguns exemplos de interfaces para controladores são mostradas a seguir:

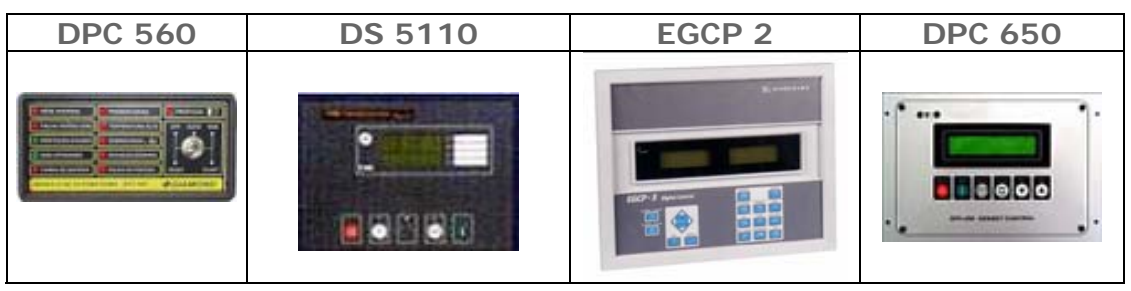

Figura 2.7 - Controladores micro-processados

Algumas das principais características destes controladores são:

- Supervisão de rede;

- Controle de partida e parada;

- Controle de transferência de carga;

- Funções de proteção do motor e gerador;

- Medição digital de grandezas elétricas;

- Sinalização de eventos por LED's e mensagens no display frontal;

- Comando e supervisão remota via porta serial;

- Saída RS-422/485 e relógio real;

- Programador de partidas (opcional);

- Sistema de controle para sincronismo/paralelismo entre geradores e entre geradores e rede;

- Sistema de transferência fechada em rampa de carga/descarga.

Os controladores são utilizados principalmente para médios e grandes sistemas de geração de energia. São indicados para aplicações isoladas da rede, geração em horário de 
ponta ou sistemas em paralelo com a rede. Podem operar sozinhos (Singelo) ou em rede (Mains)[14]. No caso de operarem em rede podem trocar informações com outros controladores de outros grupos geradores ou mesmo da rede. As principais funcionalidades atendidas por sistemas compostos por controladores são:

- Controle de Carga Ativa kW;

- Controle de processo;

- Controle de Carga Reativa kVAR;

- Controle/Proteção do Motor;

-Seqüenciamento Automático;

- Sincronização;

- Comunicações RS422/485;

- Diagnósticos;

- Proteções da Barra;

- Proteções do Gerador.

\subsection{Avaliação das Formas Contratuais}

Em 1993, a Lei n 8.631 e o Decreto $n^{\circ} 774$, que a regulamentou, estabeleceram a não equalização tarifária e a extinção da remuneração legal mínima de $10 \%$ sobre o investimento, vigente desde o Código de Águas, de 1934, fixando, a partir de então, o regime tarifário vigente.[6]

Em função do atual regime de tarifas, cresce o número de empresas que, por motivos de economia, optam pela contratação do fornecimento da energia elétrica pelo regime de tarifa horo-sazonal (tarifa azul e tarifa verde) e utilizam grupos geradores para o suprimento da energia elétrica nos horários de ponta, reduzindo, assim, seus custos. A autoprodução, portanto, vem crescendo por motivos de economia dos consumidores, que têm a possibilidade de gerar sua própria energia elétrica a partir de grupos geradores (diesel). 


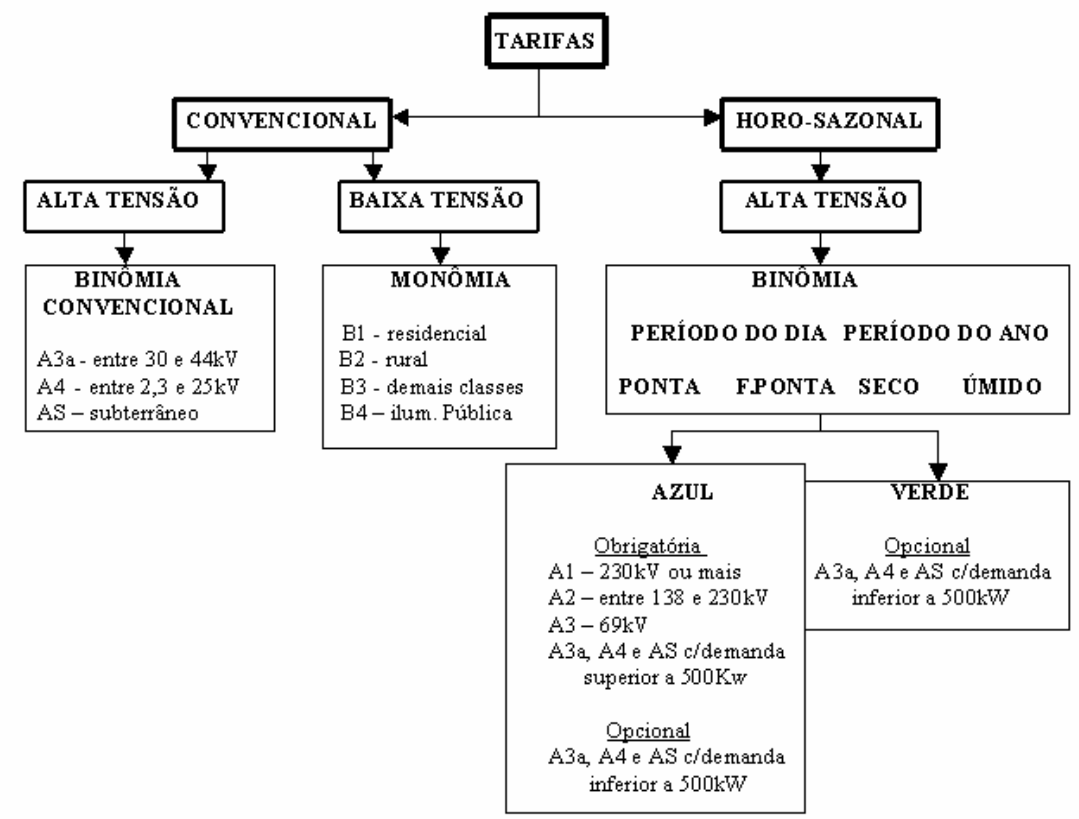

Figura 2.8 - Formas contratuais

\subsubsection{Procedimentos de distribuição [17]}

Quanto à qualidade na distribuição da energia, segundo definidos na Legislação, há os seguintes níveis permitidos para as tensões nominais e limites de fornecimento na distribuição primária: $13,8 \mathrm{kV}, 34,5 \mathrm{kV}, 69 \mathrm{kV}$ e $138 \mathrm{kV}$. Nestes limites, as variações dessa tensão primária de fornecimento, no ponto de entrega de energia, podem estar entre $+5 \% \mathrm{e}-7,5 \%$, entendendo estes como limites adequados. Valores de tensão entre $-7,5 \%$ e $-10 \%$ são considerados precários.

Neste procedimento de distribuição [17] esta sendo estabelecido que os agentes distribuidores e os consumidores livres devem assegurar que o chaveamento de seus equipamentos, e/ou cargas, não resulte em degraus de variação de tensão, no ponto de conexão acima de $5 \%(\Delta \mathrm{V} \leq 5 \%)$.

No caso de haver grupos geradores conectados ao sistema, estes não deverão reduzir a flexibilidade de recomposição da rede elétrica, seja em função de limitações dos equipamentos ou por tempo de recomposição. Os usuários, com geradores embutidos, devem prestar informações sobre as características técnicas e operacionais de sua geração, durante o pedido de consulta, tais como: dados gerais (tensão, potência aparente e ativa nominais, tipo do gerador, tipo do regulador de velocidade, regime de operação, contribuições para curto 
circuito, método de controle de tensão, detalhes do transformador do gerador quando aplicável, suprimento de stand-by e top-up, etc.). Nesta fase devem ser discutidos os arranjos de interface: sincronização da concessionária com o usuário, aterramento, equipamentos de conexão e desconexão e detalhes de precauções de segurança, caso o aterramento do neutro do gerador seja desconectado.

Algumas outras informações adicionais podem ser requeridas pela concessionária, em função do tipo e porte da geração ou do ponto de conexão no sistema de distribuição, tais como:

- Gerais: fornecer capacidade de contrato em $\pm \%$ da freqüência da rede e da tensão da rede;

- Arranjos de controle: sistema de controle automático de excitação do gerador em função do tipo, porte e ponto de conexão do gerador no sistema de distribuição;

- Coordenação com o sistema de proteção da concessionária;

- Capacidade de atendimento às ilhas do sistema de distribuição, em condição de contingência na rede.

Segundo este documento [17] as especificações das usinas termoelétricas deverão ser precedidas de análises dos modos de oscilação subsíncrona. Os equipamentos para o amortecimento de tais oscilações, função das características de impedância do sistema de distribuição, deverão ser incorporados pelos acessantes já no início da operação da usina.

As unidades geradoras deverão permanecer conectadas à rede sempre que a freqüência estiver dentro dos limites definidos nestes Procedimentos de Distribuição.

O fator de potência nominal do gerador deverá ser menor ou igual a 0,95 (adiantado ou atrasado) nos terminais do gerador, para tensão e potência nominais.. As ações e os custos incorridos para o atendimento a este requisito são de responsabilidade do Agente Gerador.

Deverão ser considerados os reflexos listados a seguir, tanto no ponto de conexão, como na área de influência do gerador, inclusive com impactos do tipo superação da capacidade de equipamentos ou necessidade de reajustes de parâmetros de proteção e controle:

- Avaliação do nível de curto-circuito com a presença da central geradora; 
- Avaliação da capacidade de disjuntores, barramentos, TCs e malhas de terra;

- Avaliação da adequação dos sistemas de proteção envolvidos com a integração do gerador e revisão dos ajustes associados aos mesmos;

- Avaliação paramétrica dos reguladores de tensão, de velocidade e dos sinais estabilizadores.

Todos os estudos necessários para avaliar o desempenho da operação do gerador conectado ao sistema interligado brasileiro deverão ser submetidos à apreciação do agente distribuidor[17].

Deverão ser estabelecidas as responsabilidades quanto aos processos de manutenção, com desligamentos programados, bem como em relação a falhas que venham trazer danos para os demais consumidores conectados à rede de distribuição.

Os geradores deverão ter sistemas de excitação com tempo de resposta, teto, capacidade de corrente negativa e outras peculiaridades compatíveis com os requisitos do sistema elétrico, a serem especificados pelo agente distribuidor[17]. A ação de limitadores ( sobre-excitação, sub-excitação, Volts/Hertz, etc.) deverá ser coordenada dinamicamente com a atuação das respectivas proteções, de forma a minimizar o desligamento de geradores. As ações e os custos decorrentes dos requisitos de controle acima descritos, bem como daqueles que venham a ser identificados pelo agente distribuidor para garantir o adequado desempenho do sistema, são de responsabilidade do agente gerador.

\subsection{Modalidades Tarifárias}

\subsubsection{Tarifa convencional}

As tarifas atuais de energia elétrica [6] são denominadas binômia por terem dois componentes básicos na definição do seu preço:

- Componente relativo à demanda (expressa em $\mathrm{kW}$ );

- Componente relativo ao consumo de energia ativa (expresso em $\mathrm{kWh}$ ).

Nesta modalidade de tarifa, denominada "convencional", as tarifações são feitas sobre o consumo de energia e pela maior demanda de potência registrada ou contratada. 
Na tarifa convencional, portanto, o horário e o período de consumo não são considerados no cálculo do custo a ser cobrado pela energia elétrica consumida.

Esta forma de tributação é indicada para empresas que utilizam processo contínuo de produção ou prestação de serviços, sem possibilidade de modulação. São também indicadas para empresas cuja maior demanda de energia elétrica ocorre no horário de ponta.

\subsubsection{Tarifas horo-sazonais}

As tarifas horo-sazonais se subdividem em duas:

- Verde: neste tipo de faturamento contabiliza-se tanto a demanda de ponta, quanto a fora da ponta e ainda as energias de ponta e fora da ponta, tanto no período seco quanto úmido.

- Azul: esta forma de faturamento considera, para efeito de cobrança, a demanda máxima de todo o período e, ainda, as energias de ponta e fora da ponta, tanto no período seco quanto úmido.

A utilização de energia elétrica em uma cidade ou região ao longo do dia pode ser mostrada na forma gráfica e é denominado "curva de carga". Essa curva apresenta a seguinte forma:

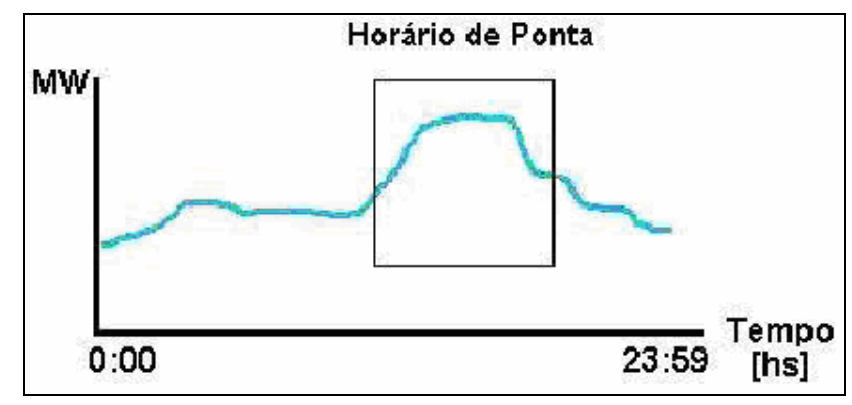

Figura 2.9 - Curva de carga diária do sistema elétrico ( Eletrobrás, 2003)

\subsubsection{Horário de ponta}

No intervalo das $17 \mathrm{~h}$ às $22 \mathrm{~h}$ ocorre o maior carregamento do dia e, devido a esse fato, é denominado "horário de ponta" da curva de carga. O aumento do uso de eletricidade, no horário de ponta, deve-se a diversos fatores relacionados aos hábitos e necessidades normais das grandes cidades. Os fatores que mais influenciam no horário de pico são: 
- Iluminação pública;

- Chuveiros elétricos das residências;

- Demanda das indústrias - muitas empresas permanecem trabalhando nesse horário;

- O comércio, com a iluminação das vitrines, principalmente nos shoppings.

No horário de ponta, o atendimento de cada novo consumidor tem custo adicional para a concessionária, porque exige a ampliação do sistema.

Outro fator que contribui na formação do preço da energia é a disponibilidade média de água nos mananciais. Em função da disponibilidade hídrica, foram classificadas duas épocas do ano: Período Seco e Úmido. A seguir são mostradas as duas tarifas "Azul" e "Verde" indicando os dois períodos e a distribuição de custos de cada tarifa.

TARIFA AZUL

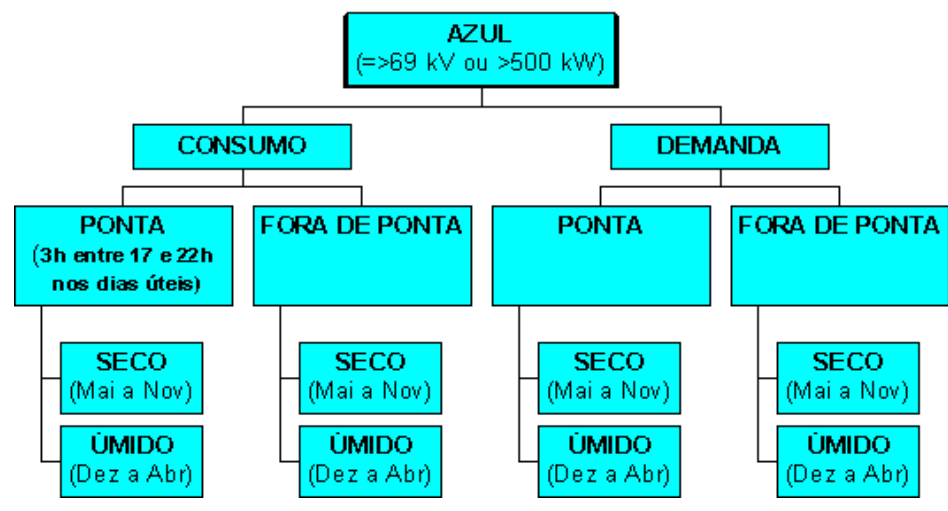

Figura 2.10 - Tarifa azul 


\section{TARIFA VERDE}

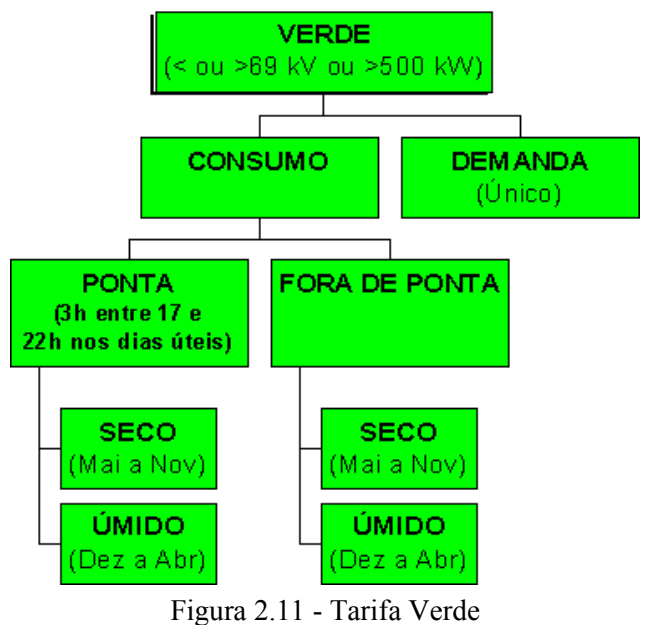

Os valores mudam de concessionária para concessionária e são reajustados periodicamente mediante resoluções da ANEEL, em função das condições dos contratos de concessão. Sobre as tarifas, incide o ICMS, calculado pela alíquota vigente em cada estado, bem como o adicional ECE, de encargo para o aumento da capacidade emergencial. 


\section{Capitulo 3 - Descrição do Sistema Desenvolvido}

\subsection{Diagrama Elétrico do Sistema}

O sistema desenvolvido está representado no unifilar da Figura 3.1. Neste unifilar estão sendo mostrados todos os equipamentos de comando e monitoração importantes ao sistema, vistos pela ótica do fluxo de energia da Micro-usina.

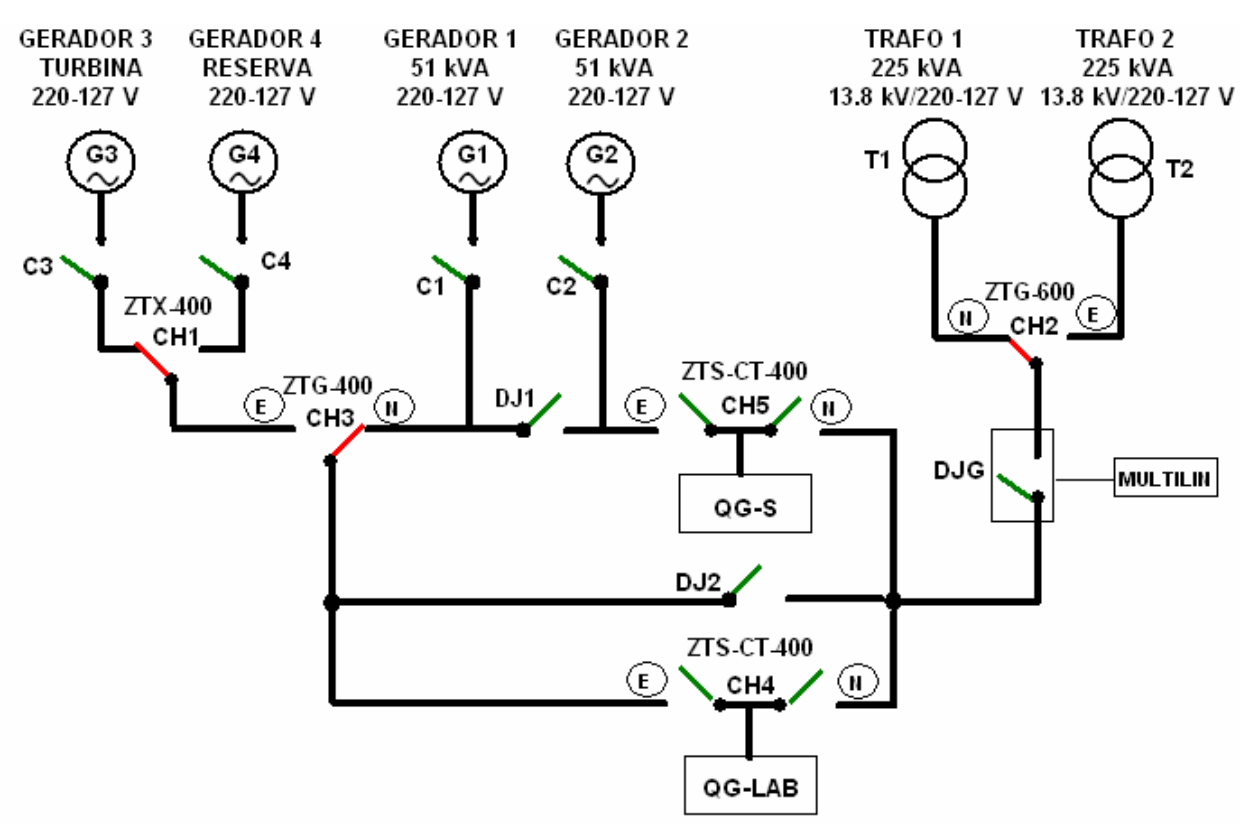

Figura 3.1 - Diagrama unifilar do sistema - Energia

No unifilar da Figura 3.1 podem ser vistos os seguintes equipamentos:

- Chaves de transferência automática da carga entre as duas fontes de energia "com interrupção" no fornecimento ou, simplesmente, "transição aberta". A característica fundamental desta chave é permitir a transferência entre circuitos em um intervalo de tempo menor que $\mathbf{1 0 0}$ ms. Neste projeto são representados por $\mathrm{CH} 1, \mathrm{CH} 2$ e $\mathrm{CH} 3$;

- Chaves de transferência da carga entre as duas fontes de energia "sem interrupção" no fornecimento ou, simplesmente, "transição fechada". As chaves utilizadas têm o tempo de permanência em que as fontes ficam interligadas de $100 \mathrm{~ms}$. Neste projeto são representados por $\mathrm{CH} 4$ e $\mathrm{CH} 5$; 
- Disjuntor motorizado para manter o paralelismo entre geradores. Utilizou-se um disjuntor com comando pulsado para abertura, fechamento e retorno do estado de aberto e fechado. Neste projeto são representados por DJ1 e DJ2 e DJG;

- Grupos Geradores (02) de 50 kVA / 220Volts e 60 Hz com módulo de sincronismo e controle tipo Woodward. Estes módulos trocam informações com o CLP através de uma rede RS485 ModBus RTU tendo também uma rede RS422 exclusiva para sincronismo entre módulos de controle. Os grupos geradores serão referenciados por seus disjuntores de saída do gerador ( fornecidos pelo próprio fabricante do equipamento) e nomeados como $\mathrm{C} 1$ e $\mathrm{C} 2$ respectivamente;

- Transformadores de entrada da concessionária. Serão referenciadas por T1 e T2 respectivamente;

- Relé de proteção de entrada da rede concessionária tipo Multilin;

- Quadros gerais dos dois grupos de cargas existentes: QG-LAB para as cargas do laboratório e QG-S para as cargas essenciais. 


\subsection{Topologia da Automação do Sistema}

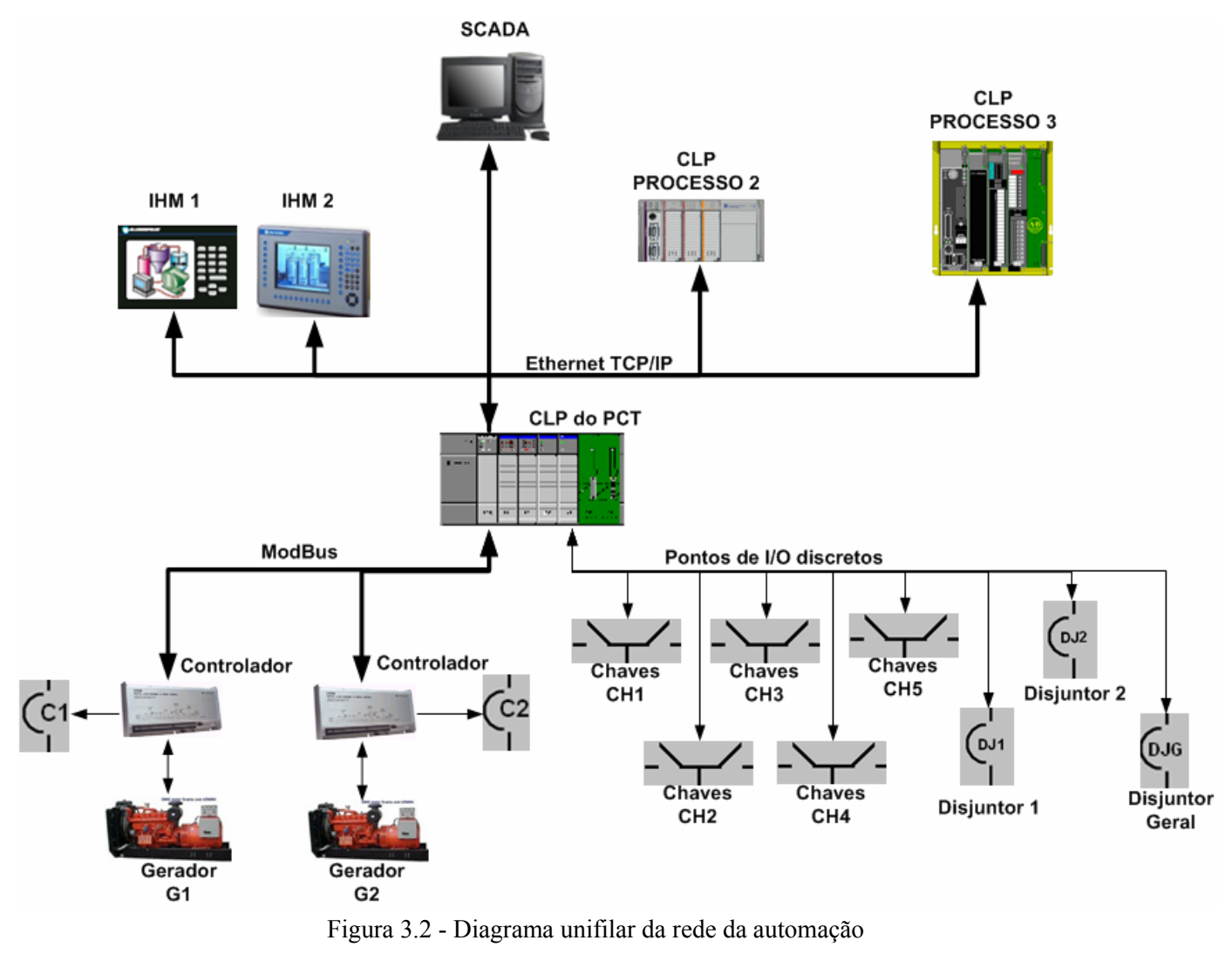

Na topologia da Figura 3.2 estão sendo mostrados os dois principais níveis da automação projetados para a Micro-usina: Nível 1 ou chão de fábrica; Nível 2 ou supervisão e controle.

No nível 1 estão presentes os sensores e atuadores responsáveis pela transferência entre geradores de energia e consumidores, permitindo o paralelismo e a cogeração desejada. Neste nível também estão equipamentos de proteção e seletividade, que irão atuar diretamente sobre os disjuntores de entrada dos barramentos ou nos disjuntores dos geradores.

No nível 2 encontra-se o Controlador Lógico Programável (CLP) que irá coletar informações, tomar decisões e também comunicar, por meio das redes, as informações de estado ou comando para os geradores, chaves, disjuntores motorizados do painel, supervisórios (SCADA) e Interfaces Homem-Máquina (IHM). 


\subsection{Formas Operacionais do Sistema}

A nomenclatura utilizada para descrever as formas operacionais será a mesma descrita no item 3.1. Desta forma os geradores serão descritos como G1, G2, G3 e G4, as cargas como QG-Lab ( ou quadro geral para o laboratório) e QG-S (quadro geral das cargas essenciais), os transformadores são descritos como T1 e T2 ( de entrada da concessionária) e os disjuntores como DJ1 (disjuntor de paralelismo entre geradores), DJ2 (disjuntor de paralelismo com a concessionária) e DJG ( disjuntor geral de entrada da concessionária).

As combinações entre os fornecedores de energia ( G1, G2, G3, G4, T1 e T2) e as cargas (QG-Lab e QG-S) geram diretamente todas as combinações possíveis para esse número de variáveis.

Em uma primeira análise não foram considerados os grupos geradores G3 e G4, que serão abordados em um próximo trabalho.

Em uma segunda análise, foram consideradas as topologias possíveis devido à disposição dos barramentos, disjuntores e chaves do painel de controle e transferência (PCT). A combinação final envolvendo as 04 fontes fornecedoras de energia já implantadas (G1, G2, T1 e T2), em modo singelo ou paralelo, com os dois grupos de cargas (QG-Lab e QG-S) gerou um total de 289 (17 por 17) possibilidades das quais 24 foram selecionadas como podendo efetivamente ser utilizadas no projeto atual.

Através do supervisório (SCADA) ou do PCT é possível selecionar qual operação será realizada na Micro-usina. Cabe ao Controlador Lógico Programável (CLP) verificar quais dos comandos devem ser feitos, intertravamentos devem ser verificados ou seqüências de eventos seguidas .Os comandos e parametrizações dos controladores de velocidade presentes nos grupos geradores serão executados via rede ModBus RTU, sendo esta rede escolhida por ser uma rede com protocolo aberto, utilizada por vários fabricantes, sendo que grande parte destes fornecedores atuam na área de energia. A taxa de comunicação configurada neste projeto foi de 9600 bps (exigência imposta pelo módulo controlador de velocidade do grupo gerador). A título de ilustração, foi colocada a tabela de comunicação utilizada neste projeto (Figura 3.3), onde são mostrados os principais comandos trocados com os controladores. Esta tabela mostra alguns dos comandos enviados aos endereços de registro de memória dos controladores dos grupos geradores. Nestes controladores deve-se informar por rede os seguintes parâmetros e comandos: 
- Parâmetro do "tipo de operação singelo ou múltiplo": A opção singelo (Registro) indica ao controlador que não haverá a necessidade de paralelismo entre grupos geradores. Desta forma apenas o gerador "Mestre" entra em funcionamento e preparação para assumir a totalidade ou parte das cargas. No modo múltiplo, o gerador principal irá iniciar seu funcionamento chegando ao fechamento do seu disjuntor principal ( entrando em paralelo com a concessionária mas sem assumir cargas). Em seguida, após o fechamento do disjuntor do primeiro gerador (C1), o segundo inicia o seu sincronismo finalizando pelo acoplamento deste ao sistema através de seu disjuntor (C2). Após o fechamento do segundo disjuntor, há o início da rampa de transferência de cargas que poderá ser parcial ou completa;

- Parâmetro do "tipo de operação com ou sem a rede concessionária": Esta opção representa o funcionamento do grupo gerador de forma isolada ou com paralelismo com a rede concessionária;

- Parâmetro do "modo de operação Peak-shave": Este modo de operação corresponde a assumir o excedente da carga contratada pela concessionária;

- Modo "Base Load": Nesta configuração os grupos geradores irão fornecer apenas um montante de potência "fixa" ou pré-ajustada;

- Comandos de início e fim de funcionamento: Comandos digitais enviados aos módulos controladores a fim de iniciar ou finalizar o funcionamento dos grupos geradores.

\begin{tabular}{|c|c|c|c|c|c|c|c|c|c|c|c|}
\hline & \multirow{2}{*}{\multicolumn{3}{|c|}{$\begin{array}{c}\text { Estado das fontes de } \\
\text { Energia }\end{array}$}} & \multicolumn{7}{|c|}{ Parâmetros de Registro e Comandos ModBus } & \\
\hline & & & & & & & & & ores & & \\
\hline itterm & G1 & G2 & $\begin{array}{c}\mathrm{T} 1 \\
\text { (rede) }\end{array}$ & $\begin{array}{l}0 \\
0 \\
0 \\
0 \\
1\end{array}$ & $\begin{array}{l}0 \\
0 \\
0 \\
0 \\
3\end{array}$ & $\begin{array}{l}0 \\
0 \\
0 \\
0 \\
1\end{array}$ & $\begin{array}{l}0 \\
0 \\
0 \\
0 \\
3\end{array}$ & $\begin{array}{l}4 \\
0 \\
0 \\
0 \\
1\end{array}$ & $\begin{array}{l}4 \\
0 \\
2 \\
6 \\
7\end{array}$ & $\begin{array}{l}4 \\
0 \\
2 \\
6 \\
8\end{array}$ & Descriçẩo \\
\hline 1 & Parado & Parado & Parado & 1 & 0 & 1 & 0 & 1 & 1 & 1 & Sem fornecimento de energia (Sistema parado) \\
\hline 2 & Run & Parado & Parado & 1 & 1 & 1 & 0 & 1 & 1 & 1 & Gerador 1 fornecendo energia para as carga e sem a Concessionária \\
\hline 3 & Run & Run & Parado & 1 & 1 & 1 & 1 & 1 & 1 & 1 & Gerador 1 e 2 fornecendo energia para as carga e sem a Concessionária \\
\hline 4 & Parado & Run & Parado & 1 & 0 & 1 & 1 & 2 & 1 & 1 & Gerador 2 fornecendo energia para as carga e sem a Concessionária \\
\hline 5 & Run & Run & Parado & 1 & 1 & 1 & 1 & 2 & 1 & 1 & Gerador 1 e 2 fornecendo energia para as carga e sem a Concessionária \\
\hline 6 & Parado & Parado & Run & 1 & 0 & 1 & 0 & 2 & 1 & 1 & Apenas a concessionária Ligada \\
\hline 7 & Parado & Run & Run & 1 & 0 & 1 & 1 & 2 & 1 & 1 & Grupo gerador 2 em paralelismo permanente com a concessionária \\
\hline 8 & Run & Run & Run & 1 & 1 & 1 & 1 & 2 & 1 & 1 & Grupos geradores 1 e 2 em paralelismo permanente com a concessionária \\
\hline 9 & Run & Parado & Run & 1 & 1 & 1 & 0 & 1 & 1 & 1 & Grupo gerador 1 em paralelismo permanente com a concessionária \\
\hline
\end{tabular}

Figura 3.3 - Principais parâmetros e operações trocados pelo CLP com o módulo controlador via rede ModBus

As 24 possibilidades, já mencionadas anteriormente e implementadas neste projeto, fornecem todas as principais topologias necessárias para reproduzir as principais configurações encontradas nas aplicações envolvendo geradores, chaves de transferência e a concessionária. Na fase de testes foi feita uma representação dinâmica do unifilar do PCT 
indicando, pelo posicionamento e cor das chaves e disjuntores, as várias configurações possíveis para a Micro-usina. A título de exemplo, são mostradas a seguir algumas das principais topologias representadas por seus diagramas unifilares resumindo os principais equipamentos que compõem a Micro-usina. Esses unifilares serão utilizados na modelagem e simulação da automação do sistema como forma de ilustrar os estados alcançados pela da Rede de Petri.

\subsubsection{Concessionária fornecendo energia para ambas as cargas QG-Lab e QG-S (essenciais)}

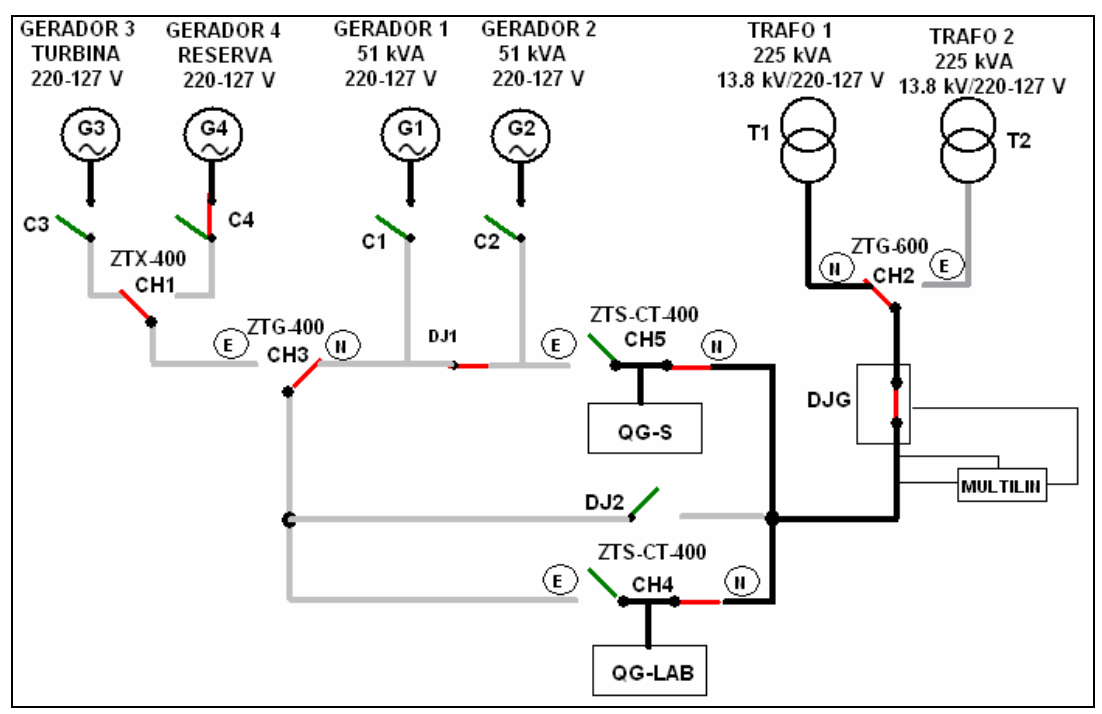

Figura 3.4 - T1 fornecendo para QG-S e QG-Lab

Nesta topologia pode-se verificar que ambos os quadros gerais de cargas são alimentados pela concessionária. Nesta forma de alimentação, havendo uma falha do fornecimento da concessionária, os geradores deverão ser acionados por seus módulos automaticamente e haverá a transferência feita pelas chaves ZTS para o lado de emergência "E" somente após a fase de partida dos grupos geradores. Trata-se de um sistema com backup de emergência, havendo interrupção do fornecimento de energia tanto na passagem para o grupo gerador quanto no retorno para a concessionária. Em alguns projetos já implementados esta configuração é complementada por no-breaks de apoio junto às cargas mais críticas. 
3.3.2 Concessionária T1 fornecendo energia para QG-Lab e o Gerador G1 fornecendo para QG-S

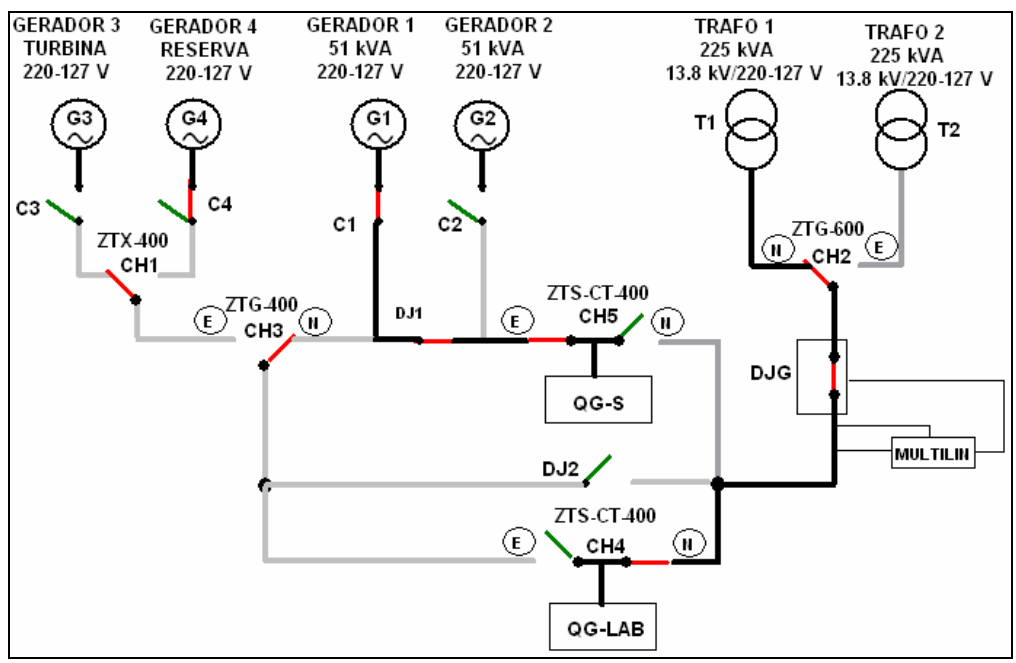

Figura 3.5 - T1 fornecendo para QG-Lab e G1 fornecendo para QG-S

Nesta topologia pode-se verificar que um dos geradores está suprindo parte das cargas (Quadro das cargas essenciais) enquanto a concessionária fornece energia para o segundo grupo de cargas (Laboratório). Nesta topologia são minimizados problemas de falhas no fornecimento pela concessionária, devido às cargas essenciais estarem garantidas pelo gerador, tendo a concessionária como backup de segurança ("hot-stand-by"). Nesta configuração haverá ainda uma rápida queda no fornecimento de energia devido ao fato de que o grupo gerador G1 não estará necessariamente em fase com a concessionária e o retorno de energia pela CH5 apenas ocorrerá após a queda ( não está ocorrendo paralelismo permanente). 
3.3.3 Concessionária fornecendo para QG-Lab e o Gerador G1 em paralelo com G2 fornecendo para QG-S

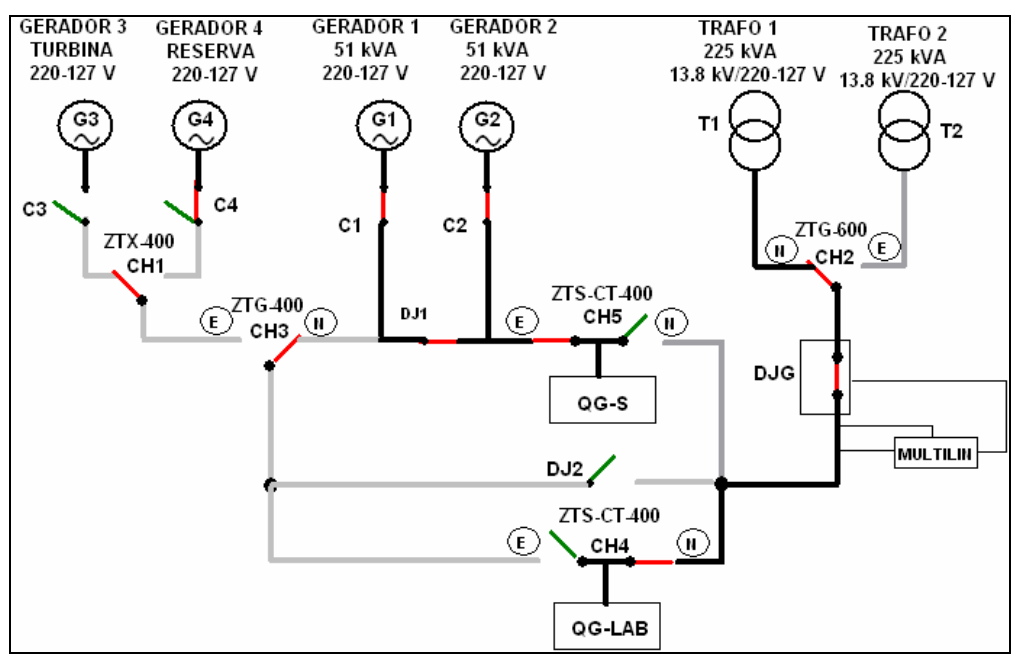

Figura 3.6 - T1 fornecendo para QG-Lab e G1//G2 fornecendo para QG-S

Nesta topologia, mais segura que a anterior, pode-se verificar que os dois geradores estão suprindo parte das cargas (Quadro das cargas essenciais), enquanto a concessionária fornece energia para o segundo grupo de cargas.

\subsubsection{Gerador G1 fornecendo para QG-Lab e para QG-S}

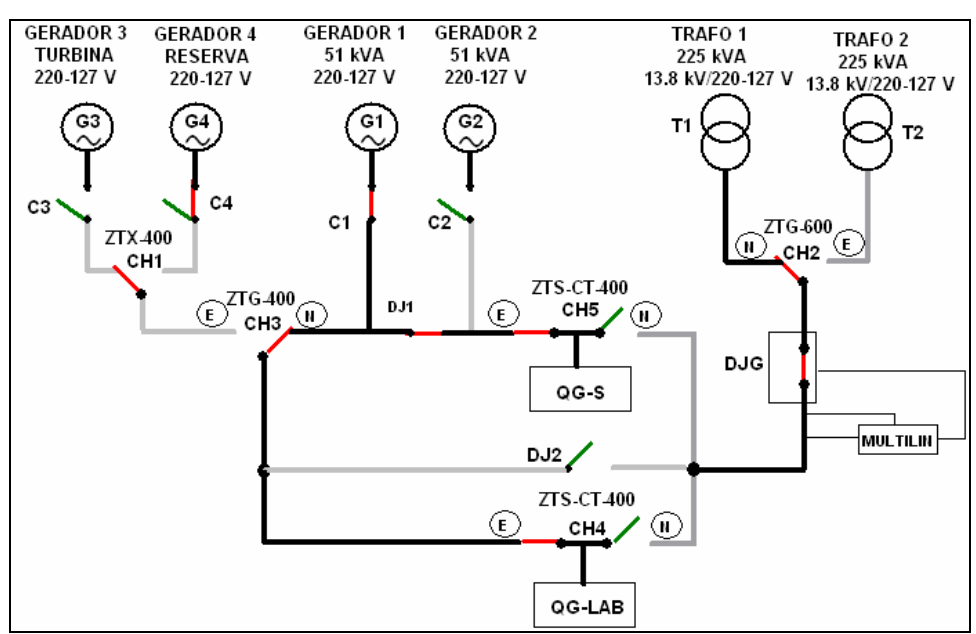

Figura 3.7 - G1 fornecendo para QG-Lab e para QG-S

Nesta topologia pode-se verificar que um dos geradores está suprindo a totalidade das cargas (Quadro das cargas essenciais e do laboratório). Esta seria uma típica operação em 
emergência ou manutenção na alimentação da concessionária com backup de segurança fornecido pelo gerador $\mathrm{G} 2$.

\subsubsection{Gerador G1 em paralelo com G2 fornecendo para QG-Lab e para QG-S}

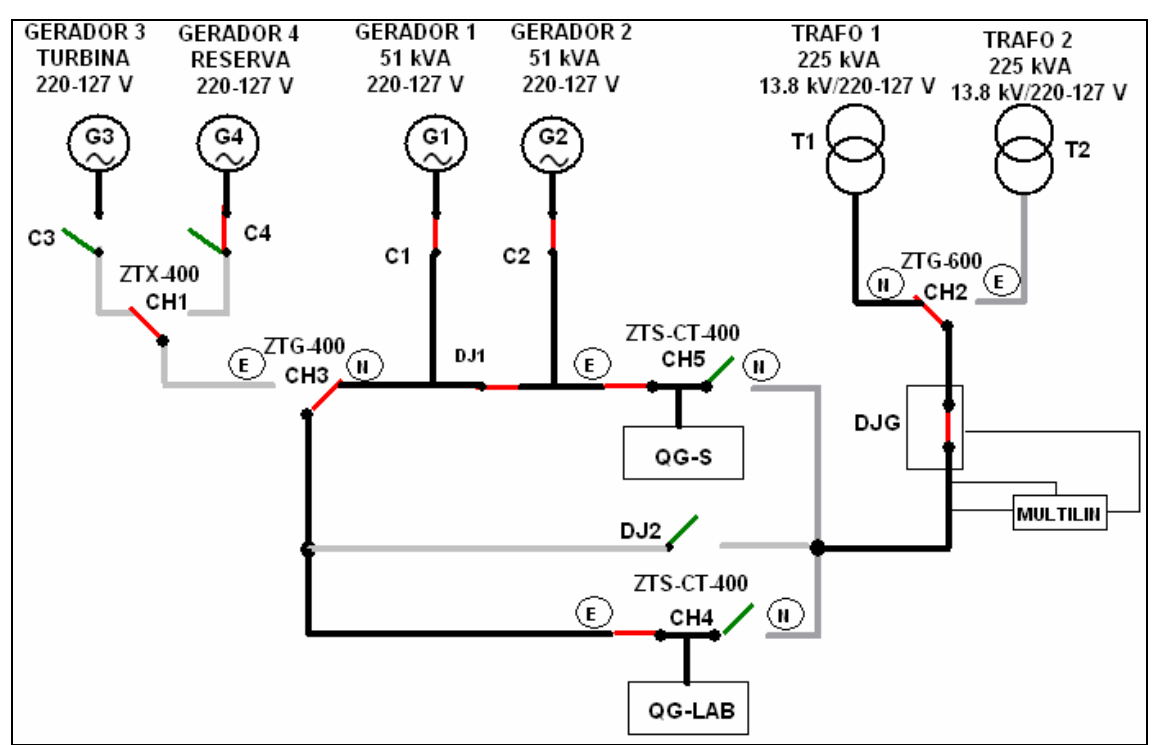

Figura 3.8 - G1//G2 fornecendo para QG-Lab e para QG-S

Nesta topologia, mais segura que a anterior, pode-se verificar que os geradores estão suprindo a totalidade das cargas (Quadro das cargas essenciais e do laboratório) com paralelismo permanente entre eles. Esta seria uma operação utilizada como de emergência ou para uma eventual manutenção na rede de alimentação da concessionária, porém com maior grau de segurança devido ao paralelismo entre geradores. 
3.3.6 Gerador G1 em paralelo com G2 e em paralelo com T1 fornecendo para QG-Lab e para QG-S

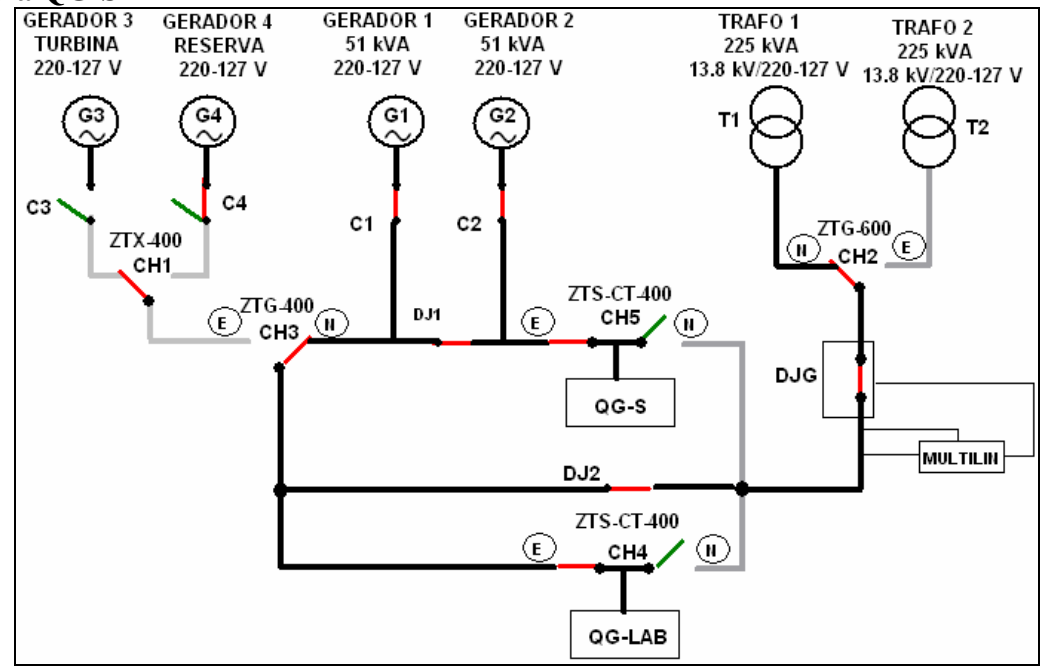

Figura 3.9 - G1//G2//T1 fornecendo para QG-Lab e para QG-S

Nesta topologia, mais segura que as anteriores, pode-se verificar que os geradores estão em paralelismo permanente com a rede concessionária compartilhando o fornecimento de energia para as cargas (Quadro das cargas essenciais e do laboratório). Esta configuração é a mais segura de todas, uma vez que três geradores de energia estão suprindo as cargas existentes segundo a configuração feita nos módulos de comando ( Peak-shave ou Base Load ou simplesmente durante a transferência em rampa). 


\section{Capítulo 4 - Modelagem e Simulação da Automação do Sistema}

\subsection{Introdução}

A Rede de Petri foi utilizada para mostrar a alcançabilidade dos estados implementados, assim como para verificar erros e falhas na passagem dos estados ou mesmo transições indevidas. Essa forma de representação, para sistemas dinâmicos e com eventos discretos, foi introduzida por C. Petri em sua tese de doutorado (1962) dedicada às comunicações com autômatos. Uma Rede de Petri é uma forma de representação utilizando grafos orientados, havendo dois tipos distintos de nós: transições (transitions) e posições (places). Os arcos existentes nesta forma de representação partem sempre de uma posição para uma transição ou vice-versa. Aos arcos associam-se números (inteiros) de marcas (tokens) e estas, sob certas condições, podem mover-se ao longo destes arcos, respeitando os sentidos destes.

As principais propriedades a serem verificadas com a rede de Petri são:

- Limitação e Segurança;

- Vivacidade e Conflitos;

- Reversibilidade.

Por Limitação e Segurança entende-se o não crescimento de marcas com o passar do tempo e das mudanças de estado. Esse crescimento tende ao infinito em sistemas mal implementados.

A vivacidade e os conflitos garantem que não haverá mais transições a serem satisfeitas e estados a serem alcançados. A rede permanecerá "viva" com o passar do tempo, não entrando em um conflito-mortal (dead-lock), no qual a situação de vivacidade não seria mantida.

Por reversibilidade entende-se como sendo a capacidade do sistema retornar a um estado específico previsto, de onde possa retornar a suas condições normais de operação. Por exemplo: havendo uma queda de energia, os geradores entram automaticamente suprindo a carga do fornecimento necessário. Voltando a concessionária, o sistema tem que ser capaz de retornar, manualmente ou automaticamente, para o estado de onde foi retirado. 


\subsection{Modelagem do sistema considerando as fontes de alimentação nas duas cargas \\ (Laboratório e Essenciais)}

Em uma análise inicial foram colocadas todas as combinações possíveis de alimentação das cargas considerando apenas as fontes geradoras G1, G2 e T1 (não considerando ainda T2). A representação com os dois transformadores, T1 e T2, será apresentada ao longo do trabalho.

O resultado obtido foi representado no grafo da figura a seguir e indica os estados (posições representadas pelos círculos) e as transições ( posições representadas pelos retângulos) deste primeiro sub-sistema analisado.

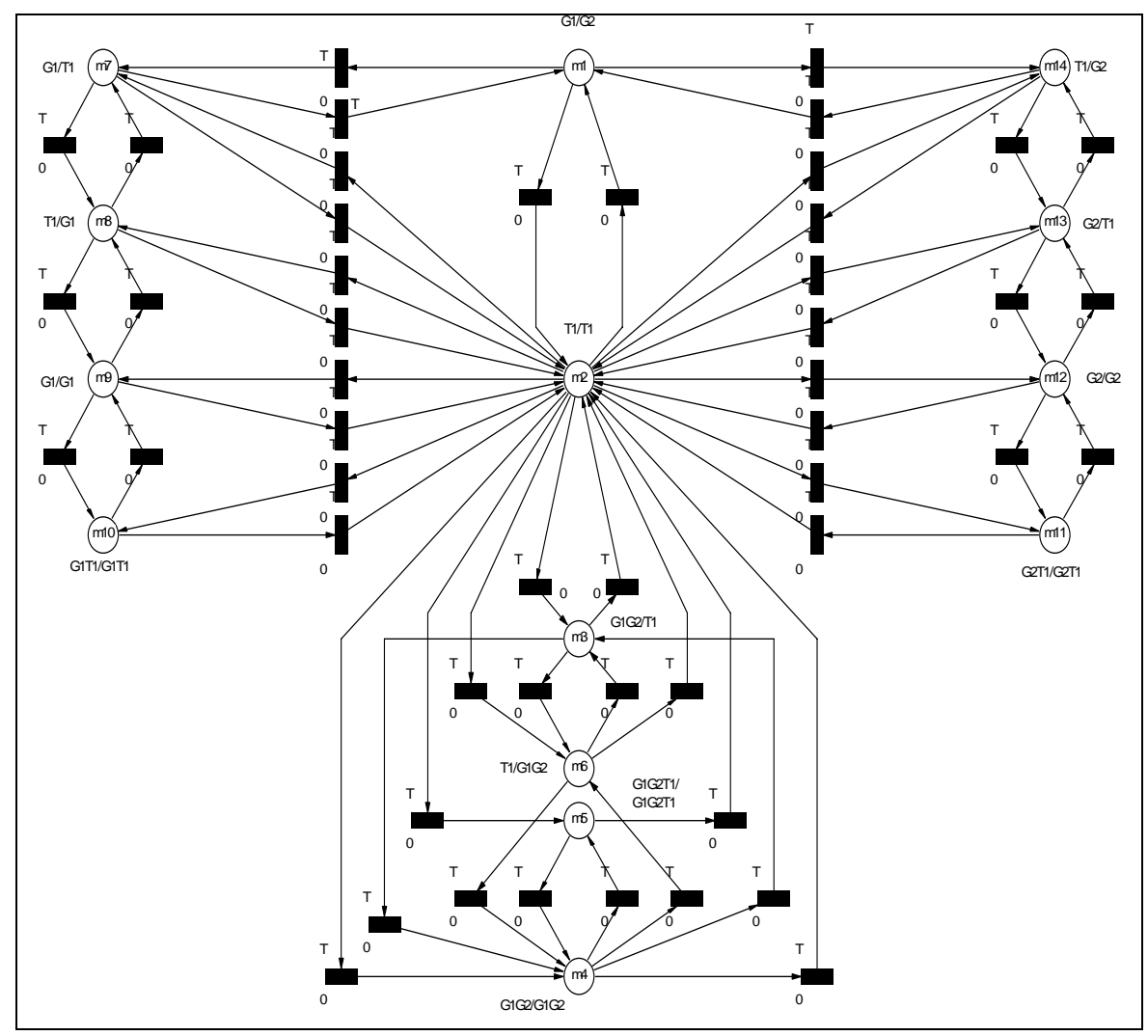

Figura 4.1 - Todos os geradores (G1, G2 e T1) fornecendo energia para QG-Lab e QG-S.

O modelo utilizado tem como objetivo principal permitir a representação dos estados operacionais do sistema e não a representação individual de seus componentes constituintes. 
A Rede de Petri será utilizada para conseguirmos analisar o sistema quanto aos seus aspectos de Vivacidade, Reversibilidade e Segurança.

A análise dos estados permite conhecer a alcançabilidade da Rede de Petri do sistema através das transições permitidas e habilitadas. As transições representam as ações externas do tipo operacionais ou circunstanciais que norteiam as mudanças de estado. As ações operacionais são aquelas causadas pela intervenção do operador solicitando alterações no sistema através das botoeiras ou supervisório. Por ações circunstanciais entende-se como sendo aquelas causadas por "falhas" nos componentes do sistema ocasionando a transição para um novo estado das chaves, disjuntores e geradores.

A importância do método usado neste projeto da Micro-usina reside no fato de mostrar, com a Rede de Petri e pela alcançabilidade, como de um estado X0 é alcançável um novo estado X1. A forma pela qual, partindo-se de um estado inicial chega-se a um estado final, pode ocorrer tanto de forma direta quanto da forma indireta. $\mathrm{Na}$ forma indireta irá percorrer caminhos específicos previstos no projeto do painel de controle e transferência.

Neste sistema pôde ser verificado que as condições de VRS (Vivacidade, Reversibilidade e Segurança) estão observadas. A simulação dos estados no software da Rede de Petri e mesmo os testes finais na planta mostraram que não havia aumento das marcas ou estados com conflitos mortais ou mesmo que todos os estados podiam ser alcançados após as operações por motivos de falhas (contingências) ou motivos normais de operação.

Características operacionais do sistema: ele possui estados operacionais bem definidos que representam, para a configuração atual inicial constituída por 03 fontes e duas cargas, todas as posições permanentes ou transitórias que o sistema pode ocupar baseado em transições permitidas em sua topologia. Para que haja a transição de uma topologia para outra, as fontes de geração podem alterar o seu estado entre ligado ou desligado e as chaves e disjuntores entre os seus estados de fechados ou abertos. A seqüência cronológica correta e segura para essas alterações foi programada e prevista no programa aplicativo do CLP, sendo que foram testadas todas as transições e condições de segurança dos equipamentos, da concessionária e dos geradores.

Os diagramas elétricos destas formas operacionais foram mostrados no capítulo anterior. 


\subsection{Análise de mudanças de estados do sistema considerando as fontes de alimentação nas duas cargas (Laboratório e Essenciais)}

A Rede de Petri no item anterior (figura 4.1) mostra uma série de características do processo que foram confirmadas nos testes de campo e que serão mencionadas a seguir.

Não há a passagem direta do gerador G2 fornecendo energia para o QG-Lab ( por exemplo no caso G2/T1) para a configuração do gerador G1 em paralelismo permanente com G2 (por exemplo G1G2/T1). O módulo de controle dos geradores não permite que haja mudanças de configuração, enquanto o gerador estiver em movimento. Esta limitação tem como objetivo o aumento na segurança das operações do gerador.

Os tipos possíveis de transições podem ser divididos em "paralelismo momentâneo" e "paralelismo permanente". As transições envolvendo as chaves de transferência automática fechadas (close-transition) são chamadas de paralelismo momentâneo e as que envolvem os disjuntores motorizados (Disjuntores DJ1 e DJ2) são de paralelismo permanente.

Na figura anterior (figura 4.1) podem ser verificadas as seguintes transições:

1 - Transferência simultânea de T1 para G1, e na transferência de G1 para T1, correspondendo ao fornecimento de energia para o QG-Lab e para QG-S respectivamente ( mostrado como G1/T1 indo para T1/G1). Nesta transferência haverá uma troca das fontes de geração com relação às cargas. Esta troca será feita pelas chaves de transferência CH4 e CH5 conforme mostrado nas figuras 4.2 e 4.3. 

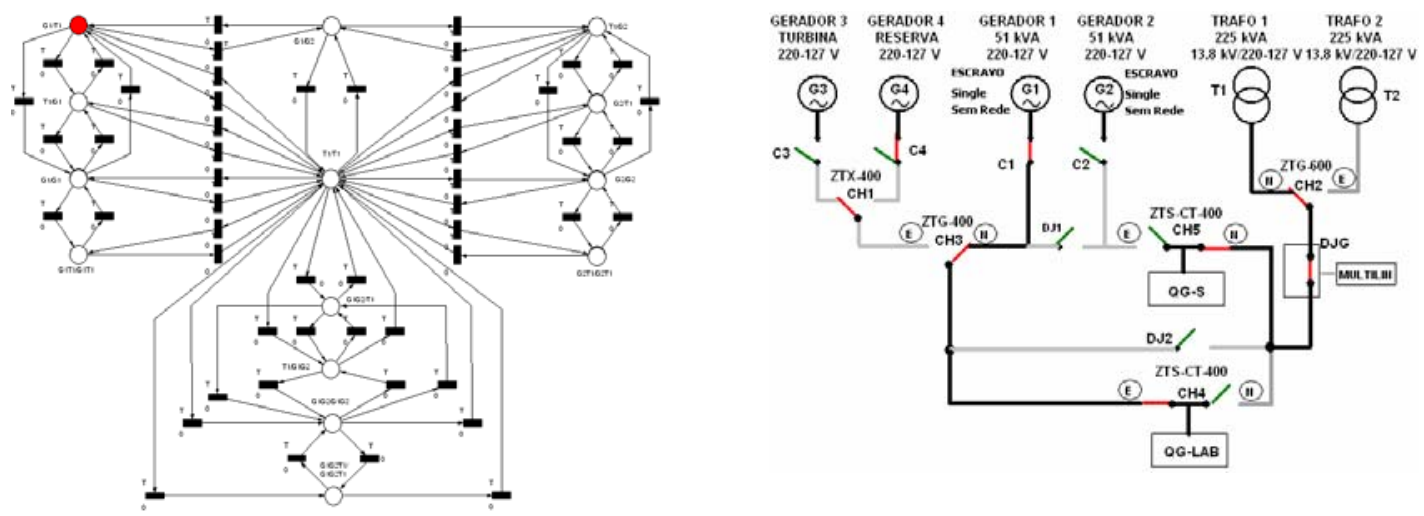

Figura 4.2 - Alimentação da carga QG-Lab pelo gerador G1 e alimentação do QG-S pelo T1 (G1/T1)
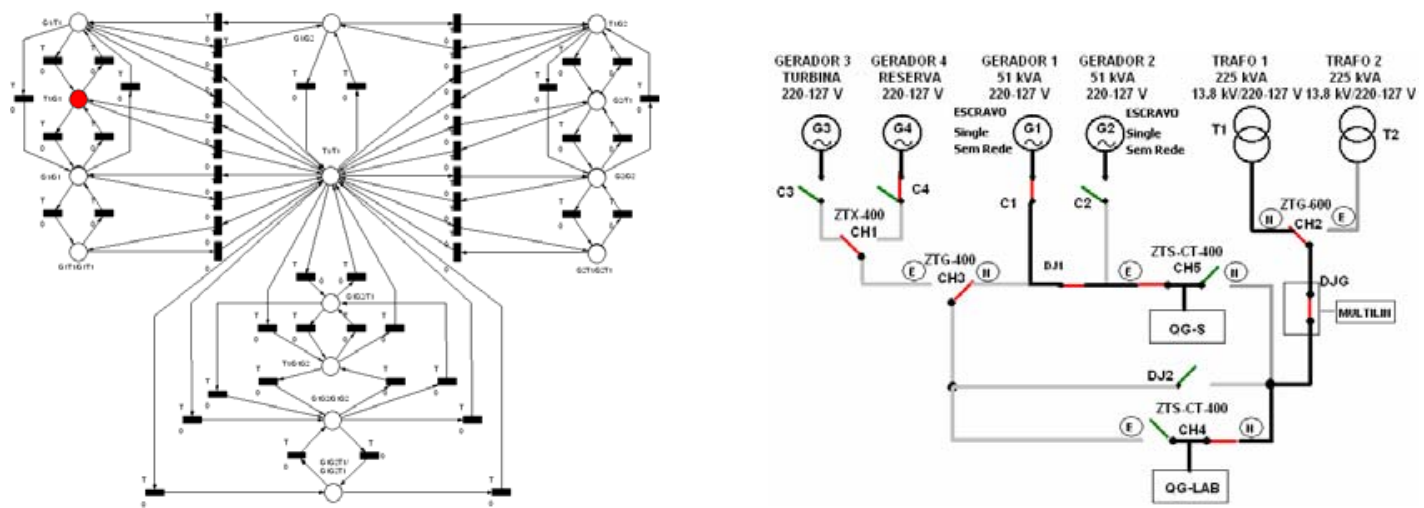

Figura 4.3 - Alimentação da carga QG-Lab pela concessionária T1 e alimentação do QG-S pelo G1 (T1/G1)

Nesta passagem de G1/T1 para T1/G1 foram utilizadas as chaves de transferência automática $\mathrm{CH} 4$ e $\mathrm{CH} 5$, conforme já comentado, sendo que, devido ao fato de ter sido uma troca dupla entre T1 e G1, não há um estado intermediário do tipo T1/T1 ou G1/G1. As duas chaves estão configuradas com os mesmos valores mínimos e máximos de tensão e fase. Esse ajuste permitem o paralelismo durante 100 ms e a transferência da entrada A para a B simultâneamente nas duas chaves.

O retorno de T1/G1 para G1/T1 ocorre da mesma maneira que a transferência de G1/T1 para T1/G1 tratando-se da mesma transferência com sentidos contrários.

2- Transferência de T1 para G1, no fornecimento de energia para o QG-Lab, permanecendo o gerador G1 fornecendo energia para QG-S ( mostrado como G1/T1 indo para G1/G1). Esta 
troca envolve a transferência de parte das cargas supridas pela concessionária para o grupo gerador G1, utilizando A chave $\mathrm{CH} 4$ conforme mostrado nas figuras 4.4 e 4.5.
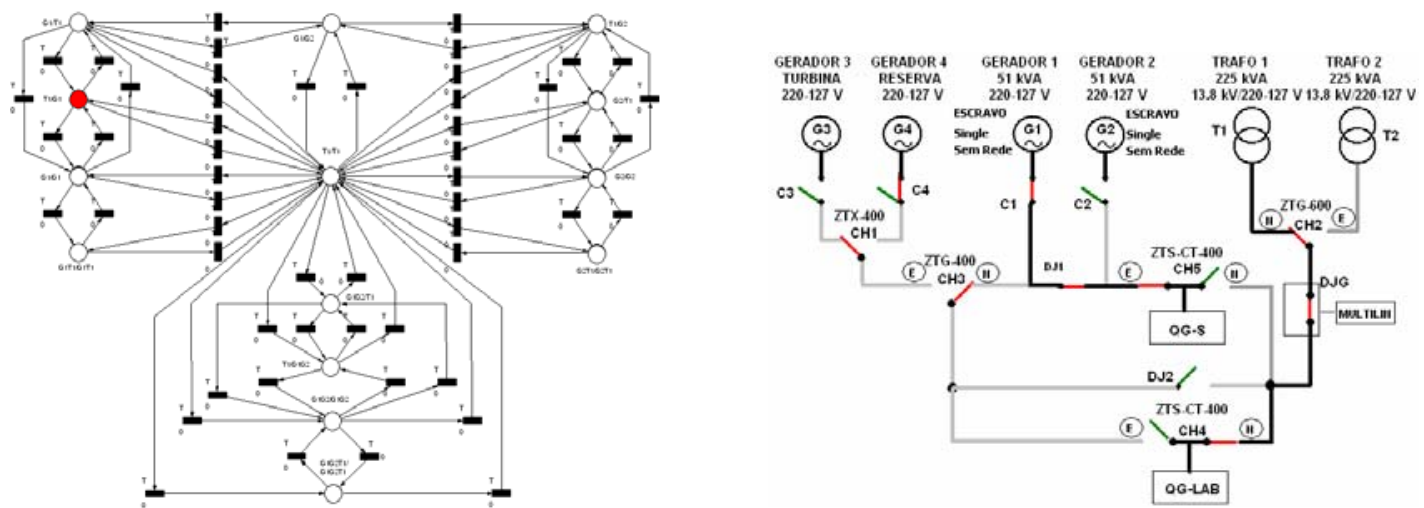

Figura 4.4. - Alimentação da carga QG-Lab pela concessionária T1 e alimentação do QG-S pelo G1 (T1/G1)
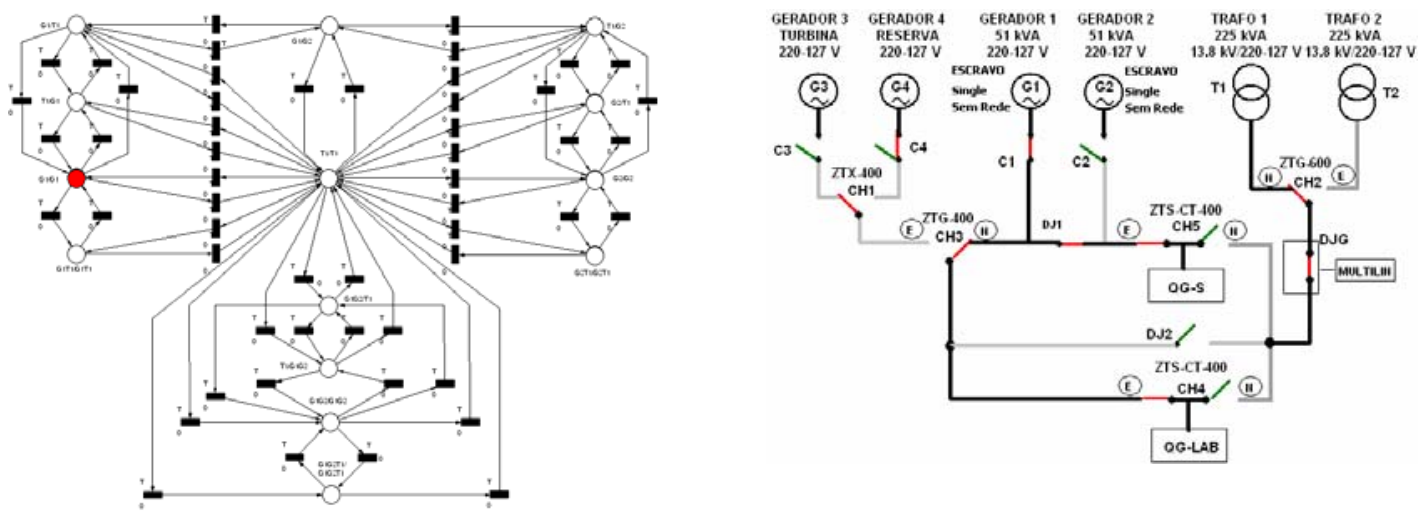

Figura 4.5 - Alimentação da carga QG-Lab e QG-S pelo gerador G1 (G1/G1)

Nesta transferência notou-se a necessidade de que a carga a ser fornecida não ultrapasse $75 \%$ da capacidade do gerador, a fim de impedir que o mesmo entre em falha. No caso do gerador entrar em falha, as chaves de transferência automáticas irão retornar para a concessionária a responsabilidade pelo fornecimento de energia, tanto para QG-Lab, quanto para QG-S (configuração T1/T1).

A transferência do Gerador para a concessionária (G1/G1 para G1/T1) irá ocorrer com sentido contrário ao descrito na transferência de G1/T1 para G1/G1 e também é feita pela chave CH5. 
3 - A transferência G1/G1 para G1T1/G1T1 envolve o disjuntor DJ2 e DJ1 sendo um paralelismo permanente entre o gerador G1 e a rede concessionária representada pelo seu transformador $\mathrm{T} 1$.
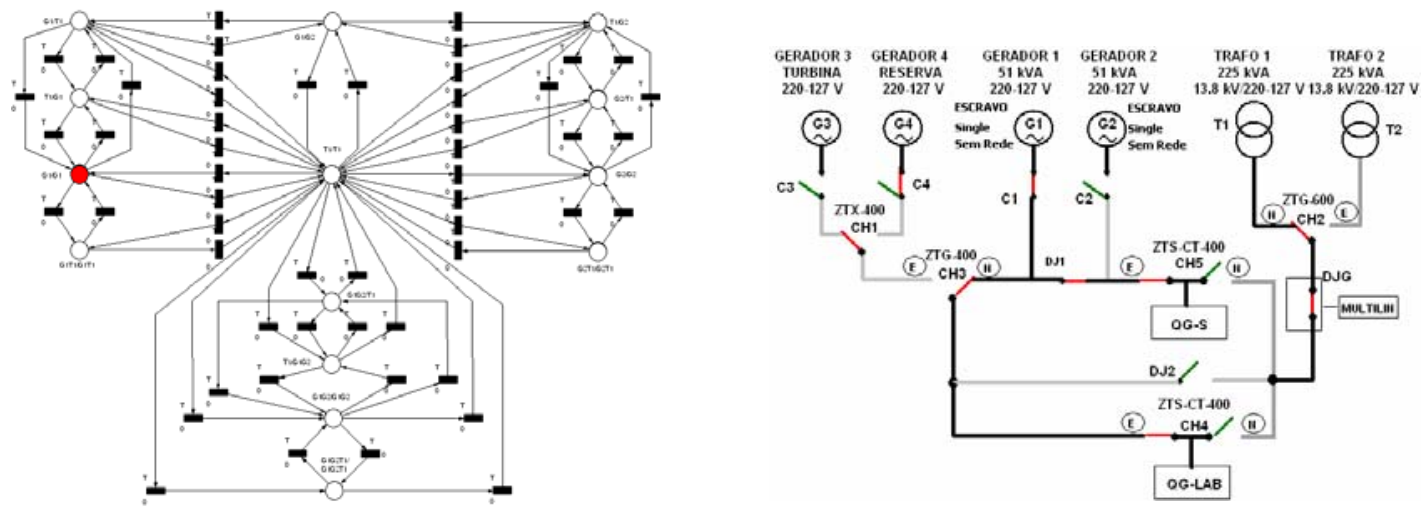

Figura 4.6 - Alimentação da carga QG-Lab e QG-S pelo gerador G1 (G1/G1)
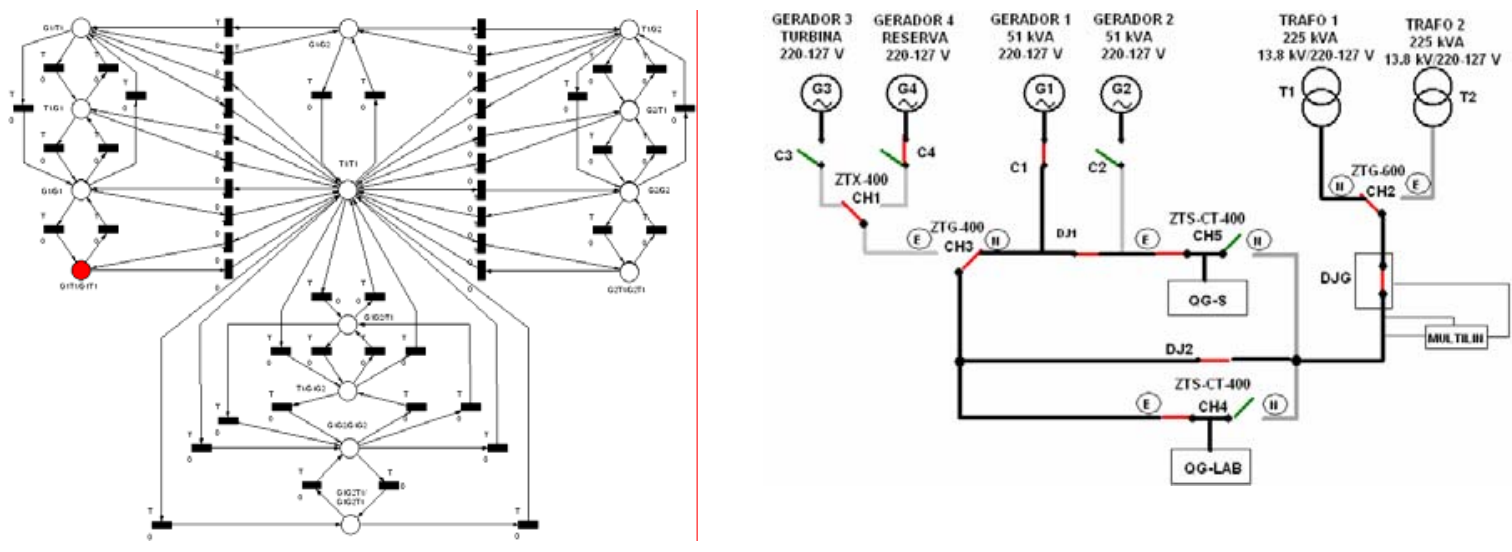

Figura 4.7 - Alimentação da carga QG-Lab e QG-S pelo gerador G1 em paralelismo permanente com a concessionária (G1T1/G1T1)

O paralelismo do gerador com a concessionária é feito pelo DJ2, conforme já descrito, sendo que cabe ao controlador do próprio gerador G1 verificar o módulo e fase da concessionária e enviar um comando para o fechamento do DJ2. O sinal de abertura e fechamento do DJ2 é enviado por sinal digital discreto (entrada digital no CLP), tendo sido evitada a comunicação por ModBus RTU para este tipo de acionamento. 
4 - A Transferência de G1/T1 para G1/G2 envolve novamente a chave de transferência fechada (close-transition) CH5 permitindo a alimentação da carga QG-S pela fonte G2. O fechamento do disjuntor do gerador G2 é feito imediatamente após o acionamento do próprio gerador, ficando com a chave 5 a responsabilidade por colocar o gerador em paralelismo momentâneo com a concessionária (por $100 \mathrm{~ms}$ ) e transfer a geração de T1 para G2 conforme mostrado a seguir.
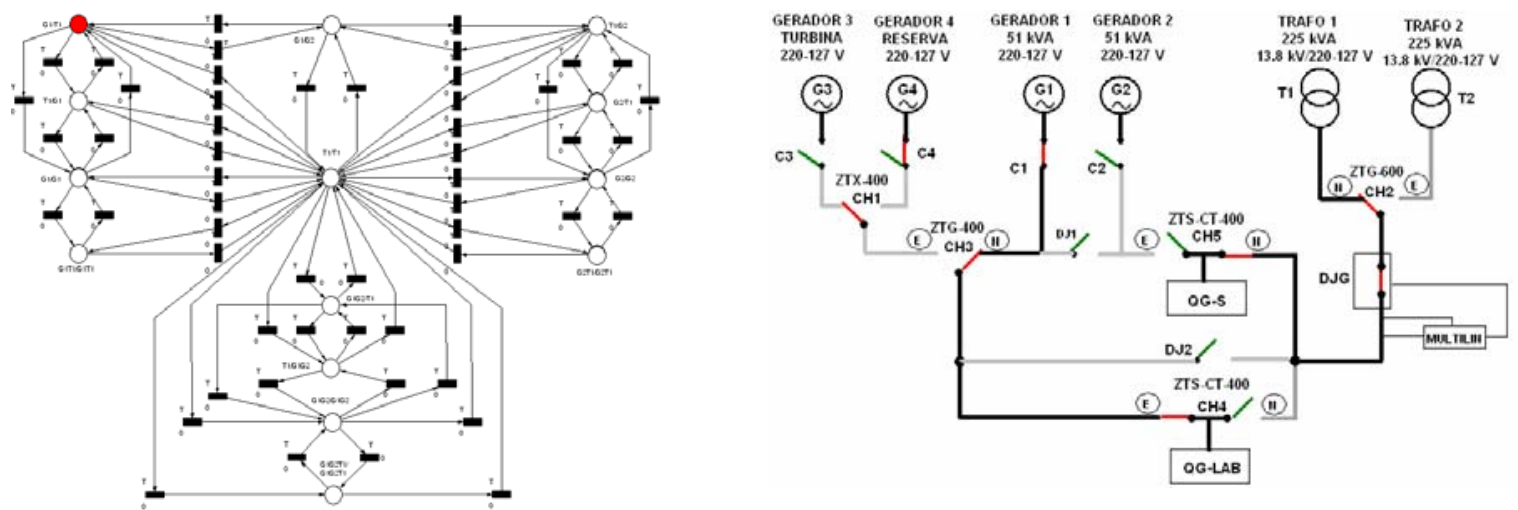

Figura 4.8 - Alimentação da carga QG-Lab pelo gerador G1 e alimentação do QG-S pela concessionária T1 (G1/T1)
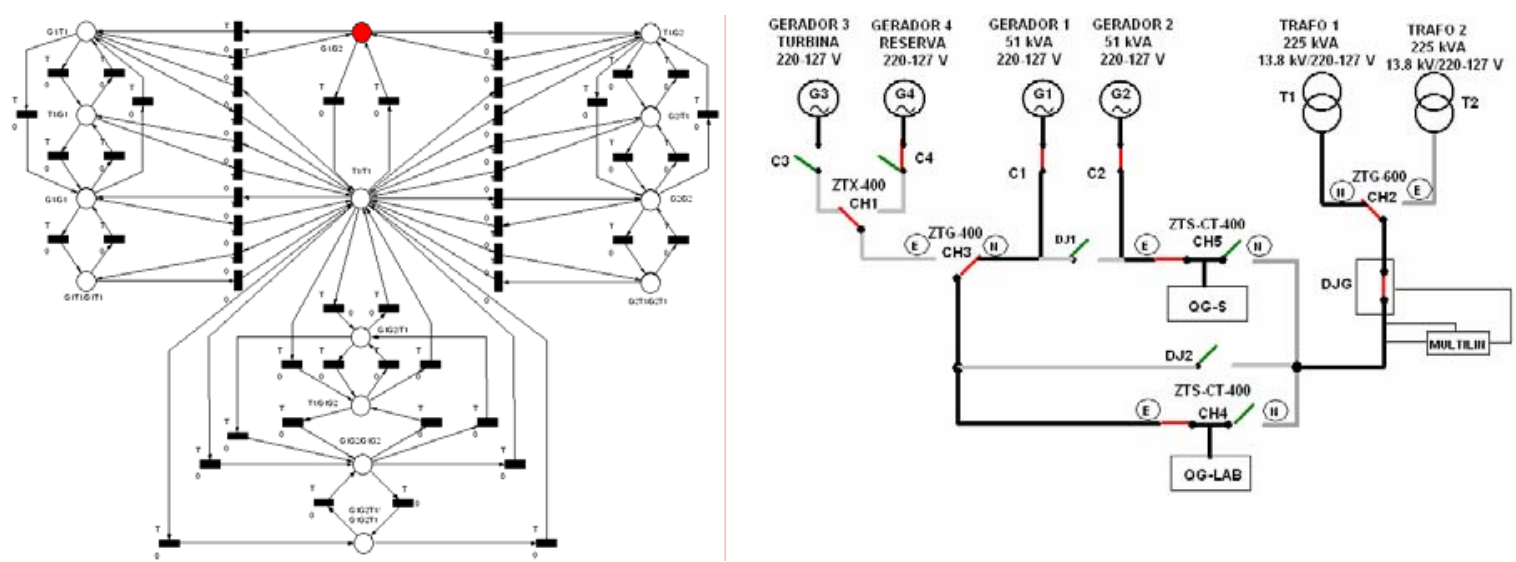

Figura 4.9 - Alimentação da carga QG-Lab pelo gerador G1 e alimentação do QG-S pelo gerador G2 (G1/G2)

5 - A transferência da configuração de fornecimento de energia feita apenas por um grupo gerador (G1/G1) para a concessionária (T1/T1) pode ser feita de duas forma distintas:

- Paralelismo transitório - Envolve apenas uma transição e é feito pela chave de transferência automática, tendo o paralelismo o tempo de duração de $100 \mathrm{~ms}$. 
- Paralelismo permanente ou "em rampa"- Nesta segunda forma de transferência, selecionada pelo operador na porta do painel ou no supervisório, há a necessidade da passagem por um estado intermediário, onde ocorre o paralelismo permanente. $\mathrm{O}$ estado inicial terá o gerador G1 fornecendo energia para ambas as cargas (G1/G1), passando pelo estado de paralelismo permanente (G1T1/G1T1) e finalizando com o estado de fornecimento integral da energia pela concessionária (T1/T1).

No paralelismo transitório de G1/G1 para T1/T1 a transferência ocorre pela chave de transferência $\mathrm{CH} 4$ e CH5 e consiste basicamente na seqüência descrita anteriormente quando da passagem de G1/T1 para T1/G1 (transferência fechada ou "close transition").

$\mathrm{Na}$ transferência em rampa envolvendo o paralelismo permanente G1T1/G1T1 e finalizando com a abertura do disjuntor do gerador (T1/T1), a concessionária assume a responsabilidade pelo fornecimento de toda energia para as cargas. Essa transferência possui características particulares na seqüência de acionamento das chaves e disjuntores e será descrita a seguir. As configurações envolvidas são:
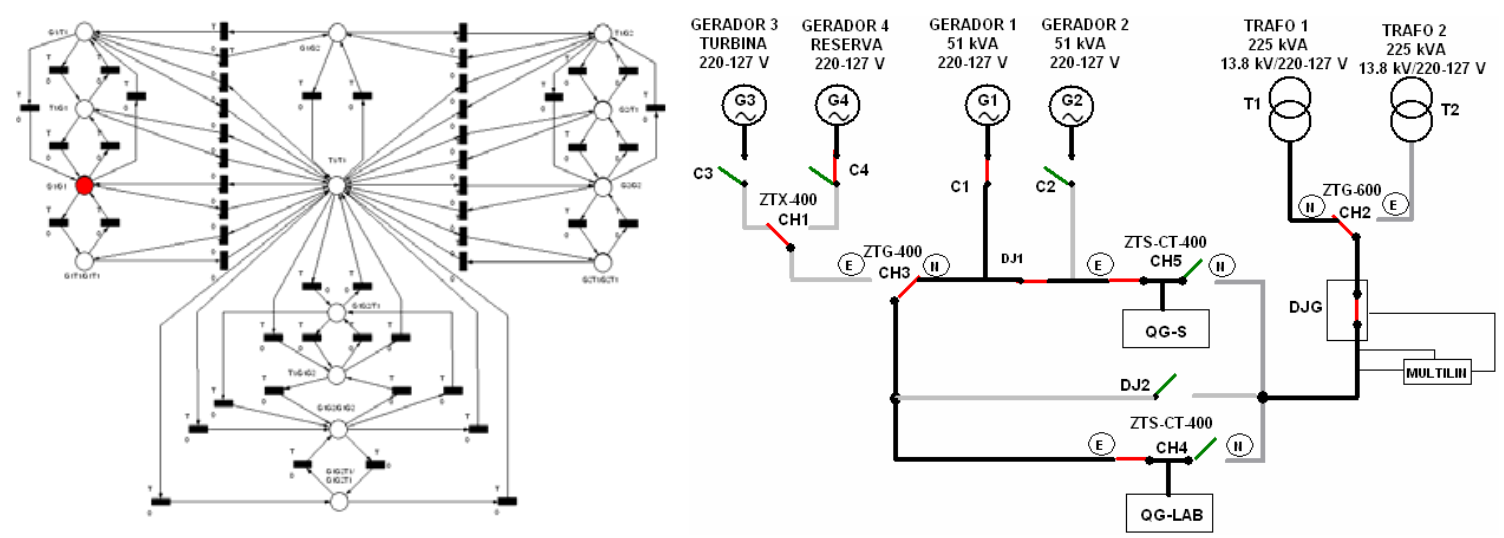

Figura 4.10 - Alimentação da carga QG-Lab e QG-S pelo gerador G1 (G1/G1) 

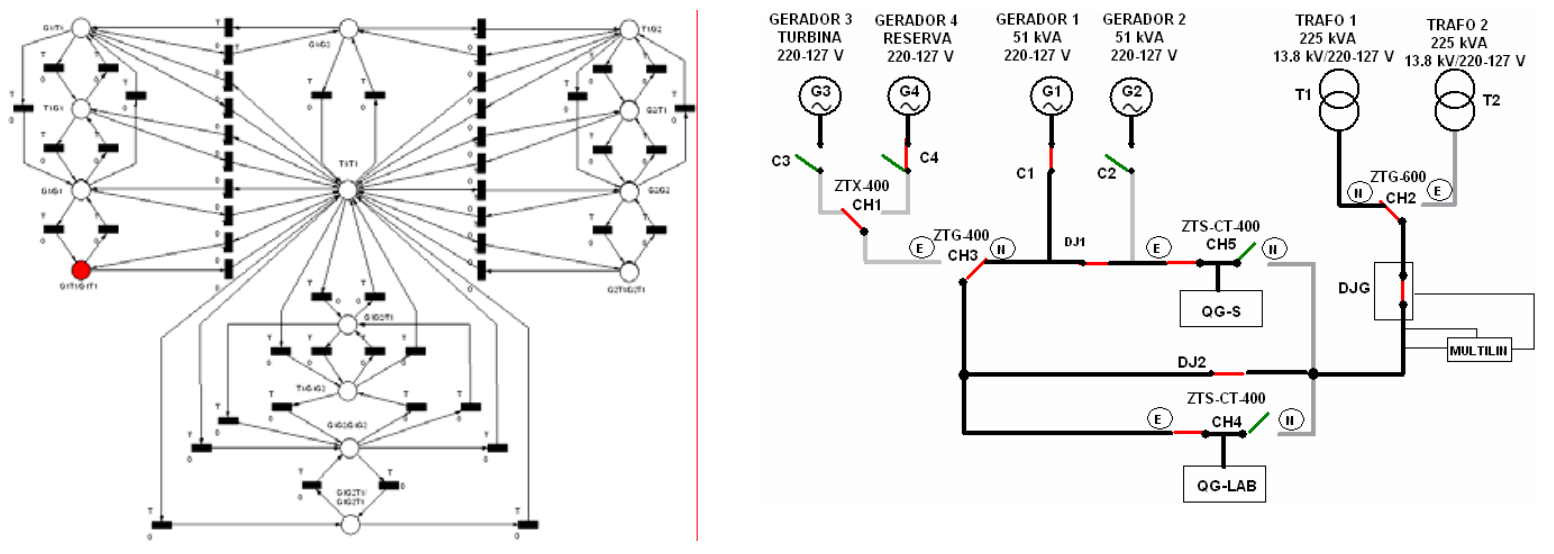

Figura 4.11 - Alimentação da carga QG-Lab e QG-S pelo gerador G1 em paralelismo permanente com a concessionária (G1T1/G1T1)
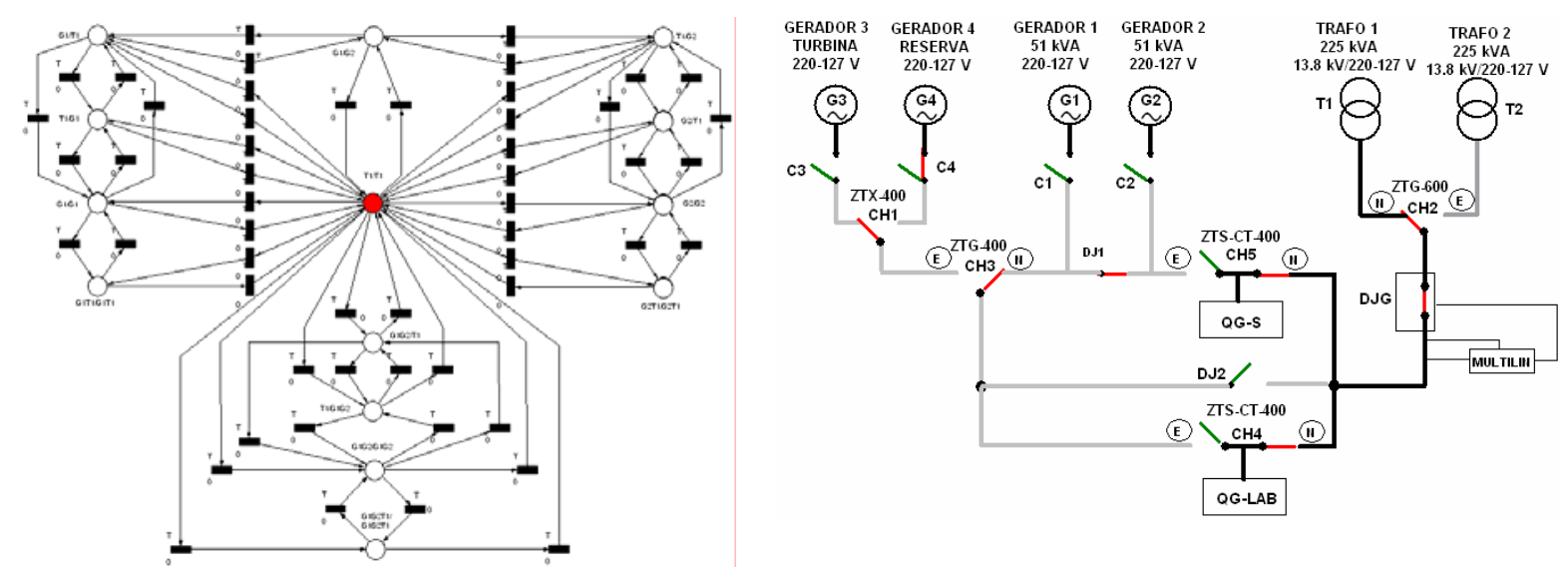

Figura 4.12 - Alimentação da carga QG-Lab e QG-S pela concessionária T1 (T1/T1)

A seqüência cronológica dos eventos das chaves e disjuntores para que possa ocorrer a transferência em rampa são as seguintes:

a) Ao ser solicitado o paralelismo do gerador com a concessionária, um sinal é enviado pelo CLP ao módulo usando a rede ModBus, e o módulo de controle passa a acelerar ou desacelerar o gerador de modo a ficar com o seu módulo e fase iguais ao sinal da concessionária. 
b) Ao ser constatado que o disjuntor de paralelismo (DJ2) pode ser fechado, o módulo envia um sinal digital para o CLP que executa o fechamento do disjuntor em um tempo mínimo de 1 scan (15 ms).

c) Após o fechamento do DJ2 as chaves $\mathrm{CH} 4$ e $\mathrm{CH} 5$ abrem os seus contatos de emergência (E) e fecham seu contato normal $(\mathrm{N})$, sendo que, o fato do disjuntor DJ2 encontrar-se fechado impõe a mesma tensão em ambas as entradas destas chaves, permitindo os seus retornos para a condição normal $(\mathrm{N})$. Nesta etapa toda a potência fornecida para as cargas está ainda sendo produzida pelo gerador.

d) O módulo regulador do gerador passa a executar uma rampa de transferência de cargas podendo ser constatada pela corrente mostrada no relé geral de proteção presente junto ao disjuntor DJG na entrada da concessionária. A corrente lida neste relé passa a mostrar valores crescentes indicando a transferência das cargas para a concessionária.

e) Quando a carga suprida pelo gerador é inferior a um valor pré-ajustado (15\%), o disjuntor do gerador é aberto passando para a configuração final T1/T1.

6 - A transferência da configuração inicial (T1/T1), onde o fornecimento de energia é feito integralmente pela concessionária (T1/T1), para uma segunda topologia híbrida onde os geradores em paralelo fornecem energia para o QG-Lab e a concessionária para QG-S (G1G2/T1), são mostradas nas Figuras 4.13 e 4.14 e descritas a seguir.
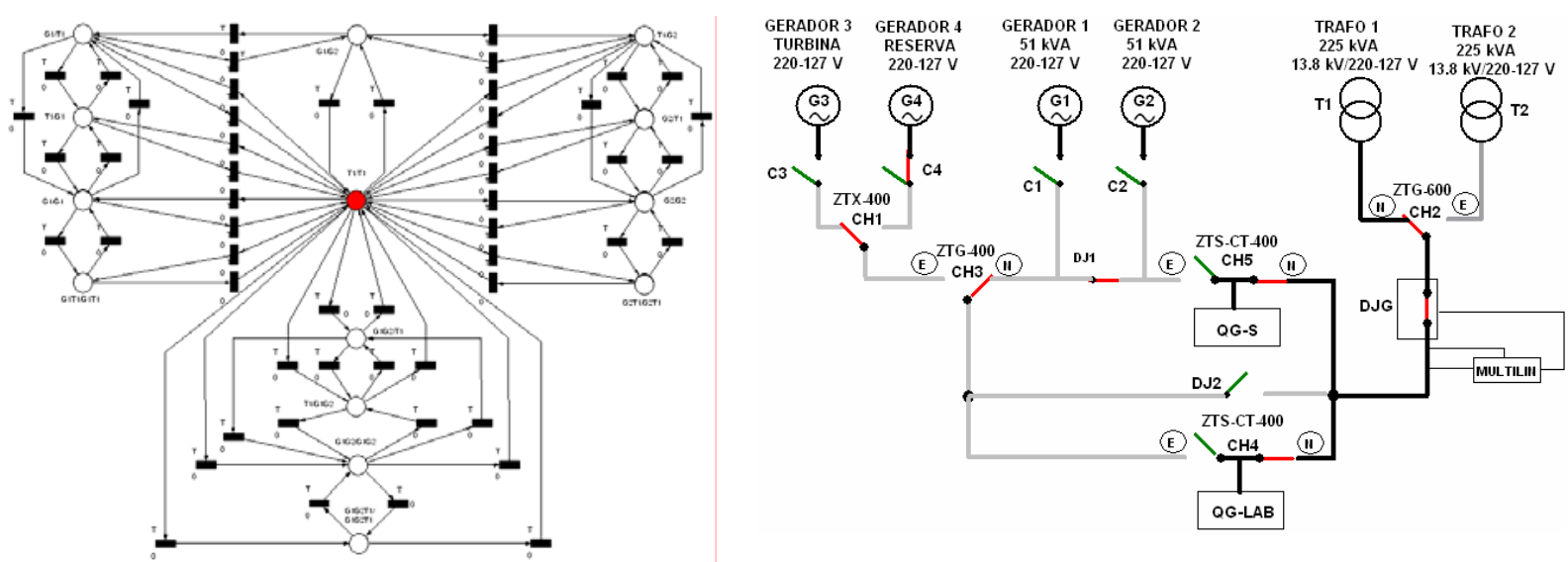

Figura 4.13 - Alimentação da carga QG-Lab e QG-S pela concessionária T1 (T1/T1) 

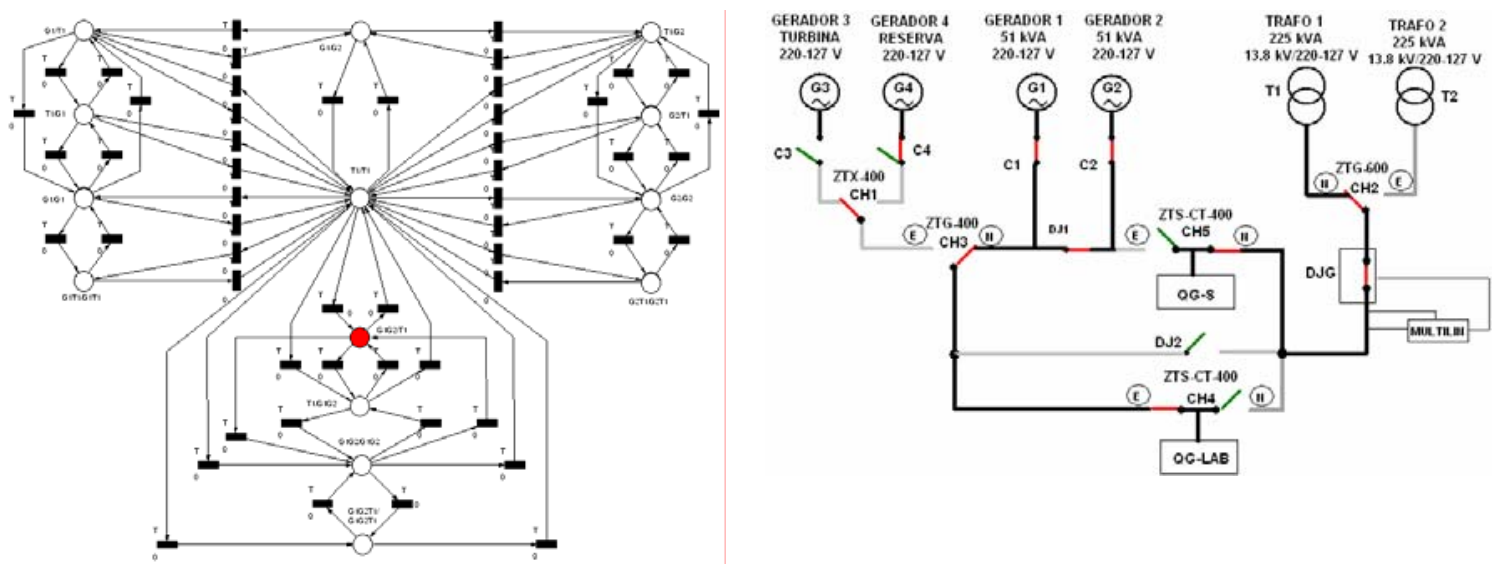

Figura 4.14 - Alimentação da carga QG-Lab pelos dois geradores em paralelo e QG-S pela concessionária T1

$(\mathrm{G} 1 \mathrm{G} 2 / \mathrm{T} 1)$

A transferência da concessionária (T1/T1) para o grupo gerador em paralelo (G1G2/T1) é feita da seguinte forma:

a) Ao ser selecionada a configuração (G1G2/T1) o disjuntor DJ1 é fechado a fim de que a tensão "sentida" no secundário do disjuntor $\mathrm{C} 1$ e $\mathrm{C} 2$ dos grupos geradores seja a mesma. O controle de entrada e saída dos geradores será feito pelo próprio módulo de controle do grupo gerador através do fechamento ou abertura do respectivo disjuntor $\mathrm{C} 1$ e $\mathrm{C} 2$;

b) Via rede ModBus a informação de que os geradores serão ligados em paralelo entre si é enviada aos módulos de controle dos geradores. O gerador "Mestre" G1 é ligado e seu disjuntor $\mathrm{C} 1$ fechado iniciando a etapa de sincronismo com a rede concessionária T1.

c) Estando sincronizado G1 com a rede concessionária a chave CH4 faz o paralelismo momentâneo fechando a entrada de emergência (E) e após 100 ms abrindo a entrada normal $(\mathrm{N})$. Ao mesmo tempo o módulo de controle de $\mathrm{G} 2$ inicia o funcionamento do gerador $\mathrm{G} 2$ tentando o paralelismo dele com G1.

d) Estando sincronizado G2 com a concessionária, é fechado o disjuntor da saída do gerador (C2), sendo considerada finalizada a seqüência G1G2/T1.

7 - A transferência da configuração de fornecimento de energia feita apenas pela concessionária

(T1/T1) para os geradores em paralelo e em paralelismo permanente com a concessionária 
fornecendo energia para o QG-Lab e QG-S (G1G2T1/G1G2T1), consiste das seguintes configurações:
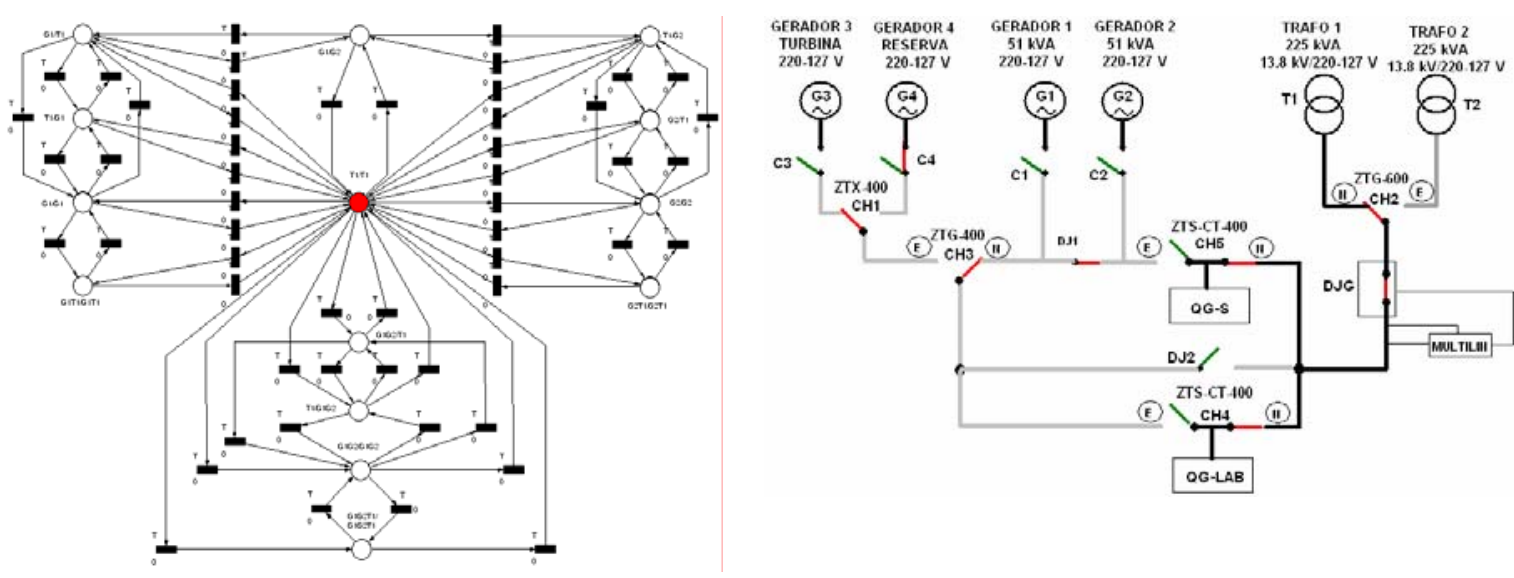

Figura 4.15 - Alimentação da carga QG-Lab e QG-S pela concessionária T1 (T1/T1)
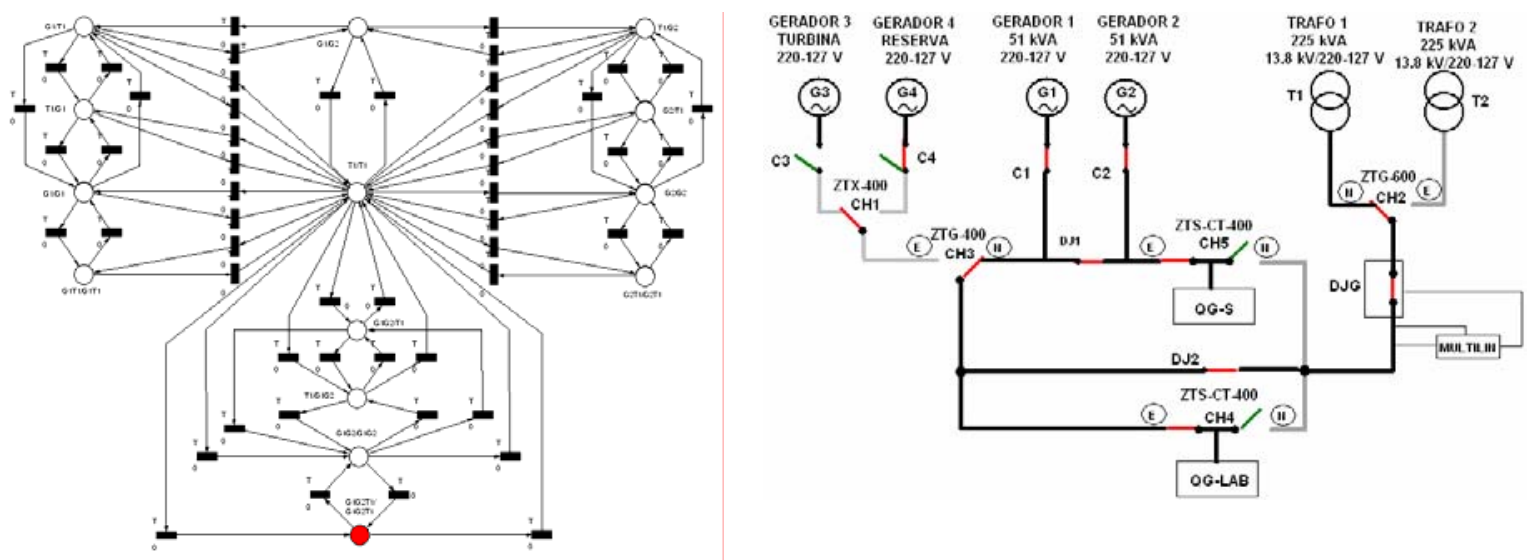

Figura 4.16 - Alimentação da carga QG-Lab e QG-S pelos grupos geradores em paralelo entre si e com a concessionária T1 (G1G2T1/G1G2T1)

A transferência da concessionária (T1/T1) para o grupo gerador em paralelo entre si e com a concessionária (G1G2T1/ G1G2T1) é feita da seguinte forma:

a) Ao ser feita a seleção G1G2T1/ G1G2T1 é fechado o DJ1 e DJ2 e é enviado um comando via rede ModBus para os módulos de controle.

b) A tensão da concessionária chega até a "cabeça" dos geradores G1 e G2 que iniciam o processo de sincronização com a concessionária. 
c) Quando os geradores G1 e G2 estão sincronizados com a rede, há o fechamento dos seus respectivos disjuntores $\mathrm{C} 1$ e $\mathrm{C} 2$ passando a fornecer energia para a rede da forma configurada. No caso do projeto executado, os geradores têm a mesma potência e foram configurados para fornecer a mesma potência para as cargas.

Caso tenha sido configurado o fornecimento de carga de pico (peak shave) ou de base (base load) os geradores passam a executar a rampa, assumindo as cargas pré-configuradas.

8 - A transição da configuração mostrada na figura 4.17 , onde os dois geradores estão em paralelismo permanente entre sí e com a concessionária (G1G2T1 no QG-Lab e no QG-S ), para uma segunda topologia mostrada na figura 4.18, onde os geradores continuam em paralelo entre si porém sem a concessionária (G1G2 no QG-Lab e também no QG-S), representa a etapa de passagem do fornecimento compartilhado entre grupos geradores e concessionária para a do grupo de geradores isolados. Nesta transição é desejável que a passagem de cargas para o grupo gerador seja feita em rampa, evitando assim eventuais problemas de atuação da proteções (trip) dos módulos de controle.
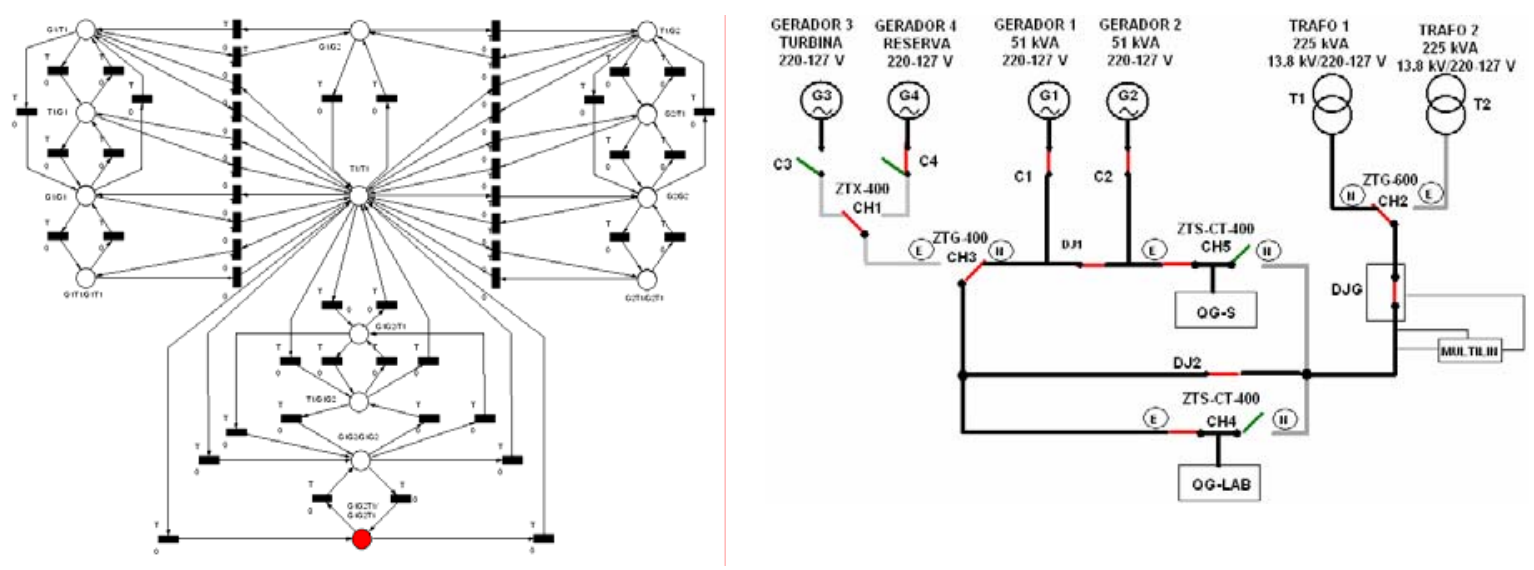

Figura 4.17 - Alimentação da carga QG-Lab e QG-S pelos grupos geradores em paralelo entre si e com a concessionária T1 (G1G2T1/G1G2T1) 

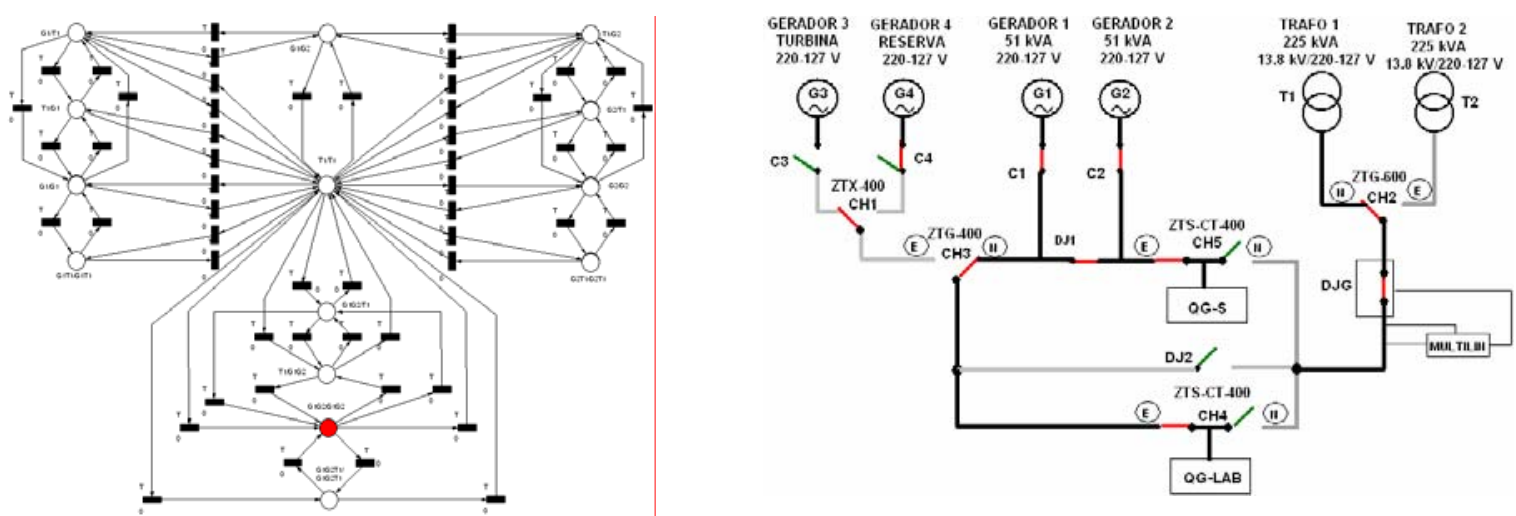

Figura 4.18 - Alimentação da carga QG-Lab e QG-S pelos grupos geradores em paralelo entre si (G1G2/G1G2)

\subsection{Formas operacionais típicas e formas operacionais atípicas}

As formas operacionais mostradas no item anterior podem ser sub-divididas em dois grupos, segundo seu maior ou menor grau de utilização. Esses grupos são:

- Formas operacionais típicas: No projeto atual foram consideradas como sendo topologias típicas ou convencionais todas as formas operacionais de uso considerado freqüente, sejam por razões econômicas, sejam por razões de aumento da confiabilidade do sistema. Exemplo deste tipo de grupo é a alimentação do QG-Lab pelo G1 e a alimentação do QG-S pela concessionária (Figura 4.19). Este tipo de aplicação é bastante utilizado quando há a necessidade de manter as cargas do laboratório pelo gerador, por exemplo para testes de transferência de carga, enquanto as cargas essenciais ficam mantidas pela concessionária. Este tipo de configuração foi bastante utilizado em nossos ensaios de transferência de carga em rampa.
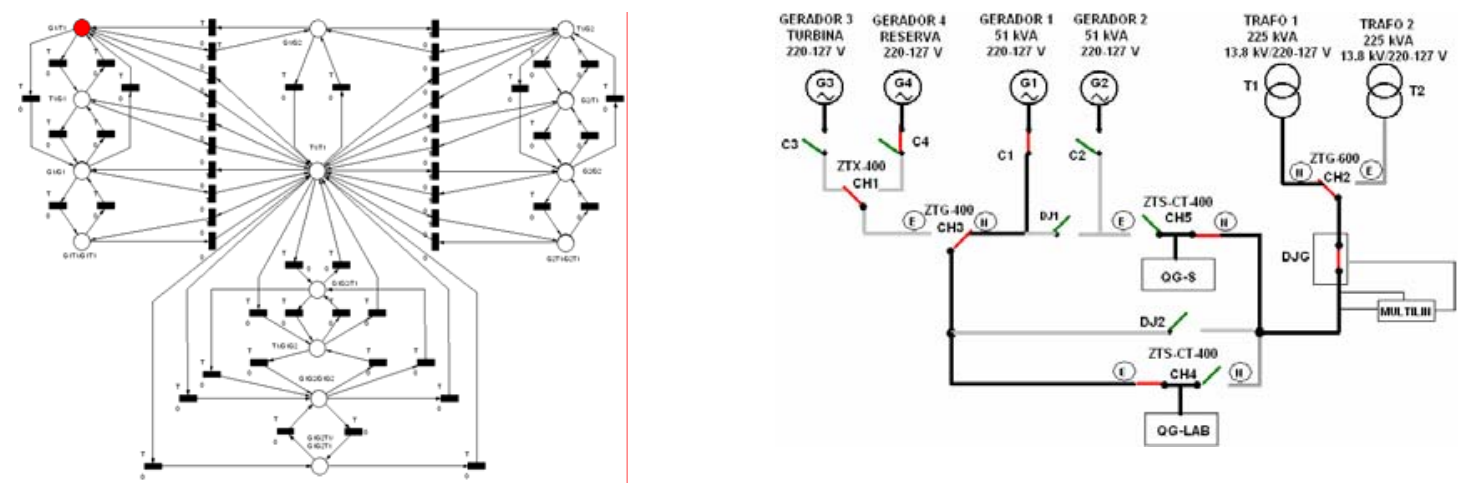

Figura 4.19 - Formas operacionais típicas ou convencionais (G1/T1) 
- Formas operacionais atípicas: Este grupo é caracterizado por estados mais raramente utilizados. Um exemplo desta forma operacional é o fornecimento de energia feito pelo grupo gerador G1 para o QG-Lab e por G2 para o QG-S (Figura 4.20). Considerou-se este estado atípico devido ao fato de se esperar que os geradores sejam utilizados com maior freqüência como grupos geradores acoplados. Nesta configuração atípica os geradores estão isolados e, devido à característica de segurança dos módulos de controle, não poderiam facilmente ser colocados em paralelo com a rede, devendo ser desligados para posterior mudança de seu modo de operação.

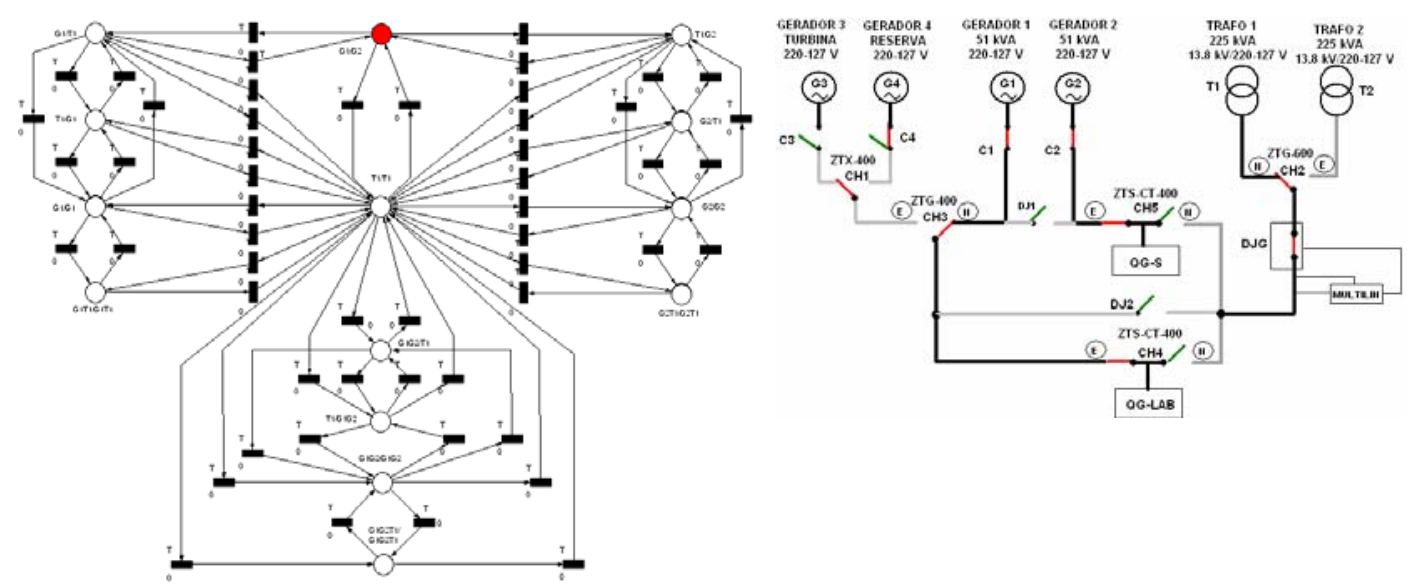

Figura 4.20 - Formas operacionais atípicas ou não convencionais

A representação de todos os estados considerados típicos encontra-se na figura 4.21 a seguir, onde está sendo mostrada também a participação do transformador T2 no sistema. 


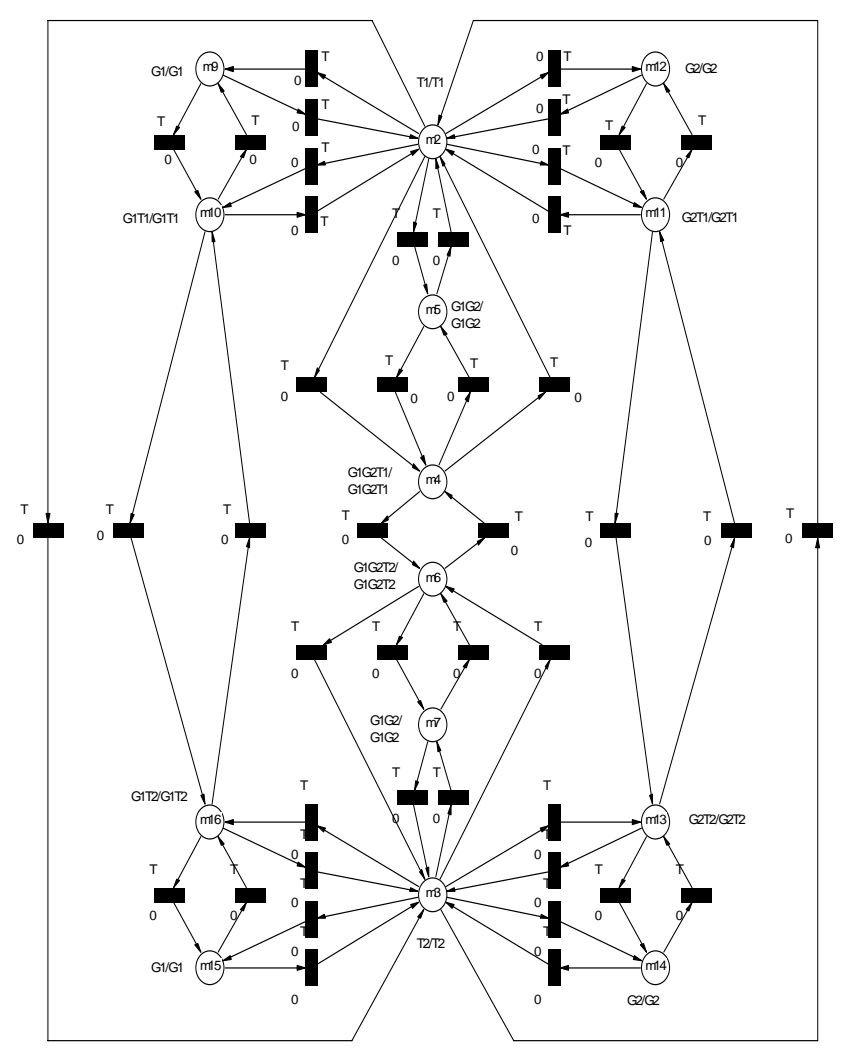

Figura 4.21 - Formas operacionais típicas ou convencionais

Na figura 4.22 mostrada a seguir são colocados todos os estados e transições considerados atípicos no processo. Nota-se claramente a impossibilidade de transição dos estados G1/G2 para, por exemplo, G1G2/T1 ou T1/G1G2, o que daria um caráter mais usual a essa topologia. 


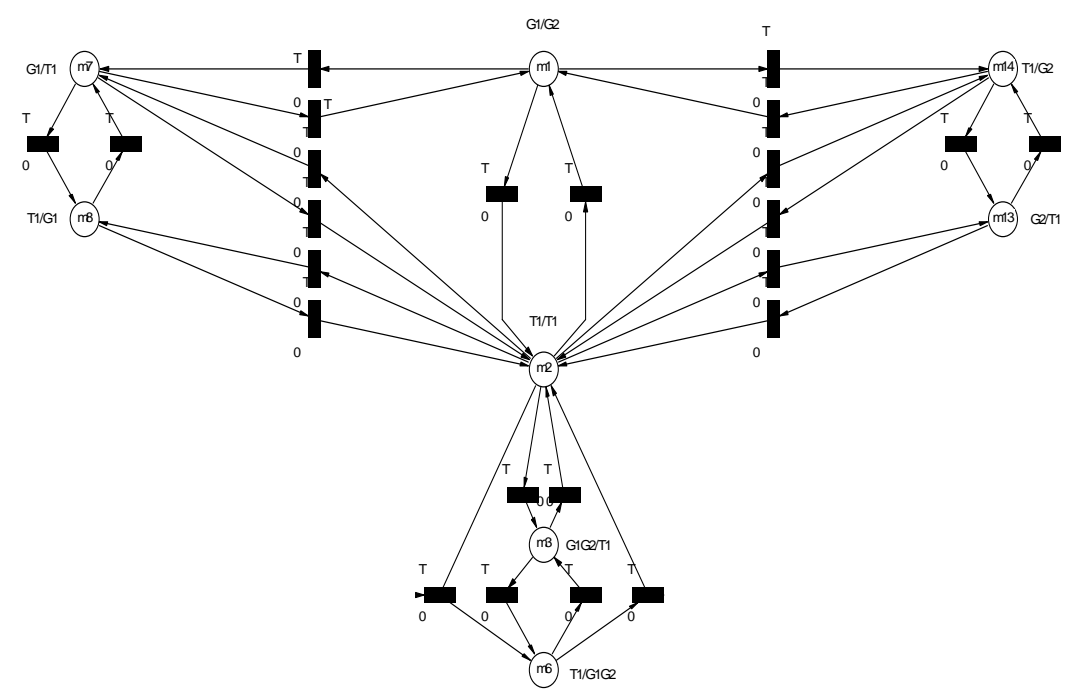

Figura 4.22 - Formas operacionais atípicas ou não convencionais

\subsection{Hardware da Automação Empregada}

Conforme descrito anteriormente, foi utilizado um CLP de última geração ( MicroLogix 1500 - 14K de memória) com um programa cuja varredura é menor que $10 \mathrm{~ms}$. Nesse tempo de varredura todas as decisões são executadas considerando os intertravamento de segurança do sistema. Ao final de cada ciclo de processamento as saídas digitais serão atualizadas comandando os disjuntores, acionando lâmpadas sinalizadoras e mudando o estado das chaves de transferências de modo a permitir alterar a topologia segundo solicitado pelo operador. A cada início de processamento, de forma análoga ao que foi feito com as saídas, uma imagem das entradas digitais do sistema é guardada a fim de executar as lógicas a serem previstas nos arquivos de programa Ladder.

Há duas formas previstas de comunicação do CLP via rede: Modbus RTU e RS232/Ethernet TCP/IP. Essas duas formas correspondem às duas portas de comunicação existentes no processador e serão utilizadas para comunicação com os controladores dos grupos geradores ( configuração Mestre-Escravo) e com o sistema supervisório (SCADA). Estas duas redes são assíncronas com relação ao processamento do CLP e estarão atualizando seus dados na medida em que foram sendo disponibilizadas no buffer de saída de suas respectivas portas. 


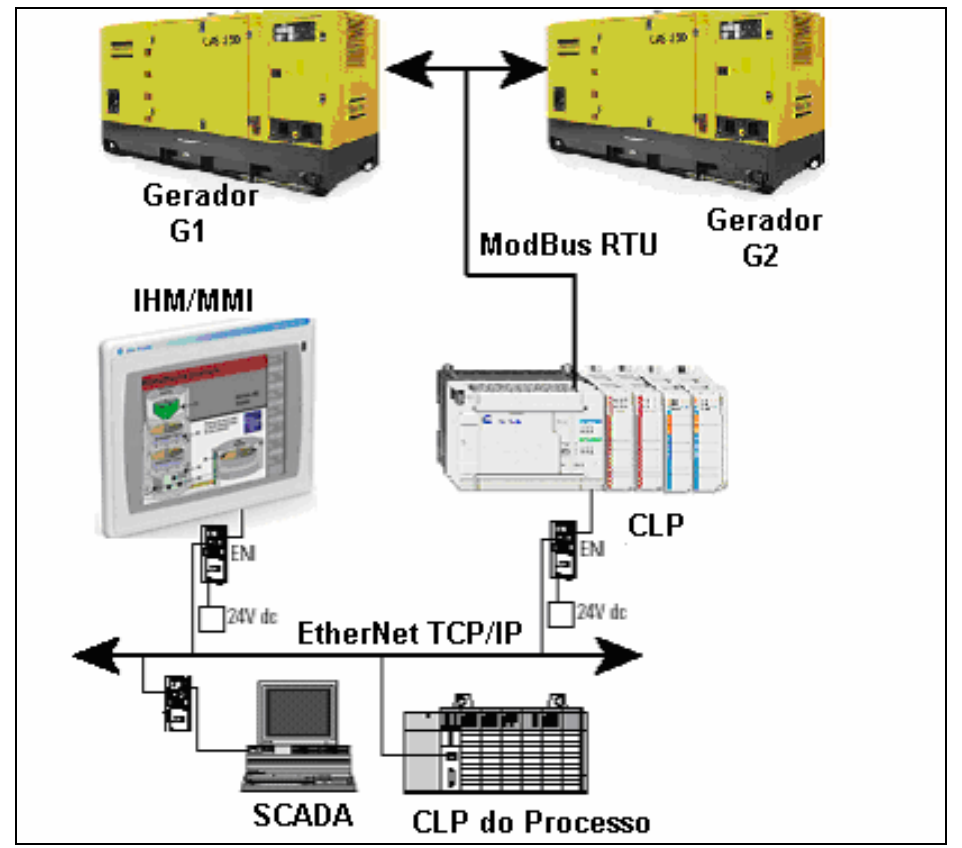

Figura 4.23 - Redes a serem implementadas

1. Rede ModBus RTU. As principais características desse tipo de rede são:

- Master-Slave (Mestre - Escravo);

-QUERY - RESPONSE (Pergunta - Resposta);

- MASTER - Pode iniciar um questionamento (queries);

- SLAVES - Responde ao mestre ou atua segundo a ordem do mestre;

- RTU ou ASCII (Modos de transmissão);

- Endereços dos Escravos (1 a 247);

-Taxa de transmissão Standard Values são: 300, 600, 1200, 4800, 9600, 19200, 38400,57600 , and 115200;

- RS232,422 ou 485. Interface serial que define a pinagem dos conectores, cabo e níveis de tensão dos sinais.

2. Rede Ethernet: Nesta rede o CLP poderá trocar informações com outros controladores da rede ( no caso de uma aplicação industrial típica) e com supervisórios (SCADA) ou mesmo IHM. 


\subsection{Topologias do Sistema}

O desenvolvimento lógico será feito utilizando-se a "Rede de Petri" [5] como forma de análise e simulação das formas operacionais da micro usina. As topologias serão divididas segundo um critério crescente de complexidade de modo a abordar todas as possibilidades de configurações envolvendo a concessionária, os grupos geradores, as chaves de transferência, os disjuntores e as duas cargas.

\subsubsection{Topologia Gerador G1, Transformador T1 e Cargas Essenciais}

Como forma inicial de abordagem das topologias possíveis para a Micro-usina, serão feitas as análises das configurações possíveis envolvendo um gerador, a concessionária e apenas um dos dois grupos de cargas. Os equipamentos utilizados foram:

-Fonte geradora 1: Grupo Gerador (G1);

- Fonte geradora 2: Transformador (T1);

- Carga 1: Carga essencial ( QG-S).

A figura 4.24 há 03 possibilidades envolvendo os 03 equipamentos acima e foi retirada da tabela geral contendo as 24 possibilidades gerais para a micro-usina. Nestas três linhas da figura 4.24 são indicadas as disposições das chaves e disjuntores em cada uma das diferentes topologias numeradas no campo"ID".

Nesta figura 4.24 são mostradas também todas as operações que devem ser feitas nos equipamentos ( grupos geradores, disjuntores e chaves) de modo a permitir que o quadro geral de cargas essenciais (QG-S) possa ter a topologia desejada. No campo "ID" encontra-se a "chave" ou código com que uma determinada topologia foi armazenada na área de memória do CLP, ou seja, dentro das 286 possibilidades presentes na memória do CLP ( das quais apenas 24 são possíveis e as demais estão reservadas para futuras utilizações); a de número 1,3 e 21 serão apresentadas na tabela da Figura 4.24.

O identificador (ID) de número 1 mostra que o disjuntor do gerador 1, representado por C1, deverá estar fechado ( indicado pela representação binária de hum "1") enquanto os geradores 2, 3 e 4 deverão estar inoperantes ( indicados como zero "0"). As demais chaves e disjuntores também estarão sempre com seus estados sendo fixados, ou seja, em todas as 
"receitas" caracterizadas pelos ID's todos os estados deverão estar obrigatoriamente sendo determinados evitando qualquer indefinição indesejada ou geradora de dúvidas. Neste contexto, ainda observando o ID de número 1, o disjuntor de paralelismo entre geradores (DJ1) estará fechado, o disjuntor de paralelismo com a concessionária (DJ2) estará aberto, o disjuntor geral (DJG) fechado ( para alimentação do No-Break), e as chaves de transferência automáticas (CH1, $\mathrm{CH} 2, \mathrm{CH} 3, \mathrm{CH} 4$ e Ch5) estarão orientadas segundo o caminho necessário a fim de colocar o Gerador 1 suprindo toda a energia necessária para o QG-S.

No caso do ID, outro exemplo mostrado na figura a seguir, tem-se um paralelismo permanente entre a concessionária (T1) e o grupo gerador 1 (G1). Nesta caso, assim como em todas as receitas indicadas pelo ID, todos os equipamentos estarão com seus comandos sendo claramente previstos e indicados.

A título de exemplo podemos considerar uma operação simples de transferência do estado 1 (ID com valor 1) para o estado 21. Nota-se que o disjuntor de paralelismo com a concessionária (DJ2) passou do comando de Abrir (0) para Fechar (1) enquanto o disjuntor geral (DJG) e o disjuntor do gerador 1 (C1) permaneceram com o comando de fechar (1) inalterados.

\begin{tabular}{|c|c|c|c|c|c|c|c|c|c|c|c|c|c|}
\hline & & $\mathrm{C}$ & $\mathrm{C}$ & $\mathrm{C}$ & $\mathrm{D}$ & $\mathrm{D}$ & $\mathrm{D}$ & $\mathrm{C}$ & $\mathrm{C}$ & $\mathrm{C}$ & $\mathrm{C}$ & $\mathrm{C}$ & $\mathrm{C}$ \\
$\mathrm{ID}$ & $\mathrm{QG} \_\mathrm{S}$ & 1 & 2 & 3 & $\mathrm{~J}$ & $\mathrm{~J}$ & $\mathrm{~J}$ & $\mathrm{H}$ & $\mathrm{H}$ & $\mathrm{H}$ & $\mathrm{H}$ & $\mathrm{H}$ & $\mathrm{C}$ \\
& & & 2 & & 1 & 2 & $\mathrm{G}$ & 1 & 2 & 3 & 4 & 5 & 4 \\
\hline 1 & $\mathrm{G} 1$ & 1 & 0 & 0 & 1 & 0 & 1 & 0 & 0 & 0 & 1 & 1 & 0 \\
\hline 3 & $\mathrm{~T} 1$ & 1 & 0 & 0 & 0 & 0 & 1 & 0 & 0 & 0 & 1 & 0 & 0 \\
\hline 21 & $\mathrm{G} 1+\mathrm{T} 1$ & 1 & 0 & 0 & 1 & 1 & 1 & 0 & 0 & 0 & 0 & 0 & 0 \\
\hline
\end{tabular}

Figura 4.24 - Possibilidades usando G1, T1 e QG - S ( cargas essenciais)

Utilizando-se a Rede de Petri neste sub-grupo inicial de três possibilidades de topologias da rede obteve-se as seguintes configurações simuladas e indicadas a seguir:

\subsubsection{Topologia 1: Gerador 1 (G1) desligado e Transformador 1 (T1) fornecendo energia para o quadro geral de carga essencial (QG-S)}

A configuração equivalente seria a de número 3 (ID), indicada na figura 4.24 e correspondendo à seguinte disposição das chaves e disjuntores: 


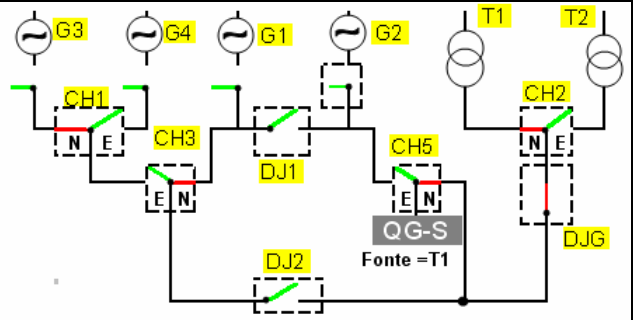

Figura 4.25 - Configuração dos equipamentos para fornecimento de energia por T1 para QG-S

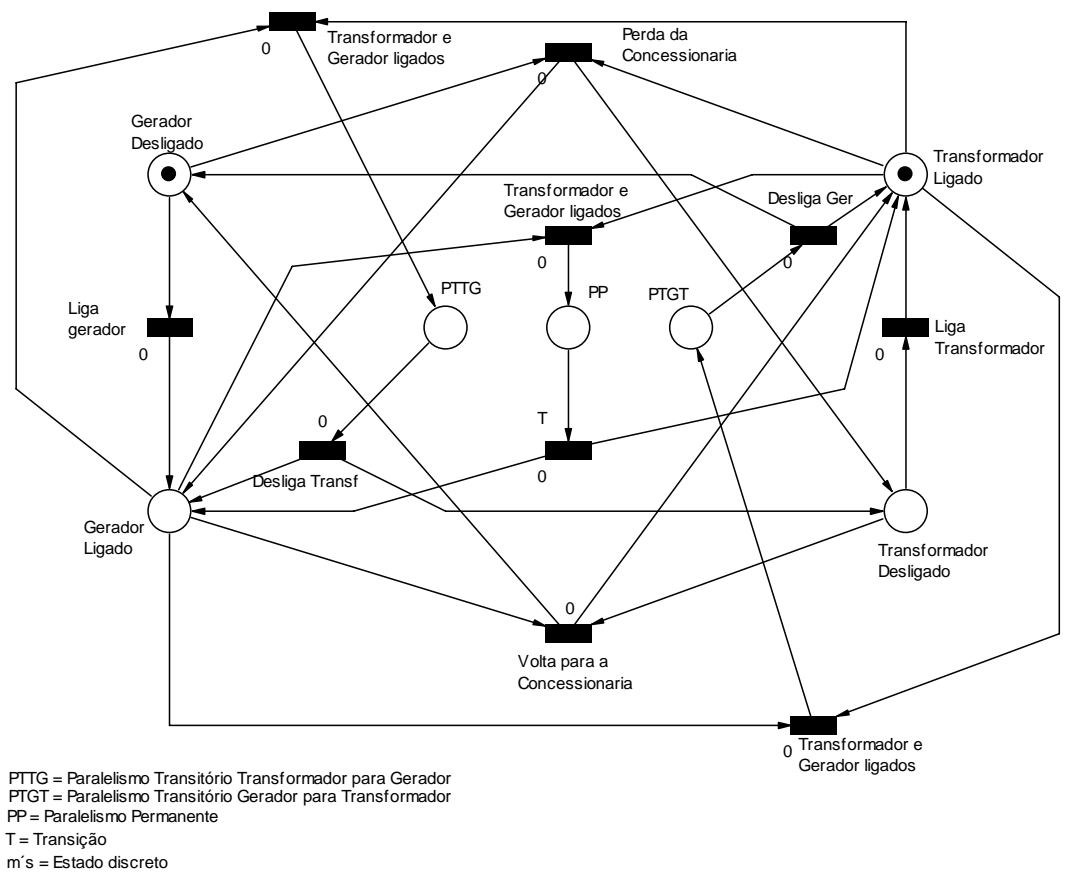

Figura 4.26 - Topologia gerador desligado e transformador ligado

\subsubsection{Topologia 2: Transformador 1 (T1) desligado e o Gerador 1 (G1) fornecendo} energia para o quadro geral de carga essencial (QG-S)

A configuração equivalente seria a de número 1 (ID), indicada na figura 4.24 correspondendo à seguinte disposição das chaves e disjuntores: 


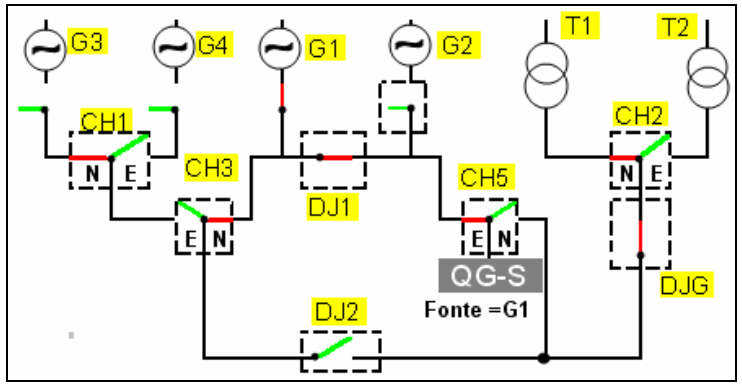

Figura 4.27 - Configuração dos equipamentos para fornecimento de energia por G1 para QG-S

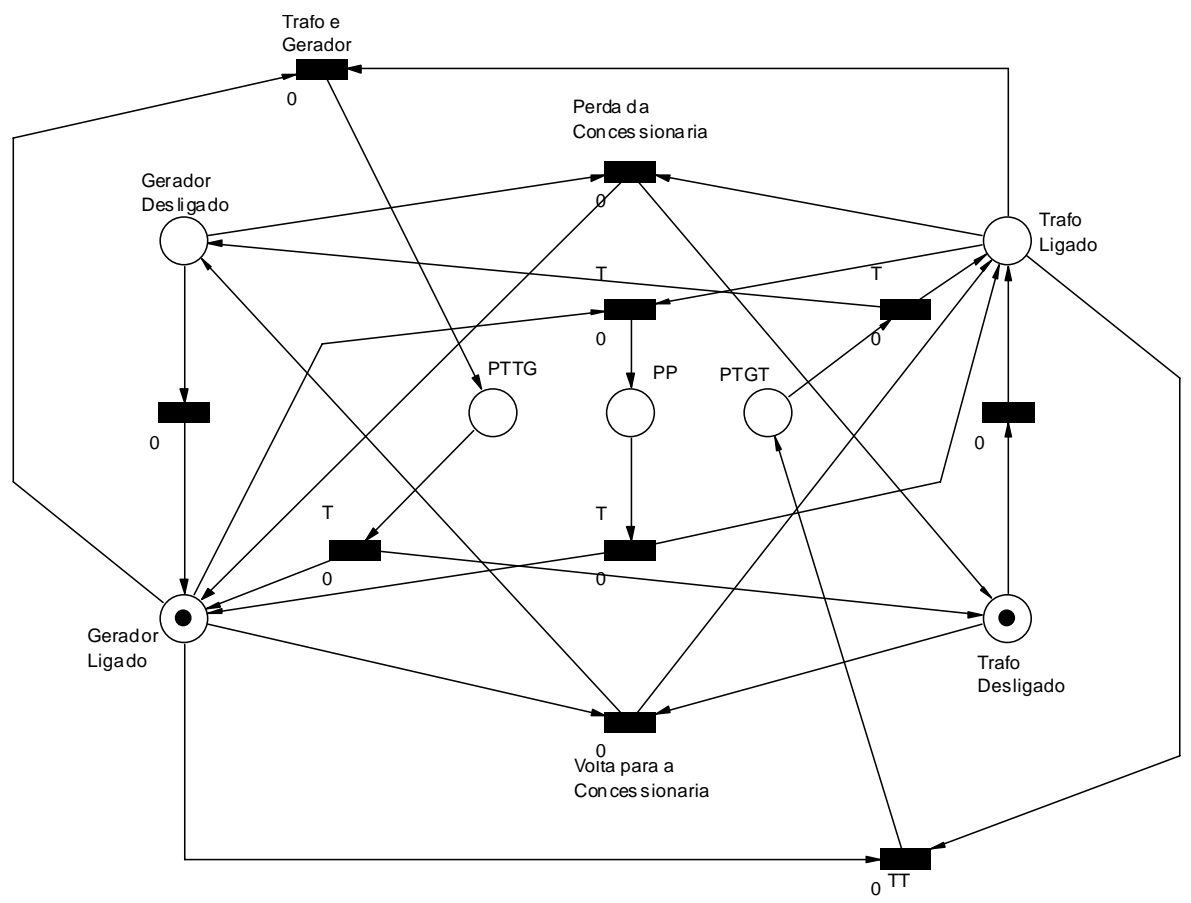

PTTG = Paralelismo Transitório Transformador para Gerador PTGT = Paralelismo Transitório Gerador para Transformador $\mathrm{PP}=$ Paralelismo Permanente

$\mathrm{T}=$ Transição

m's = Estado discreto

Figura 4.28 - Topologia gerador ligado e transformador desligado

\subsubsection{Topologia 3 : Transformador 1 (T1) ligado e em paralelo com o Gerador 1 (G1)} fornecendo energia para o quadro geral de carga essencial (QG-S) em regime permanente (PP)

A configuração equivalente seria a de número 21 (ID) indicada na Figura 4.24 correspondendo à seguinte disposição das chaves e disjuntores: 


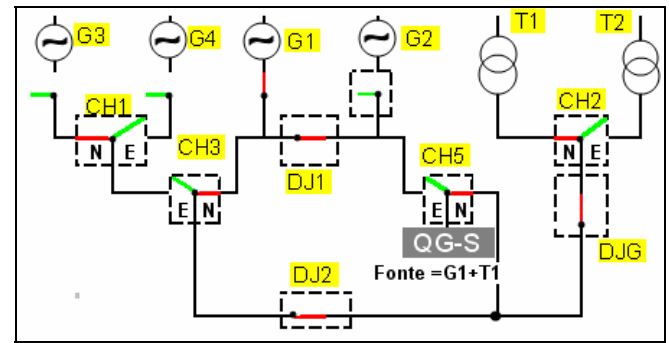

Figura 4.29 - Configuração dos equipamentos para fornecimento de energia por G1 e T1 para QG-S (paralelismo

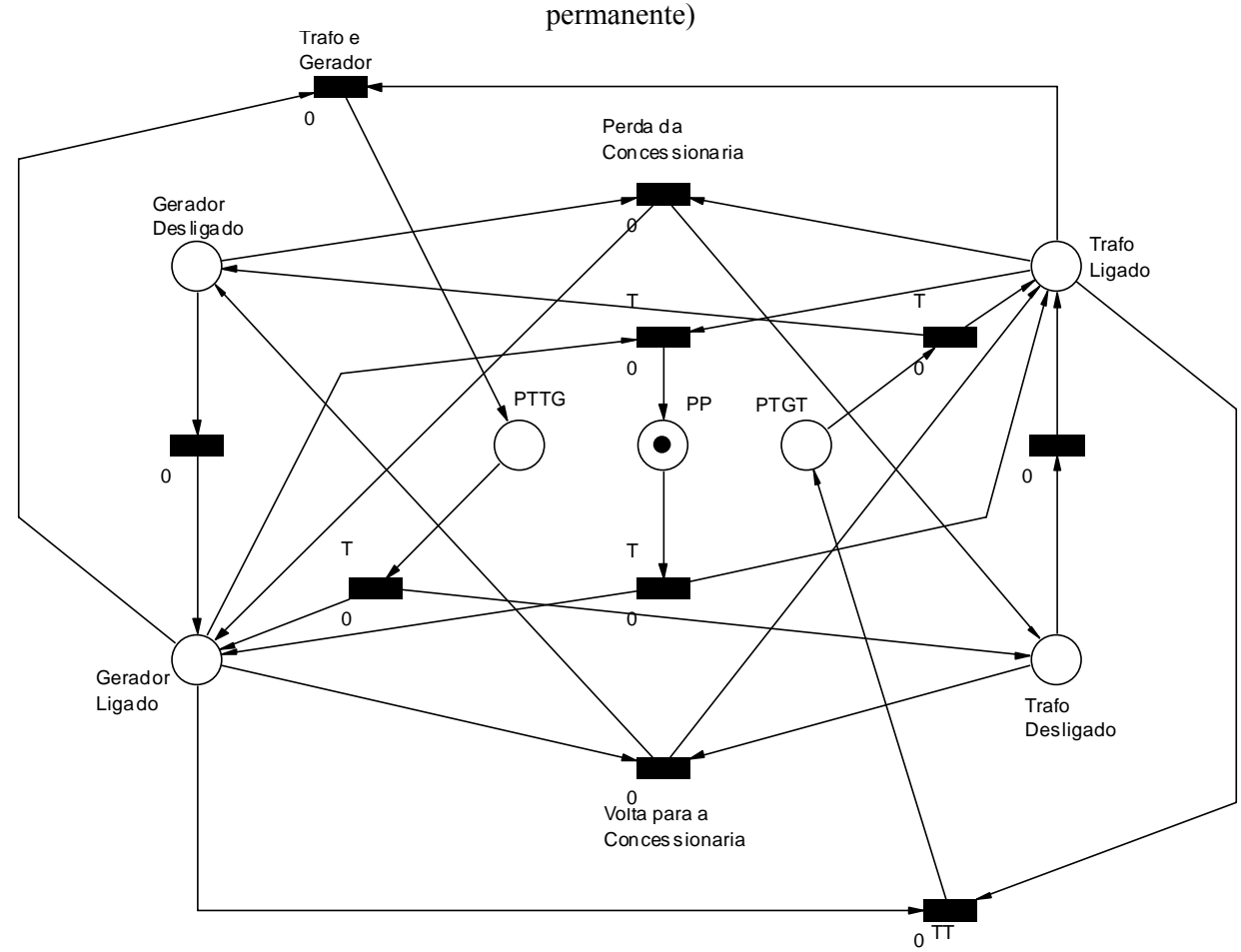

PTTG = Paralelismo Transitório Transformador para Ge rador

PTGT = Paralelismo Transitório Gerador para Transformador

$\mathrm{PP}=$ Paralelismo Permanente

$\mathrm{T}=$ Transição

m's = Estado discreto

Figura 4.30 - Topologia gerador e transformador em PP

\subsubsection{Topologias possíveis para todos o sistema}

Como foi colocado no item anterior, há 24 disposições possíveis em um universo de combinações totais de 289 (17 por 17) para a Micro-usina . Essas disposições foram acordadas no início do projeto e permitem que as principais operações reais de transferência de carga possam ser simuladas através do painel de controle e transferência (PCT). As 24 configurações são: 


\begin{tabular}{|c|c|c|c|c|c|c|c|c|c|c|c|c|c|c|c|}
\hline & $\begin{array}{l}\text { I } \\
\text { D }\end{array}$ & $\begin{array}{l}\text { Q } \\
\mathbf{G} \\
- \\
\text { L } \\
\text { A } \\
\text { B }\end{array}$ & $\begin{array}{l}\mathbf{Q} \\
\mathbf{G} \\
\overline{\mathbf{S}}\end{array}$ & $\begin{array}{l}c \\
1\end{array}$ & $\begin{array}{l}C \\
2\end{array}$ & $\begin{array}{l}C \\
3\end{array}$ & $\begin{array}{l}D \\
J \\
1\end{array}$ & $\begin{array}{l}D \\
J \\
2\end{array}$ & $\begin{array}{l}D \\
\text { J } \\
\text { G }\end{array}$ & $\begin{array}{l}C \\
H \\
1\end{array}$ & $\begin{array}{c}\mathrm{C} \\
\mathrm{H} \\
2\end{array}$ & $\begin{array}{l}\mathrm{C} \\
\mathrm{H} \\
3\end{array}$ & $\begin{array}{l}\mathrm{C} \\
\mathrm{H} \\
4\end{array}$ & $\begin{array}{l}\mathrm{C} \\
\mathrm{H} \\
5\end{array}$ & $\begin{array}{l}C \\
4\end{array}$ \\
\hline 1 & 0 & G1 & G1 & 1 & 0 & 0 & 1 & 0 & 1 & 0 & 0 & 0 & 1 & 1 & 0 \\
\hline 2 & 1 & G1 & G2 & 1 & 1 & 0 & 0 & 0 & 1 & 0 & 0 & 0 & 1 & 1 & 0 \\
\hline 3 & 4 & G1 & T1 & 1 & 0 & 0 & 0 & 0 & 1 & 0 & 0 & 0 & 1 & 0 & 0 \\
\hline 4 & 5 & G1 & T2 & 1 & 0 & 0 & 0 & 0 & 1 & 0 & 1 & 0 & 1 & 0 & 0 \\
\hline 5 & 18 & G2 & G2 & 0 & 1 & 0 & 1 & 0 & 1 & 0 & 0 & 0 & 1 & 1 & 0 \\
\hline 6 & 21 & G2 & T1 & 0 & 1 & 0 & 1 & 0 & 1 & 0 & 0 & 0 & 1 & 0 & 0 \\
\hline 7 & 22 & G2 & $\mathrm{T2}$ & 0 & 1 & 0 & 1 & 0 & 1 & 0 & 1 & 0 & 1 & 0 & 0 \\
\hline 8 & 68 & T1 & $\overline{\mathrm{G} 1}$ & 1 & 0 & 0 & 1 & 0 & 1 & 0 & $\overline{0}$ & 0 & 0 & 1 & 0 \\
\hline 9 & 69 & T1 & $\overline{\mathrm{G}} 2$ & 0 & 1 & 0 & 0 & 0 & 1 & 0 & $\overline{0}$ & 0 & 0 & 1 & 0 \\
\hline 10 & 72 & T1 & T1 & 0 & 0 & 0 & 0 & 0 & 1 & 0 & 0 & 0 & 0 & 0 & 0 \\
\hline 11 & 74 & T1 & $\mathrm{G} 1+\mathrm{G} 2$ & 1 & 1 & 0 & 1 & 0 & 1 & 0 & 0 & 0 & 0 & 1 & 0 \\
\hline 12 & 85 & T2 & G1 & 1 & 0 & 0 & 1 & 0 & 1 & 0 & 1 & 0 & 0 & 1 & 0 \\
\hline 13 & 86 & T2 & G2 & 0 & 1 & 0 & 0 & 0 & 1 & 0 & 1 & 0 & 0 & 1 & 0 \\
\hline 14 & 90 & T2 & T2 & 0 & 0 & 0 & 0 & 0 & 1 & 0 & & 0 & 0 & 0 & 0 \\
\hline 15 & 91 & T2 & $\mathrm{G} 1+\mathrm{G} 2$ & 1 & 1 & & 1 & 0 & & 0 & & 0 & 0 & 1 & 0 \\
\hline 16 & 106 & $1+G 2$ & T1 & 1 & 1 & 0 & 1 & 0 & 1 & 0 & 0 & 0 & 1 & 0 & 0 \\
\hline 17 & 107 & G1+G2 & T2 & 1 & 1 & 0 & 1 & 0 & 1 & 0 & 1 & 0 & 1 & 0 & 0 \\
\hline 18 & 108 & $\mathrm{G} 1+\mathrm{G} 2$ & $\mathrm{G} 1+\mathrm{G} 2$ & 1 & 1 & 0 & 1 & 0 & 1 & 0 & 0 & 0 & 1 & 1 & 0 \\
\hline 19 & 126 & $\mathrm{G} 1+\mathrm{G} 2+\mathrm{T} 1$ & $\mathrm{G} 1+\mathrm{G} 2+\mathrm{T} 1$ & 1 & 1 & 0 & 1 & 1 & 1 & 0 & 0 & 0 & 0 & 0 & 0 \\
\hline 20 & 144 & $\mathrm{G} 1+\mathrm{G} 2+\mathrm{T} 2$ & $\mathrm{G} 1+\mathrm{G} 2+\mathrm{T} 2$ & 1 & 1 & 0 & 1 & 1 & 1 & 0 & 1 & 0 & 0 & 0 & 0 \\
\hline 21 & 162 & $\mathrm{G} 1+\mathrm{T} 1$ & G1+T1 & 1 & 0 & 0 & 1 & 1 & 1 & 0 & 0 & 0 & 0 & 0 & 0 \\
\hline 22 & 180 & $1+T 2$ & $1+\mathrm{T} 2$ & 1 & 0 & 0 & 1 & 1 & 1 & 0 & 1 & 0 & 0 & 0 & 0 \\
\hline 23 & 198 & $\mathrm{G} 2+\mathrm{T} 1$ & $\mathrm{G} 2+\mathrm{T} 1$ & 0 & 1 & 0 & 1 & 1 & 1 & 0 & 0 & 0 & 0 & 0 & $\overline{0}$ \\
\hline 24 & 216 & $\mathrm{G} 2+\mathrm{T} 2$ & $\mathrm{G} 2+\mathrm{T} 2$ & 0 & 1 & 0 & 1 & 1 & 1 & 0 & 1 & 0 & 0 & 0 & 0 \\
\hline
\end{tabular}

Figura 4.31 - Configurações possíveis da micro usina.

Conforme mencionado anteriormente, o estudo entre as transições dos 24 estados possíveis será feito utilizando-se as ferramentas da "Rede de Petri”. Nestas simulações será verificada a existência de "conflitos mortais" (“dead-lock") e incoerências e acionamentos indevidos. 


\section{Capítulo 5 - Desenvolvimento do Projeto do Programa Aplicativo do CLP}

\subsection{Introdução}

O programa aplicativo do CLP foi desenvolvido em linguagem Ladder com a finalidade de tornar funcional todas as operações e intertravamentos previstos para o projeto. A metodologia de desenvolvimento do programa pressupõe que um conjunto de etapas sejam seguidas de modo a cumprir e constatar a qualidade mínima para o projeto. Essas etapas são:

a) Reunião inaugural: Nesta reunião são conhecidos todos os "parceiros" no desenvolvimento do projeto. No caso específico deste projeto foram:

-Engenheiros e consultores do laboratório do Centro de Estudos em Regulação e Qualidade de Energia (Enerq);

-Empresa responsável pela montagem dos equipamentos nos quadros de distribuição e controle;

-Empresa responsável pelo fornecimento da chave de transferência automática;

•Empresa responsável pelo fornecimento dos geradores.

b) Elaboração dos documentos iniciais para o desenvolvimento do projeto. Esses documentos foram:

-Elaboração da lista de entradas e saídas do CLP (Lista de I/O - Anexo 1). Esta lista mostra todas os pontos digitais que serão lidos e escritos utilizando cartões de entradas e saídas digitais. Nesta lista devem ser acrescentados os sinais de comunicação contendo os pontos de leitura e escrita feitos pela rede ModBus;

-Diagramas unifilar do painel de comando e transferência (P\&ID - Anexo 2).

c) Reuniões de esclarecimentos técnicos com os fornecedores dos equipamentos e os engenheiros do Enerq de modo a definir todas as funcionalidades a serem implementadas no projeto. 
d) Elaboração da Rede de Petri mostrando todas as etapas a serem atingidas (alcançabilidade) assim como a vivacidade, segurança e repetibilidade do sistema (este item é o objeto principal do trabalho aqui apresentado).

e) Desenvolvimento do programa aplicativo do Ladder propriamente dito.

f) Testes internos (em bancada). Nesta etapa todas as fases (R,S e T) estão individualmente curto-circuitadas para evitar danos aos equipamentos durante os testes preliminares;

g) Testes de plataforma (repetição dos testes internos na presença do engenheiro responsável pelo sistema).

h) Testes de posta-em-marcha (Start-up) do sistema. Este teste consiste em testar toda a funcionalidade do painel com todos os equipamentos em operação, ou seja, à quente.

i) Melhorias durante o projeto solicitadas pelo cliente. Esta etapa consiste em aumentar o escopo de fornecimento pretendido inicialmente pelo projeto com mudanças ou acréscimos solicitados pelos responsáveis. No nosso caso seria a implementação do programa aplicativo do supervisório.

\subsection{Distribuição dos Arquivos de Programa}

O programa aplicativo do CLP foi feito em linguagem Ladder utilizando um programador de última geração RSLogix1500. Este processador possui capacidade de gerenciamento dos I/Os em um tempo de varredura médio da ordem de $3 \mathrm{~ms}$. O programa de escrita da linguagem Ladder permite a separação em rotinas de chamada configuráveis a partir da rotina principal. No caso deste projeto as rotinas implementadas foram as indicadas na figura a seguir: 


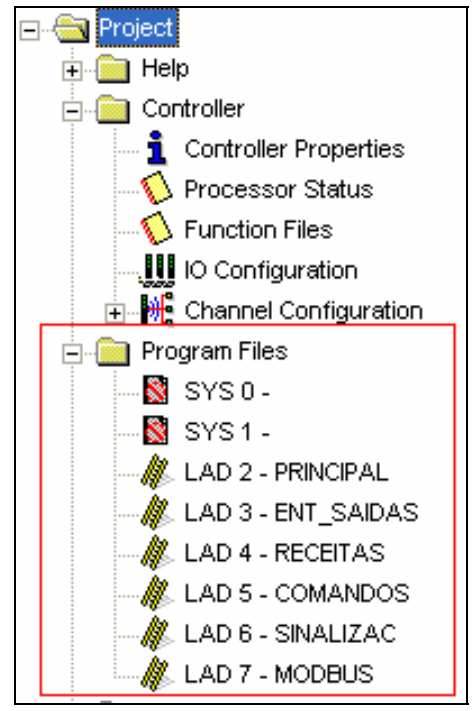

Figura 5.1 - Arquivos do programa aplicativo do CLP

Os programas desenvolvidos estão divididos segundo suas principais funções, descritas a seguir.

\subsubsection{Arquivo principal}

Este arquivo, indicado como "Lad 2 - Principal" tem a função principal de chamar os demais arquivos de programa em uma seqüência programada. Neste arquivo estão também implementadas as linhas de inicialização do sistema feitas na primeira varredura do programa. A primeira varredura ocorrerá todas as vezes que o controlador retornar para o modo de execução (RUN);

\subsubsection{Arquivo de entradas e saídas}

Neste arquivo, chamado a partir do programa principal, são feitas as conversões das entradas analógicas e também a transferência das entradas e saídas digitais (Anexo 1) para variáveis auxiliares internas e de comunicação com o supervisório. Este arquivo corresponde a uma espécie de "Borne de conexão" entre as entradas e saídas dos cartões e os endereços utilizados internamente no programa. Optou-se pela utilização desta forma de estruturação do programa porque foram feitos vários testes internos, utilizando apenas os endereços auxiliares e desabilitando os pontos de entrada e saída físicos (Figura 5.7). 


\subsubsection{Arquivo das Receitas}

Neste arquivo está a lógica de seleção e busca do estado dos equipamentos selecionados pelo operador. A seleção de uma operação feita pelo operador consiste em uma série de etapas transparentes ao operador. Essas etapas são:

- Verificação da disponibilidade da operação, ou seja, verificação da possibilidade de todos os equipamentos estarem fora de manutenção;

- Verificação de que a operação solicitada pode ser feita a partir da disposição dos barramentos e equipamentos do painel;

- Indicação no sinótico presente no painel de controle e transferência do útlimo caminho verificado. Esta funcionalidade permite ao operador verificar nos leds os equipamentos que serão acionados e desenergizados após o aceite da opção atualmente selecionada.

Estas etapas são feitas baseadas nas receitas salvas na memória do CLP. As 24 receitas válidas são indicadas na tabela a seguir:

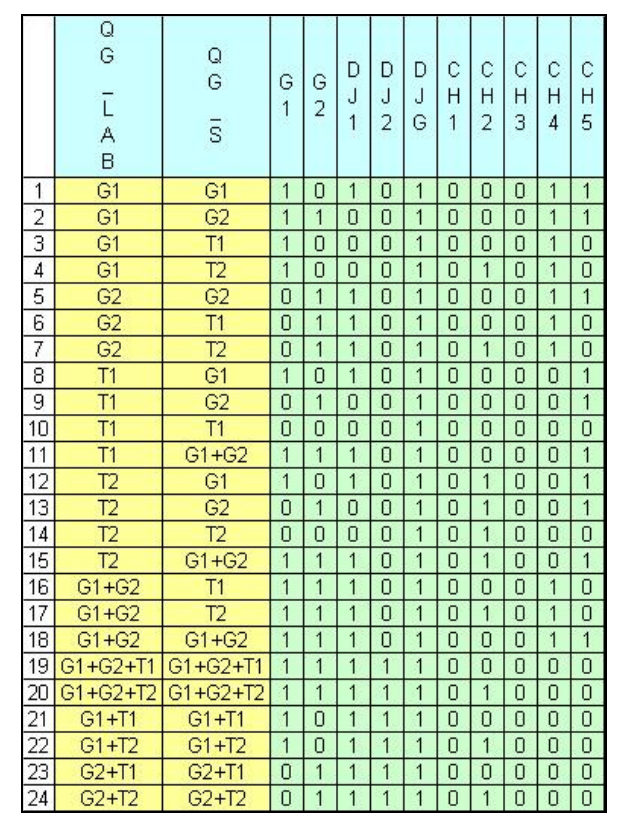

Figura 5.2 - Receitas válidas

Toda seleção feita pelo operador, desde que válida, corresponde a uma linha da tabela indicada na figura anterior. Esta seleção é feita pela combinação das colunas QG-Lab e QG-S 
indicando uma opção de geração para o laboratório e o grupo de cargas essenciais, respectivamente. Os equipamentos indicados nas colunas que vão desde G1 até CH5 são os equipamentos que deverão entrar em processo de acionamento (01) ou parada (00), respectivamente. Esta figura, portanto, resume as receitas válidas presentes na memória do CLP. A tabela total de todas as opções a serem verificadas é composta por 289 linhas.

\subsubsection{Arquivo de comandos}

Este arquivo é um dos mais importantes do CLP na medida em que todo o intertravamento de segurança está sendo considerado em suas linhas de programa. Este arquivo é responsável por verificar, em tempo real, as solicitações resultantes da seleção da receita e a compatibilidade com a realidade física dos equipamentos, ou seja, algumas seleções são consideradas proibidas e não aceitas pelo sistema.

A título de exemplo, vamos mostrar a seqüência típica de entrada e saída dos grupos geradores G1 e G2 no horário de ponta em uma configuração de "Peak shave".

Considere a situação inicial na qual toda a carga é suprida pela concessionária, representada pelo gerador $\mathrm{T} 1$, indicada na figura a seguir:
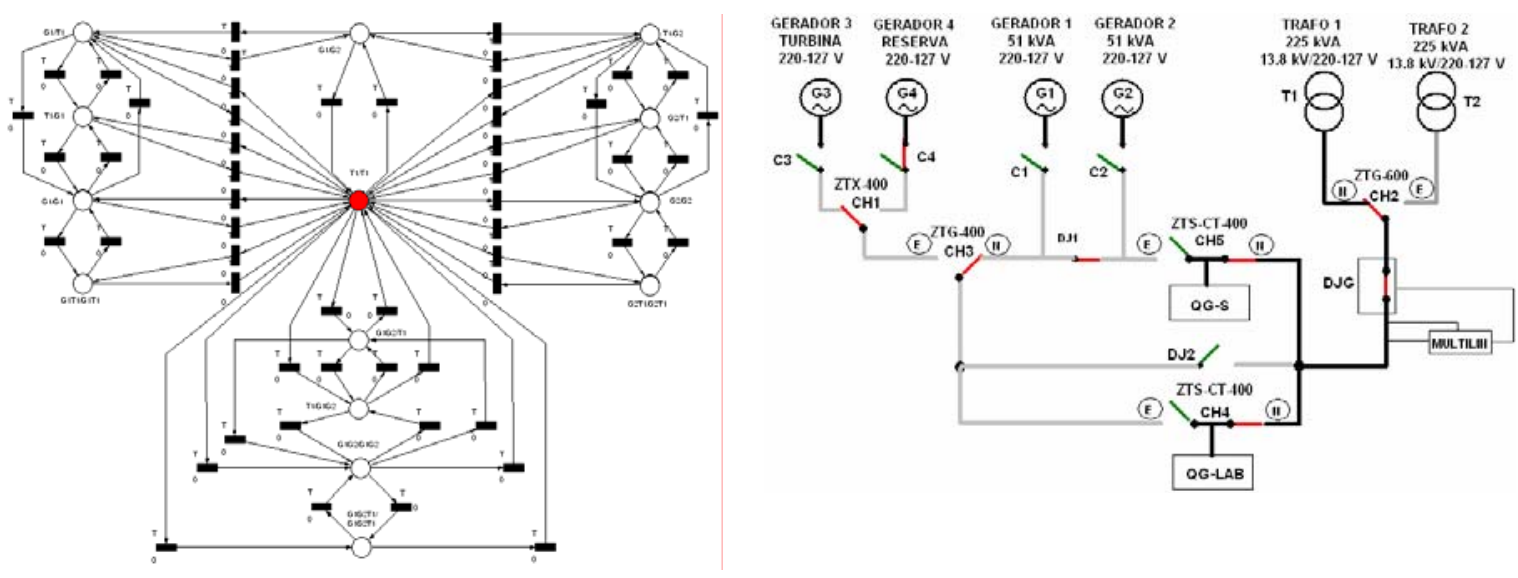

Figura 5.3 - Alimentação da carga QG-Lab e QG-S pela concessionária T1 (T1/T1)

A partir do momento em que é selecionada pelo operador a passagem para uma segunda topologia, na qual haja a entrada dos geradores em linha, o controlador do grupo gerador recebe a solicitação para passar para modo "Múltiplo" (G1 e G2), com "Paralelismo" com a rede e em 
"rampa" (Soft-transfer). Nesta configuração irá fornecer o excedente dos ativos não fornecidos pela concessionária (Peak-Shave).

Neste caso tomado como exemplo, o operador fez uma seleção pela receita 19 $(\mathrm{G} 1+\mathrm{G} 2+\mathrm{T} 1, \mathrm{G} 1+\mathrm{G} 2+\mathrm{T} 1)$. Após a seleção o arquivo de receita, dispara uma solicitação de fechamento do disjuntor de paralelismo permanente DJ2. Esse disjuntor, apesar de agendado para ser fechado imediatamente após a seleção feita pelo operador, deve aguardar até que os geradores G1 e G2 estejam devidamente acionados e em condições de entrarem em paralelismo permanente com a rede. Para tanto deve-se esperar pela informação retornada pelo módulo modo de controle. A informação recebida indica que os módulos e as fases estão sincronizados e que terminou a passagem para o modo de funcionamento com paralelismo permanente entre G1, G2 e T1 (concessionária). A topologia final é indicada na figura a seguir:
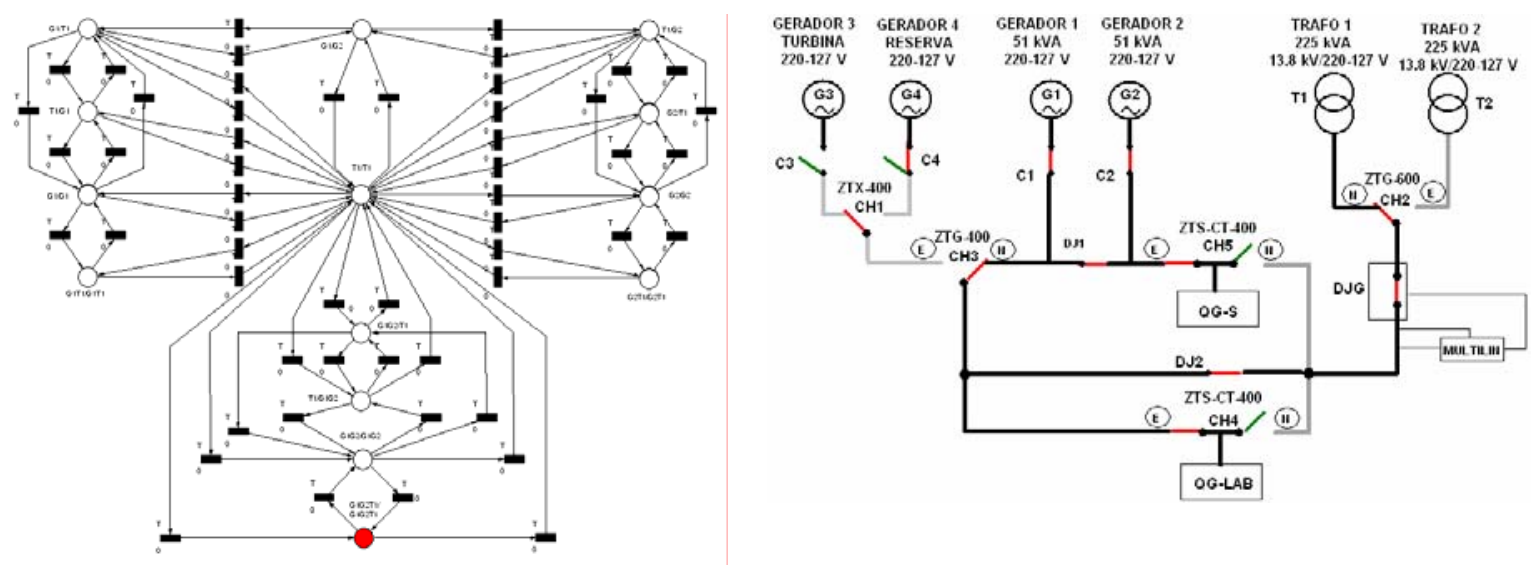

Figura 5.4 - Alimentação da carga QG-Lab e QG-S pelos grupos geradores em paralelo entre si e com a concessionária via T1 (G1G2T1/G1G2T1)

O retorno (22 horas) será iniciado, por exemplo, manualmente em um próxima seleção feita pelo operador onde ele pode optar por retornar para o fornecimento exclusivo efetuado pela concessionária. Nesta nova topologia selecionada (T1/T1), o momento crítico é o fechamento do disjuntor motorizado DJ2 devido ao fato do seu comando ser feito pelo CLP.

O comando do fechamento do DJ2 deve aguardar a finalização da rampa de transferência feita pelo gerador, de modo que o fornecimento da energia ativa por parte dos geradores caia a valores inferiores a $10 \%$. Sendo constatada a finalização da participação dos geradores no 
fornecimento de energia para as cargas, o disjuntor DJ2 pode ser aberto e os geradores desligados (passam para processo de lubrificação e resfriamento).

\subsubsection{Arquivo de sinalização}

$\mathrm{O}$ arquivo de sinalização é o responsável por mostrar na tela do supervisório ou no sinótico do painel de controle e transferência o estado atual dos componentes ou uma nova "rota selecionada", ou mesmo o estado de falha de algum equipamento acionado ou desacionado.

Toda nova seleção pode ser facilmente verificada simplesmente seguindo os "leds" do sinótico indicados no supervisório ou na tela do painel (PCT) (figura abaixo).

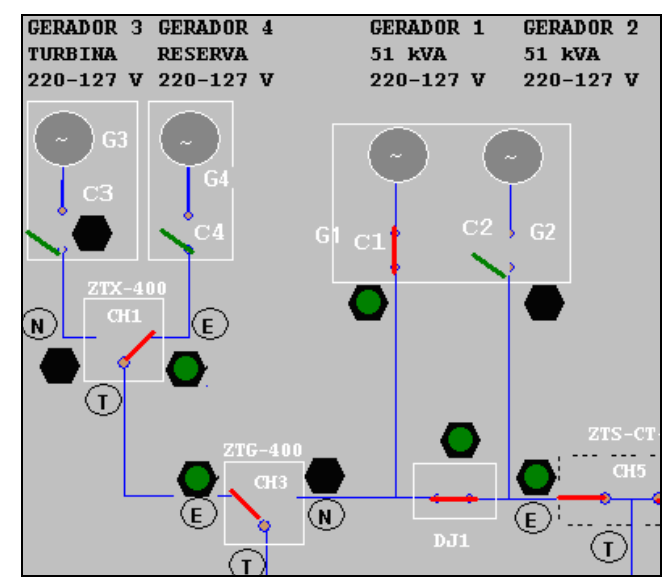

Figura 5.5 - Indicação no supervisório do estado atual das chaves e disjuntores

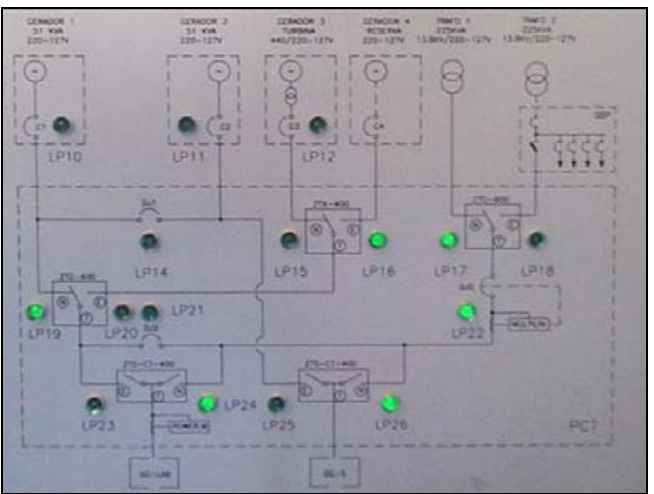

Figura 5.6 - Indicação no sinótico do painel de controle e transferência (PCT)

Em ambos os casos é possível visualizar a escolha feita e verificar o estado atual dos equipamentos. 


\subsubsection{Arquivo Modbus}

O controlador lógico programável é o mestre da rede ModBus RTU, cabendo a ele a iniciativa de enviar ou requisitar dos escravos ( módulos de controle do gerador 1 e 2) comandos ou informações. Todo o gerenciamento dessas informações é feito nesse arquivo dedicado exclusivamente a essa operação de envio de mensagens (MSG). A fim de otimizar a comunicação e evitar demoras desnecessárias devido a perdas de comunicação de um dos módulos, foi feito um chaveamento habilitando apenas uma mensagem por vez (evitando encher o buffer de saída da porta de comunicação).

\subsection{Testes do Programa Aplicativo do CLP e do Supervisório}

Os testes do programa aplicativo foram feitos utilizando uma lógica de simulação substituindo todas as saídas e entradas por uma lógica temporizada. De forma simplificada seria o equivalente a ligar as saídas de comando às entradas de retorno dos estados dos equipamentos. Foi feita uma lógica adicional que permite imputar falhas nas simulações gerando erros nos sinais de retorno do campo. Essas falhas são representadas por botões de dois estados ( "0"ou "1") que foram colocados junto aos dispositivos testados podendo ser acionados pelo supervisório. Esta forma mostrou-se bastante eficaz e prática, permitindo o teste dos efeitos que as falhas causam na dinâmica de abertura, fechamento, acionamento e desligamento dos equipamentos do sistema.

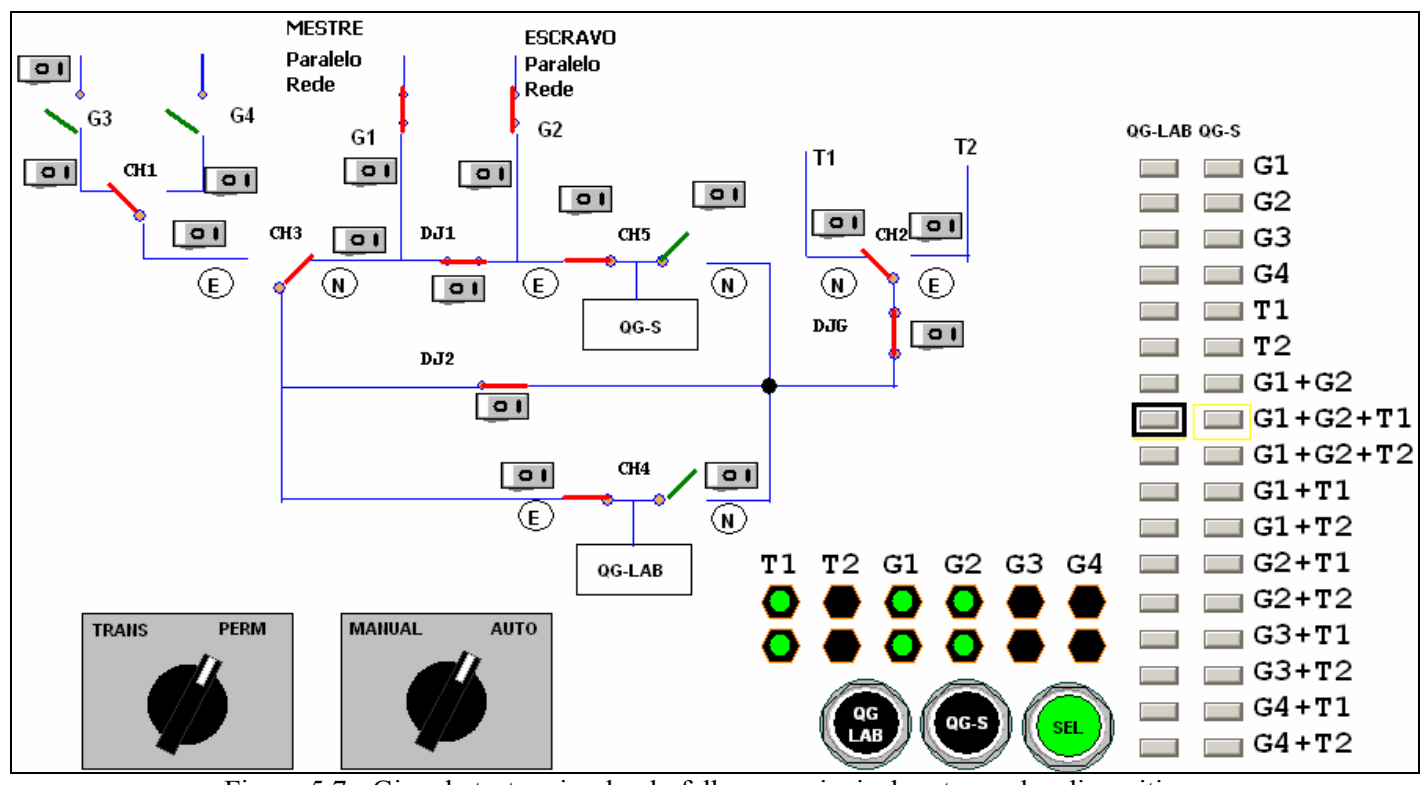

Figura 5.7 - Giga de testes simulando falhas nos sinais de retorno dos dispositivos 


\section{Capítulo 6 - Conclusões}

A utilização das Redes de Petri para simular processos industriais automatizados vêm suprir uma importante lacuna no desenvolvimento de projetos, que é o de fornecer, ainda nas primeiras etapas do projeto, uma importante ferramenta de análise da alcançabilidade, reversibilidade e segurança do sistema a ser implementado.

Neste estudo de caso da Micro-usina pode-se ver como as 24 etapas possíveis do sistema precisaram ser claramente indicadas logo no começo do projeto. Todas as partes envolvidas ( fornecedores dos grupos geradores, fornecedores dos sistema de proteção da concessionária, fornecedores do hardware da automação e engenheiros responsáveis pela coordenação) devem estar de acordo com todas as topologias e transições do projeto evitando eventuais re-trabalhos ou, o que é pior, a não compatibilidade entre as expectativas iniciais e o projeto implementado.

A forma clara e relativamente simples dos grafos orientados da Rede de Petri superam em muito os textos dos documentos de especificação do projeto. Esses documentos, criados para dar respaldo ao projeto a ser desenvolvido, são superados pela Rede de Petri na medida em que este mostra dinamicamente a seqüência de eventos do projeto em um único objeto animado. Essa forma dinâmica e completa é de extrema importância em projetos envolvendo vários fornecedores na medida em que os limites dos produtos e as informação entre os sistemas podem ser testadas e questionadas.

Pode-se dizer, devido à forma gráfica animada da Rede de Petri, que ela é o esqueleto dinâmico inicial da automação a ser desenvolvida, mostrando de forma bastante válida o que poderá ser esperado do projeto do aplicativo do CLP. 


\section{REFERÊNCIAS BIBLIOGRÁFICAS}

1. KNORR, E.; SPIER, E.B.; LEMOS, F.A. Becon - Análise da Operação Isolada de um Sistema de Distribuição com Geração Distribuída - XV Seminário Nacional de Distribuição de Energia Elétrica - SENDI 2002

2. GUTIERREZ-Vera, J.; Mini cogeneration schemes in Mexico - Power Engineering Review, IEEE Volume 21, Issue 8, Aug. 2001 Page(s):6 - 7, 11 Digital Object Identifier 10.1109/39.948251

3. VIALI, R. G. Análise Econômica de Plantas Térmicas - Cogeração - Caso Real Mahle Cofap Anéis. Escola Federal de Engenharia de Itajubá, Departamento de Produção

4. H. K. Clark, J. M. Feltes. "Industrial and cogeneration protection problems requiring simulation”, IEEE Trans. On Industry Applications, vol. 25, no. 4, pp. 766-775, july/august 1989 .

5. MORAES, C.C; CASTRUCCI, P.L. - Engenharia de automação industrial. Editora LTC

6. REZENDE, M.R.-Curso de custos marginais e tarifação - Curso ministrado no Centro de Estudos em Regulação e Qualidade de Energia - São Paulo, Outubro de 1999

7. VASCONCELLOS, A. Paralelismo de Sistemas Industriais Autogeradores e Rede Pública: Aspectos Técnicos da Integração dos Sistemas e Perspectivas Futuras.

8. RIBEIRO, P.; FERREIRA, F.; MEDEIROS, F. - Geração Distribuída e Impacto na Qualidade de Energia - VI SBQEE - agosto de 2005 
9. AES ELETROPAULO - NT 6.005, Requisitos Mínimos para Interligação de Gerador de Consumidor Primário com a Rede de Distribuição da Eletropaulo Metropolitana com Paralelismo Momentâneo - http://www.eletropaulo.com.br

10. AES ELETROPAULO - NT 6.008, Requisitos Mínimos para Elaboração de Projeto e Instalação de Grupos Geradores Particulares com Transferência Automáticahttp://www.eletropaulo.com.br

11. AES ELETROPAULO - NT 6.009, Requisitos Mínimos para Interligação de Gerador de Consumidor Primário com a Rede de Distribuição da Eletropaulo Metropolitana com Paralelismo Permanente - http://www.eletropaulo.com.br

12. Motores e geradores - Princípios de funcionamento, instalação e manutenção de grupos diesel geradores - $\underline{\mathrm{http}} / / / \mathrm{www} . j o s e c l a u d i o . e n g . b r /$ diesel1a1.html

13. ASCO Power - ASCO 7000 Series Soft Load Transfer Switch - Division 16 - Electrical Power Systems - http://www.ascopower.com/cgi-bin/redirect.pl?/main.htm

14. Woodward - EGCP-2 Communications Manual - www.woodward.com

15. GE - Power Management Lentronics F650 Digital Bay Controller Instruction manual GEK-106310J - www.geindustrial.com/multilin

16. Associação paulista de cogeração - http://www.cogensp.org.br/cogensp/cogera6.htm

17. ANNEL - PROCEDIMENTOS DE DISTRIBUIÇÃO - Versão Preliminar - Módulo 3 Escopo 12A - www.aneel.gov.br/82.htm 
Anexo 1

Lista de entradas e saídas (I/O) usadas neste Projeto

\begin{tabular}{|c|c|c|}
\hline \multicolumn{2}{|c|}{$\begin{array}{c}\text { CLP-PCT } \\
\text { Controlador: MicroLogix } 1500\end{array}$} & $\begin{array}{l}\text { Tipo de Módulo : } 1764 \text { - AWA } \\
12 \text { entradas digitais }\end{array}$ \\
\hline $\begin{array}{c}\text { End. do } \\
\text { Elemento }\end{array}$ & TAG & DESCRIÇÃO \\
\hline I:0.0 & B_EMERGENCIA & Botão de emergência \\
\hline I:0.1 & B_SEL_QGLAB & $\begin{array}{l}\text { Botão de seleção de fonte de alimentação do } \\
\text { quadro QG - LAB }\end{array}$ \\
\hline I:0.2 & B_SEL_QGS & $\begin{array}{l}\text { Botão de seleção de fonte de alimentação do } \\
\text { quadro QG - S }\end{array}$ \\
\hline I:0.3 & B_CONFIRMA & Botão de confirmação de seleção \\
\hline I:0.4 & AUTO_MAN & Chave seletora automático -manual \\
\hline I:0.5 & PARALEL_CONTINUO & $\begin{array}{l}\text { Chave de seleção de paralelismo continuo (1) } \\
\text { ou momentâneo (0) }\end{array}$ \\
\hline I:0.6 & & Reserva \\
\hline I:0.7 & & Reserva \\
\hline I:0.8 & C1_FCD & Disjuntor C1 fechado \\
\hline I:0.9 & C2_FCD & Disjuntor C2 fechado \\
\hline I:0.10 & C3_FCD & Disjuntor C3 fechado \\
\hline I:0.11 & C4_FCD & Disjuntor C4 fechado \\
\hline
\end{tabular}

\begin{tabular}{|c|c|l|}
\hline \multicolumn{2}{|c|}{ CLP-PCT } & \multicolumn{1}{c|}{$\begin{array}{c}\text { Tipo de Módulo : 1764 - AWA } \\
\text { 12 Saídas Digitais }\end{array}$} \\
\hline $\begin{array}{c}\text { End. do } \\
\text { Elemento }\end{array}$ & TAG & DESCRIÇÃO \\
\hline O:0.0 & SIN_QG_LAB_T1 & Sinalização de seleção T1 para o QG-LAB \\
\hline O:0.1 & SIN_QG_LAB_T2 & Sinalização de seleção T2 para o QG-LAB \\
\hline O:0.2 & SIN_QG_LAB_G1 & Sinalização de seleção G1 para o QG-LAB \\
\hline O:0.3 & SIN_QG_LAB_G2 & Sinalização de seleção G2 para o QG-LAB \\
\hline O:0.4 & SIN_QG_S_T1 & Sinalização de seleção T1 para o QG-S \\
\hline O:0.5 & SIN_QG_S_T2 & Sinalização de seleção T2 para o QG-S \\
\hline O:0.6 & SIN_QG_S_G1 & Sinalização de seleção G1 para o QG-S \\
\hline O:0.7 & SIN_QG_S_G2 & Sinalização de seleção G2 para o QG-S \\
\hline O:0.8 & SIN_QG_LAB_G3 & Sinalização de seleção G3 para o QG-LAB \\
\hline O:0.9 & SIN_QG_LAB_G4 & Sinalização de seleção G4 para o QG-LAB \\
\hline O:0.10 & SIN_QG_S_G3 & Sinalização de seleção G3 para o QG-S \\
\hline O:0.11 & SIN_QG_S_G4 & Sinalização de seleção G4 para o QG-S \\
\hline
\end{tabular}




\begin{tabular}{|c|c|l|}
\hline \multicolumn{2}{|c|}{$\begin{array}{c}\text { CLP-PCT } \\
\text { Controlador: 1764 - LRP }\end{array}$} & $\begin{array}{c}\text { Tipo de Módulo : 1769 - IA8I } \\
\text { 8 Entradas Digitais 120 Vac isoladas }\end{array}$ \\
\hline $\begin{array}{c}\text { End. do } \\
\text { Elemento }\end{array}$ & TAG & DESCRIÇÃO \\
\hline I:1.0 & CH1_N & Contato auxiliar indicando posição N na chave CH1 \\
\hline I:1.1 & CH1_E & Contato auxiliar indicando posição E na chave CH1 \\
\hline I:1.2 & CH2_N & Contato auxiliar indicando posição N na chave CH2 \\
\hline I:1.3 & CH2_E & Contato auxiliar indicando posição E na chave CH2 \\
\hline I:1.4 & CH3_N & Contato auxiliar indicando posição N na chave CH3 \\
\hline I:1.5 & CH3_E & Contato auxiliar indicando posição E na chave CH3 \\
\hline I:1.6 & CH4_N & Contato auxiliar indicando posição N na chave CH4 \\
\hline I:1.7 & CH4_E & Contato auxiliar indicando posição E na chave CH4 \\
\hline
\end{tabular}

\begin{tabular}{|c|c|l|}
\hline \multicolumn{2}{|c|}{ CLP-PCT } & \multicolumn{1}{c|}{$\begin{array}{c}\text { Tipo de Módulo : 1769 - IA8I } \\
\text { 8 Entradas Digitais 120 Vac isoladas }\end{array}$} \\
\hline $\begin{array}{c}\text { End. do } \\
\text { Elemento }\end{array}$ & TAG & \multicolumn{1}{c|}{ DESCRIÇÃO } \\
\hline I:2.0 & CH5_N & Contato auxiliar indicando posição N na chave CH5 \\
\hline I:2.1 & CH5_E & Contato auxiliar indicando posição E na chave CH5 \\
\hline I:2.2 & DJ1_FCD & Disjuntor DJ1 fechado \\
\hline I:2.3 & DJ2_FCD & Disjuntor DJ2 fechado \\
\hline I:2.4 & DJG_FCD & Disjuntor DJG fechado \\
\hline I:2.5 & & Reserva \\
\hline I:2.6 & & Reserva \\
\hline I:2.7 & & Reserva \\
\hline
\end{tabular}




\begin{tabular}{|c|c|l|}
\hline \multicolumn{2}{|c|}{ CLP-PCT } & \multicolumn{1}{c|}{$\begin{array}{c}\text { Tipo de Módulo : 1769-OW16 } \\
\text { 16 Saídas a Rele }\end{array}$} \\
\hline $\begin{array}{c}\text { End. do } \\
\text { Elemento }\end{array}$ & TAG & DESCRIÇÃO \\
\hline O:3.0 & Q2_CH1 & Bobina alimentada para forçar CH1 ir para posição E \\
\hline O:3.1 & Q2_CH2 & Bobina alimentada para forçar CH2 ir para posição E \\
\hline O:3.2 & Q2_CH3 & Bobina alimentada para forçar CH3 ir para posição E \\
\hline O:3.3 & Q2_CH4 & Bobina alimentada para forçar CH4 ir para posição E \\
\hline O:3.4 & Q2_CH5 & Bobina alimentada para forçar CH5 ir para posição E \\
\hline O:3.5 & DJ1_FECHA & Disj de paralelismo dos geradores 1 e 2 \\
\hline O:3.6 & DJ2_FECHA & Disj de paralelismo dos geradores com os trafos \\
\hline O:3.7 & DJG_FECHA & Disj geral da concessionária \\
\hline O:3.8 & DJ1_ABRE & Disj de paralelismo dos geradores 1 e 2 \\
\hline O:3.9 & DJ2_ABRE & Disj de paralelismo dos geradores com os trafos \\
\hline O:3.10 & DJG_ABRE & Disj geral da concessionária \\
\hline O:3.11 & SIN_PERMIT & Sinaleiro de seleção permitida \\
\hline O:3.12 & SIN_NAO_PERMIT & Sinaleiro de seleção não permitida \\
\hline O:3.13 & FALHA & Falha na seleção \\
\hline O:3.14 & & Reserva \\
\hline O:3.15 & & Reserva \\
\hline
\end{tabular}

\begin{tabular}{|c|c|l|}
\hline \multicolumn{2}{|c|}{ CLP-PCT } & \multicolumn{2}{c|}{$\begin{array}{c}\text { Tipo de Módulo : 1769-OW16 } \\
\text { 16 Saídas a Rele }\end{array}$} \\
\hline $\begin{array}{c}\text { End. do } \\
\text { Elemento }\end{array}$ & TAG & DESCRIÇÃO \\
\hline O:4.0 & LED_C1 & Led de sinalização do disjuntor C1 \\
\hline O:4.1 & LED_C2 & Led de sinalização do disjuntor C2 \\
\hline O:4.2 & LED_C3 & Led de sinalização do disjuntor C3 \\
\hline O:4.3 & LED_DJ1 & Led de sinalização do disjuntor DJ1 \\
\hline O:4.4 & LED_DJ2 & Led de sinalização do disjuntor DJ2 \\
\hline O:4.5 & LED_DJG & Led de sinalização do disjuntor DJG \\
\hline O:4.6 & LED_CH1_E & Led de sinalização de posição E na chave CH1 \\
\hline O:4.7 & LED_CH2_E & Led de sinalização de posição E na chave CH2 \\
\hline O:4.8 & LED_CH3_E & Led de sinalização de posição E na chave CH3 \\
\hline O:4.9 & LED_CH4_E & Led de sinalização de posição E na chave CH4 \\
\hline O:4.10 & LED_CH5_E & Led de sinalização de posição E na chave CH5 \\
\hline O:4.11 & LED_CH1_N & Led de sinalização de posição N na chave CH1 \\
\hline O:4.12 & LED_CH2_N & Led de sinalização de posição N na chave CH2 \\
\hline O:4.13 & LED_CH3_N & Led de sinalização de posição N na chave CH3 \\
\hline O:4.14 & LED_CH4_N & Led de sinalização de posição N na chave CH4 \\
\hline O:4.15 & LED_CH5_N & Led de sinalização de posição N na chave CH5 \\
\hline
\end{tabular}

